\title{
Effect of Src Kinase Inhibition on Metastasis and Tumor Angiogenesis in Human Pancreatic Cancer
}

\author{
Ivan A. Ischenko
}


Aus der Chirurgischen Klinik und Poliklinik Großhadern der Ludwig Maximilians Universität München

Direktor: Professor Dr. med. Dr. Karl-Walter Jauch

\title{
Effect of Src Kinase Inhibition on Metastasis and Tumor Angiogenesis in Human Pancreatic Cancer
}

\author{
Dissertation \\ Zum Erwerb des Doktorgrades der Medizin (Dr. Med.) \\ an der Medizinischen Fakultät der \\ Ludwig-Maximilians-Universität zu München
}

\begin{abstract}
Vorgelegt von
Ivan A. Ischenko
\end{abstract}

aus Donezk, Ukraine 
Mit Genehmigung der Medizinischen Fakultät der Universität München

Berichterstatter:

Mitberichterstatter:

Mitbetreuung durch den

Promovierten Mitarbeiter:

Dekan:

Tag der mündlichen Prüfung:
Priv. Doz. Dr. med. Christiane J. Bruns

Priv. Doz. Dr. med. H. Schnurr

Professor Dr. med. B. Göke

Priv. Doz. Dr. Christiane J. Bruns

Professor Dr. med. Dietrich Reinhardt 
Advancing Knowledge, Saving Lives 


\section{TABLE OF CONTENTS}

1. ACKNOWLEDGEMENTS

2. ABSTRACT

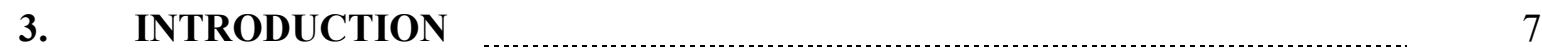

$3.1 \quad$ Pancreatic cancer

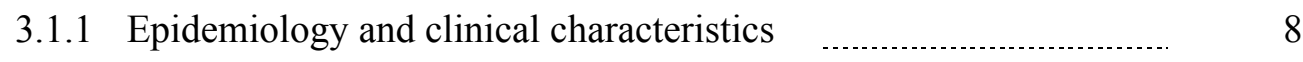

3.1.2 Standard chemotherapy of pancreatic cancer $\quad$......................... 9

3.1.3 Molecular mechanisms of pancreatic carcinogenesis $\quad$............ $\quad 10$

3.2 The role of angiogenesis in local and systemic tumor growth

3.2.1 Tumor angiogenesis _............................................................ 11

3.2.2 The angiogenic switch

3.2.3 Formation of tumor vessels …............................................... 12

3.2.4 Structure and function of tumor vessels _.................................. 13

3.3 Angiogenic phenotype of pancreatic cancer _.......................................... 14

3.4 Therapeutic angiogenesis

3.5 Kinases of the Src family nonreceptor protein tyrosine kinases $\quad \ldots . . . . . . . . . . . \quad 16$

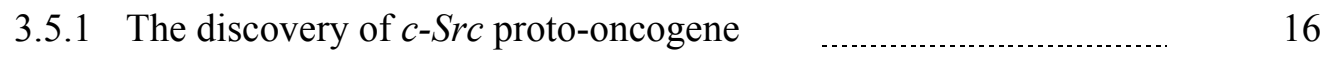

3.5.2 Src family members $\ldots$

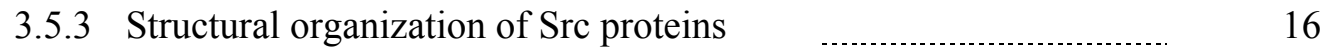

3.5.4 Structural differences between v-Src and c-Src proteins $\quad \ldots \ldots \ldots \ldots . . . . \quad 20$

3.5.5 Regulation of Src kinases _................................................... 20

3.5.6 Src substrates 22

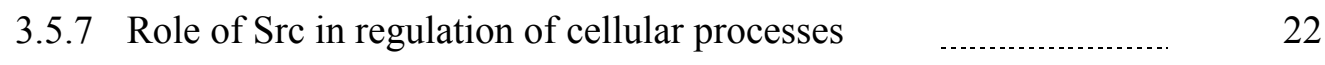

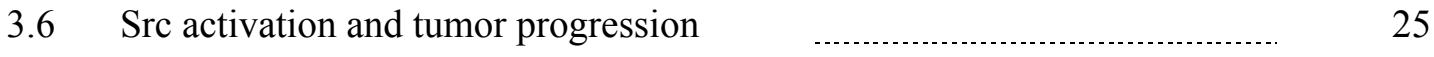

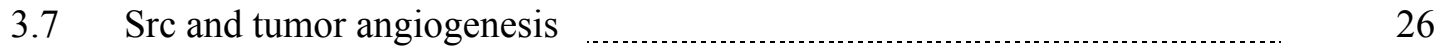

4. THESIS PROPOSAL 
5. MATERIALS AND METHODS

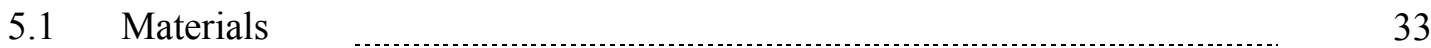

5.1.1 Laboratory equipment _................................................. 33

5.1.2 Chemical reagents and other research solutions

5.1.3 Drugs _........................................................................ 35

5.1.4 Cell lines 36

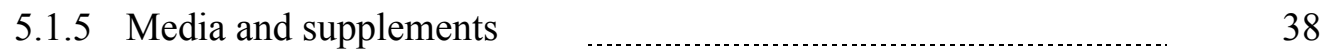

5.1.6 Growth factors 39

5.1.7 Kits and other research products

5.1.8 Antibodies 40

5.1.9 Animals for in vivo experiments _........................................ 40

5.1.10 Materials used for in vivo studies $\quad$......................................... 40

5.1.11 Software

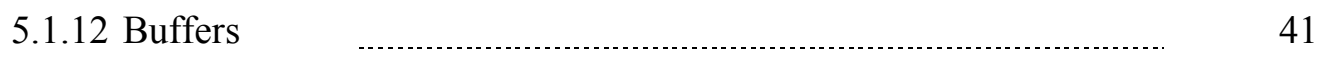

5.2 Methods 45

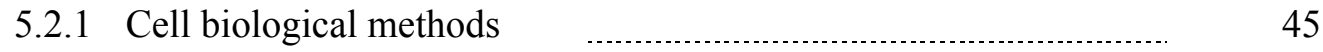

5.2.1.1 Cell culture techniques _......................................... 45

5.2.1.2 Cell quantification and evaluation of viability $\quad \ldots \ldots \ldots \ldots . . . . . . .46$

5.2.1.3 Cell stimulation with different factors $\quad \ldots 6$

5.2.1.4 Storage of cells _..................................................... 46

5.2.1.5 Detection of viable cells

5.2.1.6 Inhibition of growth factor-mediated proliferation ............ 48

5.2.1.7 Chemotaxis assay _..................................................... 48

5.2.2 Biochemical methods $\quad$....................................................... 49

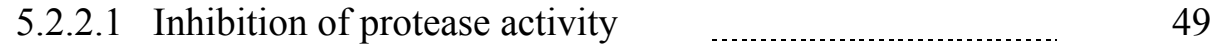

5.2.2.2 Preparation of cellular extracts using RIPA buffer ............ 49

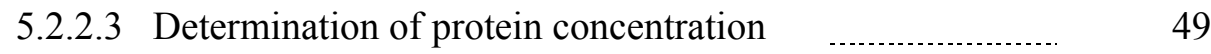

5.2.2.4 Immunoprecipitation of proteins …............................. 50

5.2.2.5 SDS-Polyacrylamidgelelectrophoresis PAGE 50

5.2.2.6 Transfer of proteins to PVDF membrane _....................... 51

5.2.2.7 Ponceau S staining of proteins on PVDF membrane .......... 52

5.2.2.8 Analysis of proteins on PVDF membrane

by immunoblotting .................................................... 52

5.2.2.9 Stripping and re-probing of western blot $\ldots \ldots \ldots \ldots \ldots \ldots \ldots \ldots \ldots \ldots \ldots$ 
5.2.3 Determination of apoptotic cells by FACS analysis via propidium iodide staining 53

5.2.4 Enzyme-linked immunoassays

5.2.4.1 Determination of human vascular endothelial growth factor concentrations in cell culture supernates $\quad \ldots . . . . . . . . . . \quad 53$

5.2.4.2 In vitro Src kinase inhibition test .................................. 54

5.2.5 In vitro study of angiogenesis

5.2.5.1 Aortic ring assay _....................... 55

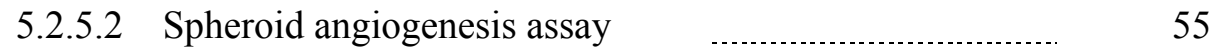

5.2.6 Orthotopic xenograft pancreatic tumor model $\ldots \ldots \ldots \ldots \ldots \ldots \ldots \ldots . . . . . . . . . . . .56$

5.2.6.1 Tumor cell implantation _............................................ 56

5.2.6.2 Treatment of established tumors growing in the pancreas of nude mice $\quad 58$

5.2.6.3 In vivo evaluation of plasma concentration levels of AZM475271

5.2.6.4 Monitoring of mouse body weight and tumor volume ....... 58

5.2.6.5 Necropsy procedure and histopathological studies ............ 58

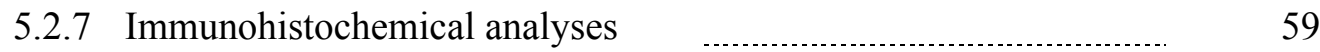

5.2.7.1 Immunohistochemistry of paraffin embedded tissues ....... 59

5.2.7.1.1 Haematoxylin and Eosin staining ..................... 59

5.2.7.1.2 Staining for Ki-67 antigen (The assessment of cell proliferation) $\quad$................................... $\quad 59$

5.2.7.2 Immunohistochemistry of snap-frozen tissues $\ldots$

5.2.7.2.1 Terminal deoxynucleotidyl transferasemediated nick end labeling (TUNEL) staining... $\quad 60$

5.2.7.2.2 Staining for CD31 ……............................ 61

5.2.7.2.3 Immunofluorescence double staining for CD31 and TUNEL _................................. 61

5.2.8 Statistical analysis $\quad 62$

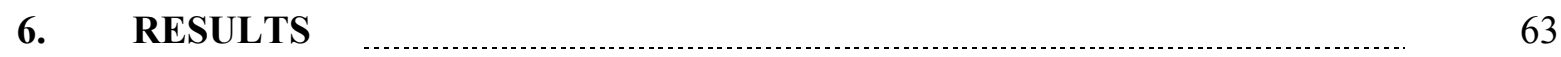

6.1 In vitro enzyme inhibition in HUVE and L3.6pl cells $\quad \ldots$

6.2 In vitro selectivity profile of AZM475271 _......................................... 64

6.3 AZM475271 inhibits tumor growth and metastasis in 
an orthotopic nude mouse model

6.4 In vivo evaluation of plasma concentration levels

6.5 Histological analysis of tissue sections ……................................... 72

6.5.1 In vivo effect of AZM475271 on tumor cell proliferation $\quad . . . . . . . . . . . \quad 72$

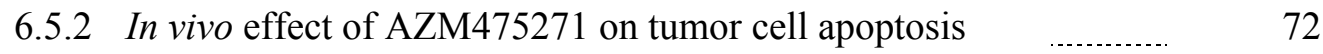

6.5.3 Quantification of microvessel density

in primary pancreatic tumors

6.5.4 In vivo effect of AZM475271 on endothelial cell survival _......... 75

6.6 In vitro antiproliferative activity of AZM475271

in L3.6pl and HUVE cells

6.7 In vitro effects of AZM475271 on VEGF- and EGF- dependent endothelial cell proliferation ............................................................ 79

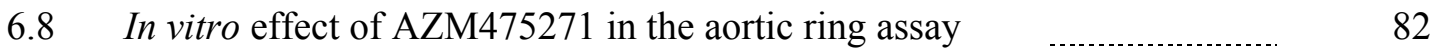

6.9 AZM475271 inhibits endothelial sprouting in vitro

in the spheroid angiogenesis model

6.10 Inhibition of VEGF production by L3.6pl and HUVE cells following treatment with AZM475271

6.11 In vitro induction of cell death in HUVECs ……................................ 88

6.12 In vitro inhibition of migration of HUVECs by AZM475271

6.13 AZM475271 abolishes VEGF-induced

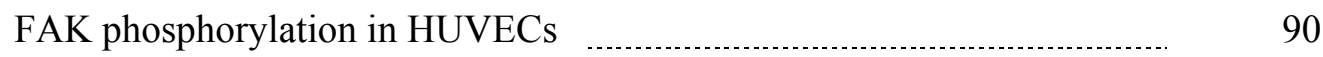

7. DISCUSSION

8. SUMMARY

9. ZUSAMMENFASSUNG

10. REFERENCES

11. ABBREVIATIONS

12. CURRICULUM VITAE

13. OWN PUBLICATIONS 


\section{Chapter 1}

\section{ACKNOWLEDGEMENTS}

This work was carried out at the Department of Surgery University of Munich-Grosshadern LMU.

First of all I would like to thank my family for their continuous support in my whole life, their love and friendship.

I would like to express my gratitude to Professor Dr. med. Dr. h.c. Karl-Walter Jauch, Director of the Department of Surgery for his friendly reception of this undertaking and the opportunity to develop my thesis in his clinic.

I am extremely grateful to PD Dr. Christiane Bruns, the best group leader, who gave me a primary opportunity to attend research work, for her continuous support and guidance.

I am very thankful to my colleagues, especially PD Dr. Markus Guba, PD Dr. Christian Graeb, Professor Christopher Heeschen, Dr. Peter Čamaj, Dr. Gerald Schmid, Dr. Barbara Mayer, Dr. Armine Papyan and all other members of the laboratory for their intellectual support, friendship, help and cooperation.

I would like to thank Michael Brueckel, Sabine Schroeferl and Michael Eder for their excellent technical assistance. 


\section{Chapter 2}

\section{ABSTRACT}

Tumor angiogenesis is a process that requires migration, proliferation, and differentiation of endothelial cells. We hypothesized that decrease in pancreatic tumor growth due to inhibition of src activity is associated with the inability of src kinase to trigger a network of such signaling processes, which finally leads to endothelial cell death and dormancy of angiogenesis.

The therapeutic efficacy of Src kinase inhibitor AZM475271 was tested in nude mice orthotopically xenografted with L3.6pl pancreatic carcinoma cells. No liver metastases and peritoneal carcinosis were detected and a significant effect on the average pancreatic tumor burden was observed following treatment with AZM475271, which in turn correlated with a decrease in cell proliferation and an increase in apoptotic endothelial cells. AZM475271 was shown to significantly inhibit migration of human umbilical vein endothelial cells in an in vitro Boyden Chamber cell migration assay. In a rat aortic ring assay we could demonstrate as well inhibition of endothelial cell migration and sprouting following therapy with Src kinase inhibitor at similar doses. Furthermore, we could show reduced proliferation of HUVECs determined with the TACS MTT Cell Viability Assay Kit. The blockade of Src kinase significantly reduced the level of VEGF in L3.6pl medium, the effect which was found also in the cell culture supernate from HUVECs. Inhibition of Src kinase by AZM475271 also showed prevention of survival signalling from VEGF and EGF receptors. Treatment with AZM475271 resulted in VEGF dependent inhibition of tyrosine phosphorylation of FAK. HUVECs were also examined using propidium iodide staining for cell cycle analysis by FACS. Inhibition of src kinase promoted HUVEC apoptosis in a dose-dependent manner.

Taken together, our results suggest that the Src kinase inhibitor AZM475271, in addition to its effects on tumor cells, suppresses tumor growth and metastasis in vitro and in vivo potentially also by anti-angiogenic mechanisms. 


\section{Chapter 3}

\section{INTRODUCTION}

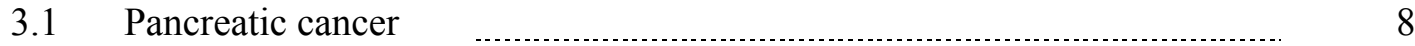

3.1.1 Epidemiology and clinical characteristics ……........................... 8

3.1.2 Standard chemotherapy of pancreatic cancer $\quad \ldots$

3.1.3 Molecular mechanisms of pancreatic carcinogenesis $\quad \ldots \ldots \ldots . . . . . \quad 10$

3.2 The role of angiogenesis in local and systemic tumor growth $\quad \ldots \ldots \ldots . . . . . . . .11$

3.2.1 Tumor angiogenesis _............................................................ 11

3.2.2 The angiogenic switch

3.2.3 Formation of tumor vessels ……….......................................... 12

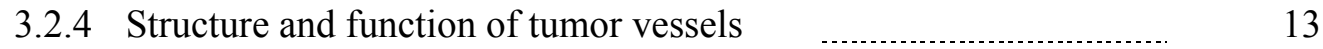

3.3 Angiogenic phenotype of pancreatic cancer ……................................... 14

3.4 Therapeutic angiogenesis

3.5 Kinases of the Src family nonreceptor protein tyrosine kinases $\quad \ldots . . . . . . . . . . . .16$

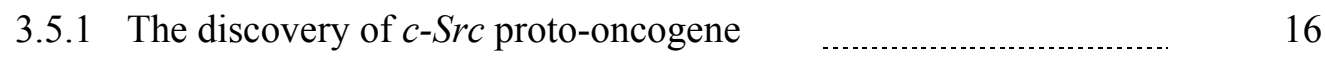

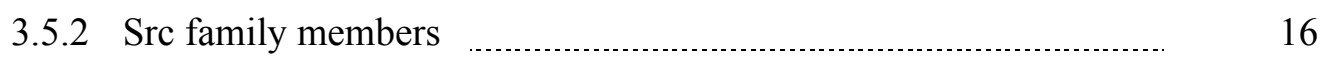

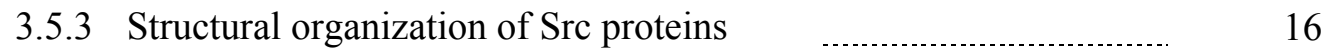

3.5.4 Structural differences between v-Src and c-Src proteins _........... 20

3.5.5 Regulation of Src kinases _..................................................... 20

$\begin{array}{lll}3.5 .6 & \text { Src substrates } & 22\end{array}$

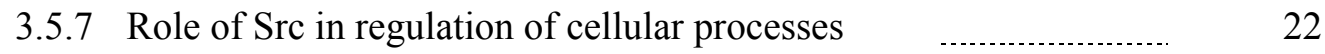

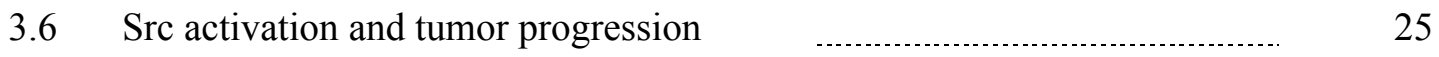

3.7 Src and tumor angiogenesis 26 


\subsection{Pancreatic cancer}

\subsubsection{Epidemiology and clinical characteristics}

Pancreatic cancer is one of the most fatal malignancies in humans and continues to be a major medical challenge in the western world. The incidence rate of about 10 per 100,000 equals the mortality rate, underscoring the devastating nature of this disease (Van Cutsem et al., 2004). The five-year survival rate for pancreatic cancer is very low, less than $3 \%$ (Jemal et al., 2002), the median overall survival is 3-6 months with a 12-month survival rate of 10\% (Bramhall et al., 1995). The very poor prognosis is due to late symptoms and the inability to detect this disease at early stages. Even with current diagnostic modalities, the inaccessible location of the pancreas often makes the diagnosis of pancreatic cancer a real challenge. Pancreatic cancer spreads early and most of the patients show liver or lymph node metastases at the time of diagnosis. More than $80 \%$ of patients have disease-related symptoms, such as jaundice, pain, asthenia, weight loss, and poor performance status (Cascinu et al., 1999). Even though painless jaundice occurs in about $50 \%$ of patients with respectable lesions of the pancreatic head, in general early symptoms are non-specific, and jaundice may also occur as a late symptom of large tumors of the body of the gland. Pain is the most frequent symptom and is present in $80 \%$ of patients with locally advanced tumors and metastatic disease (Van Cutsem et al., 2004). Nearly 90\% of pancreatic neoplasms are adenocarcinomas, arising from the exocrine ductal system. They are most often multicentric and $75 \%$ are located in the head of the pancreas. The etiology of pancreatic cancer is not well understood but risk factors such as smoking, chronic pancreatitis and positive family history are implicated (Ahlgren, 1996; Hruban et al., 1998; Li et al., 2004). To date, surgical resection is the only potentially curative treatment, but the majority of patients are not surgical candidates due to advanced disease or significant co-morbidity (Brand 2001). For over 80\% of pancreatic carcinoma patients, palliative treatment protocols represent the only reasonable therapeutic option (ASCO, 2006 Gastrointestinal Cancers Symposium).

This information indicates that current interventions to prevent, diagnose, and cure the disease are far from satisfactory. Only the understanding of the molecular mechanisms of pancreatic carcinogenesis will provide novel clues for preventing, detecting and ultimately curing patients with this life-threatening disease. 


\subsubsection{Standard chemotherapy of pancreatic cancer}

Gemcitabine (2',2'-difluoro-2'-deoxycytidine) represents the current standard drug for cytotoxic therapy of advanced pancreatic cancer. Gemcitabine is a pyrimidine analog with a wide spectrum of antitumor activity (Abbruzzese, 1996). It is metabolized intracellulary by nucleoside kinases to the active species gemcitabine-diphosphate (dFdCDP) and gemcitabine-triphosphate (dFdCTP). Incorporation of $\mathrm{dFdCTP}$ into DNA is responsible for the cytotoxic effects of gemcitabine, via inhibition of DNA synthesis, DNA repair and ultimately via induction of apoptosis. Moreover, gemcitabine is a radio-sensitizing agent which acts specifically in the $\mathrm{S}$ and G1/S phase of the cell cycle.

5-Fluorouracil (5-FU), a fluoropyrimidine analogue, is also one of the most commonly used anticancer drugs for the treatment of pancreatic cancer. Some studies reported that the cytotoxicity of fluoropyrimidines is mediated, in large part, by inhibition of the thymidylate synthase (Carreras et al; 1995). Thymidylate synthase (TS) is the critical target for fluoropyrimidine cytotoxic drugs. It provides the sole de novo source of thymidylate for DNA synthesis. TS catalyzes the methylation of dUMP (deoxyuridine-5'-monophosphate) to dTMP (deoxythymidine-5'-monophosphate), which forms a tight-binding covalent complex with TS (Danenberg, 1977).

Based on the results from different randomized trials, first-line and second-line gemcitabine treatment in patients with advanced pancreatic cancer reveal significant advantages compared to 5-FU treatment regarding disease stabilization, overall survival and clinical benefit response measured as a decrease in pain, functional impairment and weight loss (Burris et al., 1997; Carmichael et al., 1996; Casper et al., 1994; Rothenberg et al., 1996). Several studies have focused on gemcitabine plus cisplatin (Philip, 2002; Lund et al., 1996). However, a very recent meta-analysis of larger Phase II and Phase III trials did not show a significant advantage for gemcitabine-cisplatin combinations over gemcitabine monotherapy, regarding 6-month survival rate, clinical benefit and toxicity (Xie et al., 2006). Similary, combination of gemcitabine and irinotecan resulted in superior response rates but not in improvement of progression-free or overall survival (Rocha Lima et al., 2002, 2004; Stathopoulos et al., 2003). Other combinations with gemcitabine, such as the addition of docetaxel, pemetrexed and exatecan mesylate, have proved disappointing in larger trials (Jacobs, 2002; Kindler 2002; O’Reilly et al., 2004; Richards et al., 2004; Stathopoulos et al., 2001).

Taken together, gemcitabine represents the current standard drug for therapy of advanced pancreatic cancer, and surgical patients might benefit from adjuvant gemcitabine therapy. New 
conventional cytotoxic agents and other gemcitabine combinations might improve survival, but the improvement is likely to be small. Therefore, there is an urgent need for a better understanding of the mechanisms that contribute to pancreatic cancer growth and metastasis and for the design of more effective therapies for it.

\subsubsection{Molecular mechanisms of pancreatic carcinogenesis}

Over the past few years, our knowledge of the pathogenesis of pancreatic cancer has advanced significantly because of a rapid increase in our understanding of the molecular biology of it. Like many other malignant diseases, pancreatic cancer results from the accumulation of inherent and acquired genetic and epigenetic alterations. The multigenic nature of most pancreatic cancers is reflected by abnormalities of three broad classifications of genes: oncogenes, tumor suppressor genes and genomic maintenance genes (Sohn et al., 2000; Sakorafas et al., 2001). Accumulated alterations of such genes are believed to occur over a predictable time course. Based on the understanding of the histological and molecular genetic profiles of pancreatic cancer, investigators have developed a progression model that describes pancreatic ductal carcinogenesis: the pancreatic ductal epithelium progresses from normal epithelium to increasing grades of pancreatic intraepithelial neoplasia to invasive cancer (Hruban et al., 2000).

The majority of pancreatic cancers occur sporadically and have been fairly well characterized at the genetic level. Pancreatic cancer pathogenesis is apparently involved in the activation of several oncogenes and/or inactivation of various tumor suppressor genes (Sohn et al., 2000; Kern, 2000). Since the identification of the first notable genetic alteration of the K-ras oncogene, there has been an explosion in our understanding of pancreatic cancer genetics (Sohn et al., 2000; Kern, 2000). For examples, more than $85 \%$ of pancreatic cancers have an activating point mutation in the K-ras gene at a very early stage of development (Almoguera et al., 1988). Also, the tumor suppressor gene p16 is inactivated in about $95 \%$ of pancreatic cancers, and inactivation typically occurs late in pancreatic carcinogenesis. TP53, a well-characterized tumor suppressor gene located on chromosome $17 \mathrm{p}$, is the second most frequently inactivated gene. Furthermore, DPC4 or SMAD4 is inactivated in 55\% of pancreatic adenocarcinomas. Both TP53 and DPC4 inactivation are late events in pancreatic tumorigenesis. Other less common genetic alterations continue to be described in pancreatic cancer. In a comprehensive mutational analysis of 42 pancreatic cancers, Rozenblum et al. (1997) found that all of the tumors harboured mutations of the K-ras oncogene. The individual mutational frequency of the tumor suppressor genes p16, TP53, MADH4 and BRCA2 was $82,76,53$ and $10 \%$, respectively. Presumably, these 
alterations promote cellular proliferation, suppress apoptotic pathways, and facilitate tumor angiogenesis, invasion and metastasis.

However, the molecular mechanisms that link these genetic changes with the aggressive nature of pancreatic cancer remain poorly understood. These genetic alterations are generally perceived to eventually lead to various abnormalities in the expression and functions of a variety of growth factors and their receptors and to affect their downstream signal transduction pathways involved in the control of cell proliferation and differentiation (Li et al., 2004; Sakorafas et al., 2001; Kern, 2000; Korc, 2003). For example, pancreatic cancer cells overexpress many families of growth factors and their receptors, including epidermal growth factor (EGF), vascular endothelial growth factor (VEGF), fibroblast growth factor (FGF) and its receptor and plateledderived growth factor (PDGF), as well as many cytokines, such as transforming growth factor (TGF)- $\beta$, tumor necrosis factor- $\alpha$, interleukin (IL)-1, IL-6 and IL-8, which enhances mitogenesis (Korc, 2003; Xie et al., 2001, 2003 and 2004). Pancreatic cancer also exhibits loss of responsiveness to various growth-inhibitory signals, such as members of the TGF- $\beta$ family (Korc, 2003). The disturbed production and function of growth-promoting and -inhibiting factors are believed to confer a tremendous survival and growth advantage to pancreatic cancer cells, as manifested by the development of angiogenic, invasive and metastatic phenotypes that are resistant to all conventional treatments. The clinical importance of the findings described above is underscored by numerous experimental and clinical observations (Korc, 2003). For example, the concomitant presence of EGF receptor (EGFR) and either EGF or TGF- $\beta$ in the cancer cells is associated with disease progression and decreased survival. EGFR blockade with an antiEGFR antibody attenuates pancreatic tumor growth, and inhibition of EGFR tyrosine kinase activity suppresses pancreatic angiogenesis (Bruns et al., 2000). These findings are among the many that support the hypothesis that dysregulated production and function of growth factors has an important role in pancreatic cancer.

\subsection{The role of angiogenesis in local and systemic tumor growth}

\subsubsection{Tumor angiogenesis}

Tumor angiogenesis is the formation of new blood vessels from existing vessels and new circulating endothelial progenitor cells from bone marrow (Folkman, 1990). In 1971, Folkman proposed that tumor growth and metastasis are angiogenesis-dependent, and hence, blocking angiogenesis could be a strategy to arrest tumor growth (Folkman, 2000). This possibility stimulated an intensive search for pro- and anti-angiogenic molecules. In 1976, Gullino showed 
that cells in pre-cancerous tissue acquire angiogenic capacity on their way to becoming cancerous (Gullino, 1978). He proposed that this concept be used to design strategies to prevent cancer (Gullino, 1978), a hypothesis later confirmed by genetic approaches (Hanahan et al., 2000).

\subsubsection{The angiogenic switch}

It is now widely accepted that the "angiogenic switch" is "off" when the effect of pro-angiogenic molecules is balanced by that of anti-angiogenic molecules, and is "on" when the net balance is tipped in favour of angiogenesis (Hanahan et al., 2000; Bouck et al., 1996). Various signals that trigger this switch have been discovered (Table 3.1). Pro- and anti-angiogenic molecules can emanate from cancer cells, endothelial cells, stromal cells, blood and the extracellular matrix (Fukumura et al., 1998). Their relative contribution is likely to change with tumor type and tumor size, tumor growth, regression and relapse.

\subsubsection{Formation of tumor vessels}

Tumor vessels develop by sprouting or intussusception from pre-existing vessels. Circulating endothelial precursors, shed from the vessel wall or mobilized from the bone marrow, can also contribute to tumor angiogenesis (Asahara et al., 2000; Rafii, 2000). In addition, tumor vessels lack protective mechanisms that normal vessels acquire during growth. For example, they may lack functional perivascular cells, which are needed to protect vessels against changes in oxygen or hormonal balance, provide them necessary vasoactive control to accommodate metabolic needs, and induce vascular quiescence (Benjamin et al., 1999). Finally, the vessel wall is not always formed by a homogenous layer of endothelial cells (Jain, 1988). Instead, it may be lined with only cancer cells or a mosaic of cancer and endothelial cells. 


\section{Activators}

VEGF family members

VEGFR, NRP-1

Ang1 and Tie2

PDGF-BB and receptors

TGF- $\beta$ and receptors

FGF, HGF

Integrins

Plasminogen activators, MMPs
Function

Stimulate angio/vasculogenesis and permeability

Integrate angiogenic and survival signals

Stabilize vessels, inhibit permeability

Recruit smooth muscle cells

Stimulate extracellular matrix production

Stimulate angiogenesis

Receptors for matrix macromolecules and proteinases

Remodel matrix, release and activate growth factors
Inhibitors

VEGFR-1, soluble VEGFR-1

Ang2

TSP-1,-2

Angiostatin

Endostatin

Platelet factor-4

Prolactin

Interferons and interleukins
Function

Sink for VEGF, VEGF-B

Antagonist of Ang1

Inhibit endothelial migration, growth, adhesion and survival Suppresses tumor angiogenesis

Inhibits endothelial survival and migration

Inhibits binding of bFGF and VEGF

Inhibits bFGF/VEGF

Inhibit endothelial migration; downregulate bFGF

Table 3.1 Angiogenesis activators and inhibitors

\subsubsection{Structure and function of tumor vessels}

Tumor vessels are structurally and functionally abnormal: their walls have numerous "openings" and a discontinuous or absent basement membrane. In addition, the endothelial cells are abnormal in shape, growing on top of each other and projecting into the lumen. These defects make tumor vessels leaky (Hobbs et al., 1998; Hashizume et al., 2000; Dvorak et al., 1999). 


\subsection{Angiogenic phenotype of pancreatic cancer}

Although pancreatic cancer is not a grossly vascular tumor, it often exhibits enhanced foci of endothelial cell proliferation. Moreover, several (Korc, 2003; Seo et al., 2000; Linder et al., 2001; Fujioka et al., 2001; Mirecka et al., 2001; Stipa et al., 2002; Niedergethmann et al., 2002; Khan et al., 2002; Kuwahara et al., 2003; Shibaji et al., 2003; Karademir et al., 2000; Ikeda et al., 1999; Ellis et al., 1998) but not all (Fujimoto et al., 1998) studies have reported a positive correlation between blood vessel density and disease progression in cases of pancreatic cancer, supporting the important role of angiogenesis in this disease.

At the molecular level, numerous factors have been shown to be involved in pancreatic cancer angiogenesis. Among this growing list of growth factors, VEGF is believed to be critical for pancreatic cancer angiogenesis (Korc, 2003; Xie et al., 2004). Several studies have shown that VEGF expression correlates with microvessel density and disease progression (Korc, 2003; Seo et al., 2000; Niedergethmann et al., 2002, 2000; et al., 1999; Knoll et al., 2001). Additionally, VEGF-c is overexpressed in pancreatic cancer and correlated with enhanced lymph node metastasis (Tang et al., 2001). Moreover, pancreatic cancers overexpress several other mitogenic growth factors that are also angiogenic, such as EGF, TGF- $\alpha$, HGF, FGFs and PDGF- $\beta$ (Korc, 2003; Balaz et al., 2001). Together, these factors may produce mitogenic activity in an autocrine and paracrine fashion, promoting pancreatic tumor cell growth and angiogenesis and eventually enhancing pancreatic tumor invasion and metastasis.

\subsection{Therapeutic angiogenesis}

Inhibition of neo-angiogenesis is a new and attractive target for tumor therapy, since it theoretically offers the hope of long-term control of tumor progression. Antiangiogenic therapy offers a number of potential benefits including lack of resistance to some agents, synergistic interaction to other modalities, lack of significant toxicity compared with conventional agents, and a potent antitumor effect. Administration of angiogenesis inhibitors might keep the tumor and its metastases dormant (rather than killing it), and co-administration of cytotoxic drugs might kill it (Teicher et al., 1995; Satoh et al., 1998).

Consistent with the roles of the factors described above, anti-angiogenic therapies have been demonstrated to suppress tumor growth in animal models of pancreatic cancer (Bruns et al., 2000-2004). 
Based on successful preclinical data, several anti-angiogenic agents alone or in combination with conventional therapies are now in clinical trials (Table 3.2; www.cancertrials.nci.nih.gov). Numerous studies have been conducted to investigate the effects of different receptor tyrosine kinase inhibitors (Table 3.2).

\begin{tabular}{ll} 
Drug & \\
\hline $\begin{array}{l}\text { Phase I } \\
\text { PTK787/ZK2284 }\end{array}$ & Mechanism \\
Matuzumab & EGFR1 monoclonal antibody \\
Erlotinib & EGFR kinase inhibitor \\
Vatalanib & VEGFR kinase inhibitor \\
SU6668 & Blocks VEGF-, FGF- and PDGF-receptor signaling \\
Phase II & \\
Imatinib & PDGFR kinase inhibitor \\
Cetuximab & EGFR1 monoclonal antibody \\
Erlotinib & EGFR kinase inhibitor \\
Phase III & \\
SU5416 & Blocks VEGF-receptor signaling \\
Thalidomide & Unknown \\
AG3340 & Synthetic MMP inhibitor \\
Interferon- $\alpha$ & Inhibition of bFGF and VEGF production \\
IM862 & Unknown mechanism \\
Marimastat & Synthetic MMP inhibitor
\end{tabular}

Table 3.2 Angiogenesis inhibitors in clinical trials for cancer (including pancreatic cancer)

However, as tumors grow, they begin to produce a wider array of angiogenic molecules. Therefore, if only one molecule (for example, VEGF) is blocked, tumors may switch to another molecule (for example, bFGF or IL-8). Thus we may require a cocktail of antibodies/inhibitors.

Several oncogenes and their intracellular protein products such as v-src and v-ras induce the upregulation of angiogenic factors such as VEGF, EGF, bFGF and PDGF and increase the production of cytokines and proteolytic enzymes (Mukhadopathyay et al., 1995; Jiang et al., 1997; Kerbel et al., 1998; Okada et al., 1998; Kypta et al., 1990; Arbiser et al., 1997). In this respect, targeting intracellular proteins might be a promising approach in angiogenesis therapy of pancreatic cancer. 


\subsection{Kinases of the Src family nonreceptor protein tyrosine kinases}

One of the potential intracellular therapeutic targets receiving considerable recent attention is activation of c-Src, a nonreceptor protein tyrosine kinase. In pancreatic adenocarcinomas, src is activated in more than $70 \%$ of primary tumors (Coppola, 2000).

\subsubsection{The discovery of c-Src proto-oncogene}

In 1911, Peyton Rous first described a viral agent capable of inducing tumors in chickens providing evidence for the transmissible nature of cancer (Rous, 1911). This seminal work went largely unappreciated and uncorroborated until the 1950s, when tumor cells were shown to arise from infection with the Rous sarcoma virus (Rubin, 1955). This finding was confirmed when temperature sensitive activated $\mathrm{v}$-Src mutants failed to transform cells at non-permissive temperatures, demonstrating a requirement for the active virus in cellular transformation (Martin, 1970). In the 1970s, Brugge and colleagues isolated and identified v-Src as the transforming protein of the oncogenic Rous sarcoma virus utilizing tumor bearing rabbit serum (Brugge et al., 1977). Additional experiments demonstrated that the viral Src gene (v-Src) has a highly conserved and ubiquitously expressed cellular homologue, c-Src, which is present in normal cells (Stehelin et al., 1976). Src was not only the first proto-oncogene identified, it was also the first demonstrated to possess intrinsic protein kinase activity (Collett et al., 1978; Levinson et al., 1978) spawning both a search for similar protein tyrosine kinases and investigations into the role of Src in regulating cellular behavior. The last two decades have witnessed an explosion in Src research, including the recent development of selective small molecule inhibitors that target Src.

\subsubsection{Src family members}

The non-receptor protein tyrosine kinase Src is the prototypical member of a kinase family that includes Yes, Fyn, Lyn, Lck, Hck, Fgr, Yrk, Frk and Blk. This group is collectively known as the Src family kinases (SFKs), and, in contrast to receptor protein tyrosine kinases (VEGFR, EGFR, PDGFR), is not comprised of transmembrane proteins (Neet et al., 1996).

Tyrosine kinases catalyze the transfer of phosphate from ATP to a tyrosine residue of specific cell protein targets.

\subsubsection{Structural organization of Src proteins}

As a result of mutational studies and structural modeling based on crystallography data, the structure of Src has been well characterized. 
In vertebrates the proteins of the Src family have similar structure (Brown et al., 1996). The proteins of this group, ranging in molecular mass from 52 to $62 \mathrm{kD}$, comprise six distinct functional domains (Fig. 3.1 and 3.2): Src homology domain 4 (SH4), a unique domain, SH3 domain, $\mathrm{SH} 2$ domain, a catalytic domain (SH1), and a C-terminal regulatory region.

The SH4 domain is a region containing from 15 to 17 amino acid residues which comprises signals for modification with fatty acids (Rech, 1993). The glycine at position 2 is myristylated, thus binding protein tyrosine kinase (PTK) to the cell membrane. Nonmyristylated Src molecules do not bind to membranes. On the other hand, some Src molecules carrying this modification can be found unlinked in the cytosol. Myristylation probably does not guarantee association of the protein with the membrane. In addition to myristylation signals, the Src SH4 domain contains basic amino acid residues which are substrates for post-translational palmitylation. Only myristylated molecules are palmitylated and consequently this process probably occurs on the membrane. Palmitylation is a reversible process. Regulated depalmitylation and repalmitylation
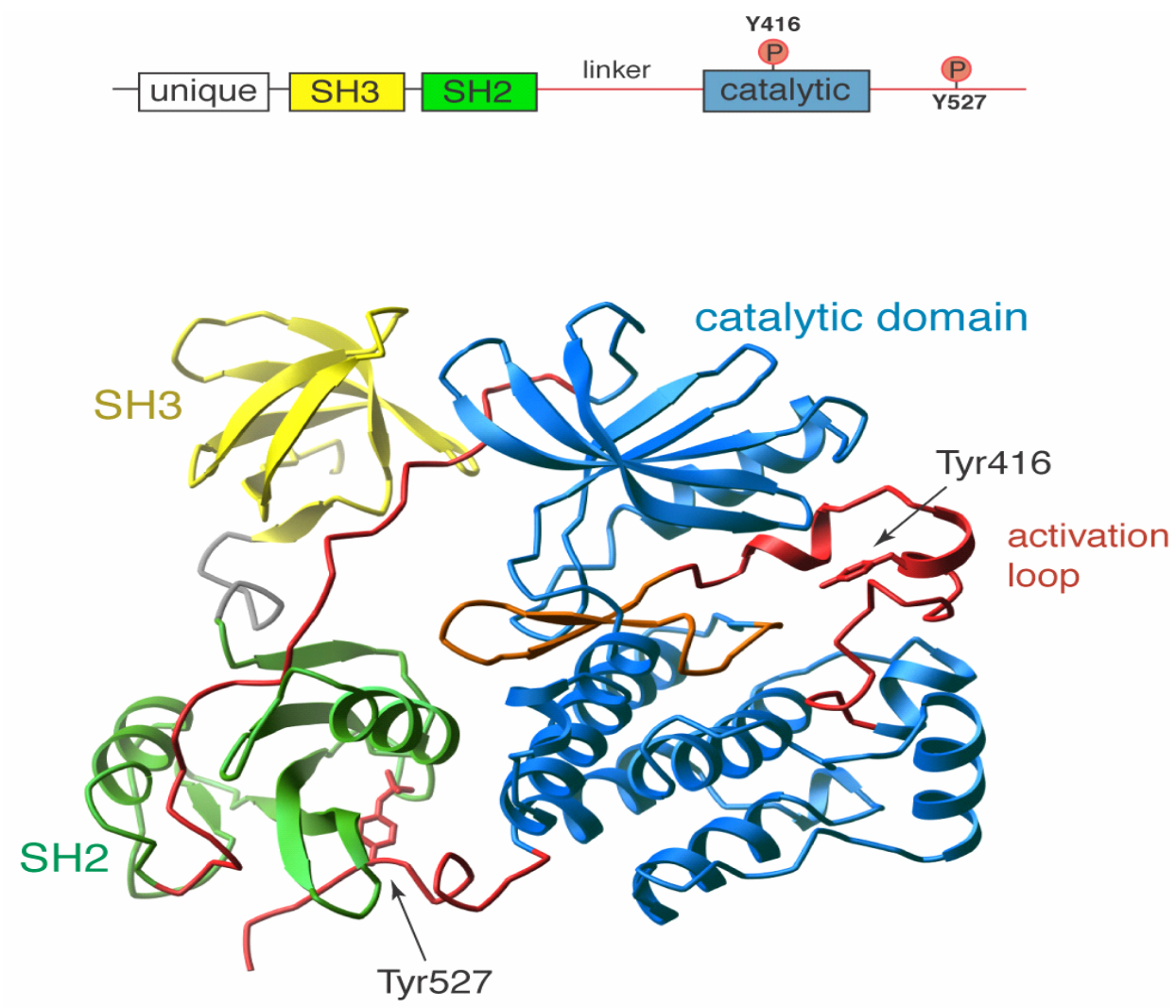

Figure 3.1 Ribbon diagram illustrating the structure of human Src. Key phosphorylation sites are included. 


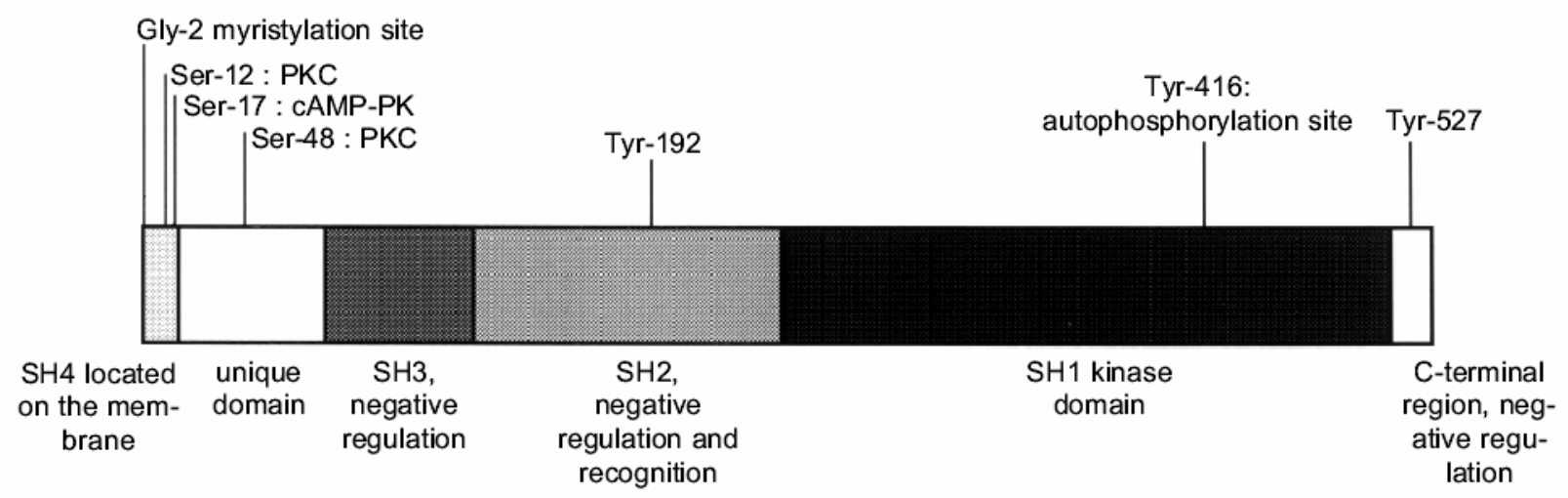

Figure 3.2 Domain structure of Src protein. Key phosphorylation sites are included.

may be a mechanism for the changing of the Src family kinases localization in response to corresponding stimulation (Kaplan et al., 1988; Pellman et al., 1985).

The unique domain (amino acid residues 18-84) is specific for each Src family protein. This region is suggested to be responsible for specific interaction of the PTK with particular receptors and protein targets (Thomas et al., 1997). At the same time, Src is a single member of the Src kinase group which is phosphorylated at Thr-34, Thr-46, and Ser-72 by a cyclin-dependent kinase (Cdc2) and cyclin B complex in M phase (Superti-Furga et al., 1995). The effect of this phosphorylation is unclear. Moreover, the unique domain contains the protein kinase $\mathrm{C}$ (PKC) binding sites - Ser-12 and Ser-48 - which are phosphorylated in the cells during PKC activation. The SH3 domain (amino acid residues 85-140) is necessary for interactions with protein substrates and it also ensures the intramolecular bindings controlling catalytic activity, protein localization in the cell, and association with protein targets (Pawson, 1995). The SH3 domain of Src has a globular structure, one side of which is slightly hydrophobic and contains a cluster of acidic residues. This domain binds to the proline-rich regions of PTK substrates. All known SH3 ligands carry a consensus sequence PXXP. Amino acid residues adjacent to pro-line determine specificity of SH3 domains (Riskles et al., 1995). The SH3 ligands may bind to this domain both in $\mathrm{NH}_{2}-\mathrm{COOH}$ and $\mathrm{COOH}-\mathrm{NH}_{2}$ orientation (Yu et al., 1994).

The SH3 sequences as well as the SH2 and the catalytic domains shown below, have been found in cellular proteins of different classes.

The SH2 domain is a second modulating region (amino acid residues 141-260), which controls the range of proteins interacting with the Src family kinases. The SH2 domains of different PTK recognize a short amino acid sequence carrying phosphotyrosine. From three to five amino acid 
residues following tyrosine determine the specificity of individual SH2 domains (Songyang et al., 1993). In kinases of the Src family this region is more conserved than the SH3 domain and can be tightly bound with specific proteins phosphorylated by tyrosine. The SH2 domains of Src and Lck kinases carry deep hydrophobic pockets for interactions of amino acid Ile at position $\mathrm{pY}$ +3 . Some proteins interacting with Src contain an optimum binding structure, pYEEI. However, not all proteins binding to the SH2 domain of Src possess such phosphorylated sequence.

A mutation in the SH2 domain in the region of amino acid residues from 142 to 169 leads to cell transformation (Raymond et al., 1987). This mutation probably affects Src binding to substrates, cytoskeletal proteins in particular (see below).

The kinase domain (amino acid residues 265-516) is found in all proteins of the Src family as well as in other PTK. It is responsible for tyrosine kinase activity and plays a crucial role in substrate specificity (Hesketh, 1995). Certain amino acid residues within this domain are identical in all kinases and involved in ATP binding and the phosphotransferase reaction (Hughes, 1996).

The kinases of the Src family may bind some substrates after phosphorylation, thus promoting phosphorylation of other sequences of one or several neighboring substrate molecules (Mayer et al., 1995). A strict specificity towards Tyr but not towards Ser or Thr is due to the close proximity of a conserved loop present in all tyrosine kinases ( $\mathrm{FP}^{425} \mathrm{IKWTA}$ in Src) to the main chain of the substrate. Proline facilitates binding to the phenylalanine ring of tyrosine, but is ineffective in binding substrates carrying serine or threonine.

Phosphorylation of Tyr-416 stimulates complete activation of Src and provides a binding site for SH2 domains of other cellular proteins. The elimination of Leu-516, highly conserved in all protein tyrosine kinases and located in the catalytic domain, interferes with the transforming activity of p60 v-Src (Yaciuk et al., 1986).

The C-terminal region (amino acid residues from 517 to 536 ) plays a significant role in regulation of Src kinase activity. All kinases of the Src family have a C-terminal region of 15-19 amino acid residues with tyrosine at the constant position surrounded by conserved amino acids (Tyr-527 in Src). It has been shown that elimination of phosphotyrosine from the normal Src increases its kinase activity (Schwartzberg, 1998). Phosphorylation of the C-terminal Tyr inhibits kinase activity by more than $98 \%$ and suppresses all stimulating effects caused by phosphorylation of Tyr-416 in the catalytic domain (Van Hoek et al., 1997). 


\subsubsection{Structural differences between v-Src and c-Src proteins}

The main difference between v-Src and c-Src is found in the structure of their C-terminal regions (Fig. 3.3). The last "tail" 19 amino acids of c-Src contain Tyr-527, which plays a regulatory role controlling kinase activity (Yaciuk et al., 1986; Dorai et al., 1991). In v-Src these 19 amino acids are replaced by 12 amino acids present in all known RSV strains. The only exception is v-SrcLM whose atypical structure is associated with a decreased metastatic potential of transformed cells (Tatosyan et al., 1996). It has been recently demonstrated that in metastases of human colon cancer, the c-Src protein has mutations just in this region. It should be mentioned that now this is the most reliable example of the role of mutations in the src gene in human carcinogenesis (Irby et al., 1999).

\section{Src structural domains}

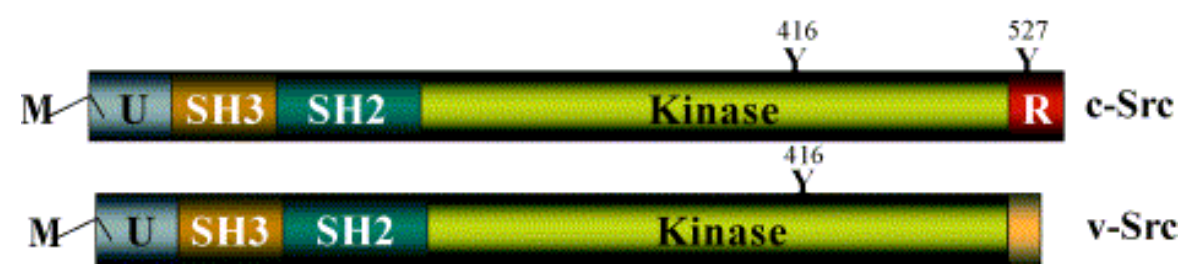

Figure 3.3 Domain structure of cellular (c-) and viral (v-) Src

\subsubsection{Regulation of Src kinases}

The SH2 and SH3 domains play a key role in regulation of catalytic activity of the Src family kinases. X-Ray analysis has demonstrated how intramolecular interactions between $\mathrm{SH} 2$ and SH3 domains stabilize inactive conformational structure of Src kinases. Both domains are adjacent to the kinase domain from the side opposite to the catalytic cleft. The SH3 domain interacts with the catalytic domain and linker sequences located between SH2 and catalytic domains (Fig. 4) (Xu et al., 1999). The SH2 domain interacts with phosphotyrosine at position 527 localized in the C-terminal region of the protein. Tyr-527 in c-Src, as well as the corresponding tyrosine residues in other PTK are the primary phosphorylation sites in vivo. This base is phosphorylated by the cytoplasmic kinase Csk (Nada et al., 1991). The loss of Tyr-527 or its dephosphorylation leads to stimulation of Src catalytic activity. This conclusion is based on a number of experimental data: the substitution of Tyr-527 by another amino acid residue constitutively activates c-Src (Kmiecik et al., 1987); this region is absent from the v-Src protein (Reynolds et al., 1987); the inhibition of the csk gene activity stimulates activity of PTK of the 
Src family (Imamoto et al., 1993). Therefore, it has been suggested that phosphorylation of the C-terminal tyrosine by Csk kinase provides intramolecular interaction of this region with the $\mathrm{SH} 2$ domain thus preserves the Src protein in a closed inactive form.

Mutations in the SH3 domain also lead to activation of Src kinases, although the role of the SH3 domain in inhibition of protein enzymatic activity is obscure. The kinase domain apparently remains accessible even in "closed" conformation, namely, when the $\mathrm{SH} 2$ domain is associated with phosphotyrosine at position 527 (Fig. 3.4). The SH3 domain forms an independent intramolecular contact with the N-terminal fragment of the kinase domain. Accordingly, kinase inactivation may result from the formation of a rigid structure stabilized by double bonds between the $\mathrm{SH} 2$ and $\mathrm{SH} 3$ domains and the catalytic region of the protein. Such structure prevents any movement inside the kinase domain. Mutations in any of the interacting regions of the Src protein disrupt the rigid structure of the molecule; this, in turn, destabilizes other intramolecular interactions. Consequently, both the $\mathrm{SH} 2$ and $\mathrm{SH} 3$ domains regulate kinase activity by intramolecular contacts. Abnormal interactions may be the main activation

a

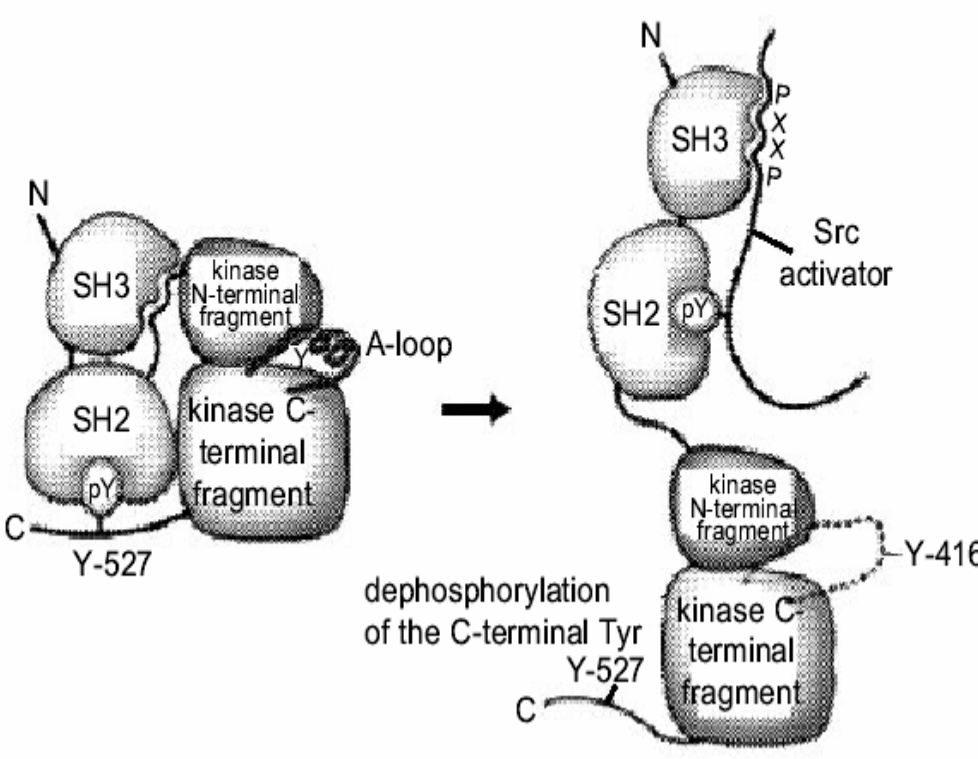

b

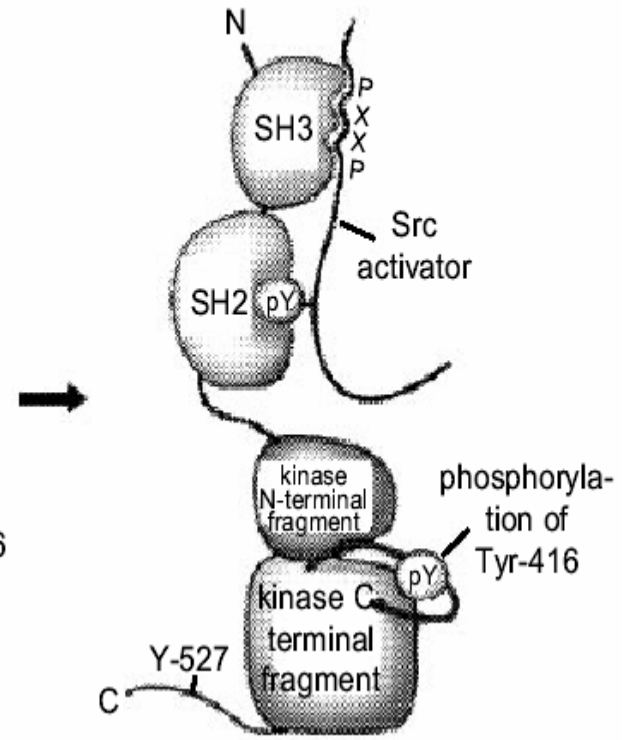

Figure 3.4 Regulation of Src activity:

a) Closed autoinhibited state;

b) Open intermediate state induced either by interactions of the $\mathrm{SH} 3$ and $\mathrm{SH} 2$ domains with the Src protein partners or by dephosphorylation of the C-terminal Tyr-527. This makes Tyr-416 accessible for phosphorylation;

c) Open activated form with phosphorylated Tyr-416 
mechanism of the Src proteins. It cannot be excluded that these domains play a similar role in regulation of kinase activity in proteins that lack phosphotyrosine in the $\mathrm{C}$-terminal region (Fps, Abl) (Pawson et al., 1992). It should be noted that the above-mentioned mechanism not only precisely regulates kinase activity of the Src proteins, but controls the interactions of SH2 and SH3 domains with other molecules, thus providing different levels of Src regulation.

As shown above, the regulation of Src activity occurs at two sites, the modification of each of them leads to opposite results. The phosphorylation of Tyr-416 in the activating loop of the kinase domain activates the enzyme, while the phosphorylation of the C-terminal Tyr-527 causes its inactivation. Different regulatory elements controlling Src activity affect only particular regions in the kinase domain. These effectors contain amino acid residues involved in catalysis or substrate binding (Sichei et al., 1997). They may be the activating loop (amino acid residues 404-432), the catalytic loop (the region around the amino acid at position 382), and the C-helix (the region around the amino acid at position 310). The modulation of their position and conformation by phosphorylation and interaction with regulatory subunits may control catalytic activity.

In vivo the Src kinase can be phosphorylated only at one of two tyrosine residues. The model for Src tyrosine kinase activation includes three subsequent stages (Fig. 3.4).

The activating loop plays a central role in regulating kinase activity. Its phosphorylation at Tyr416 in Src (or homologous amino acid residues in other tyrosine kinases) is necessary for complete activation of most kinases studied so far. In the absence of phosphorylation, the activating loop acquires different conformations, which often inhibit protein-protein interactions. A nonphosphorylated activating loop can inhibit kinase activity either directly, disturbing the region involved in activation, or indirectly, conferring a specific conformation, which prevents substrate binding. Conversely, in the phosphorylated state, the conformation of the activating loop is similar in all known kinases. In this active conformation the loop forms a part of the site recognized by the substrates (Xu et al., 1997).

\subsubsection{Src substrates}

The proteins tyrosine phosphorylated as a result of $\operatorname{src}$ gene function are briefly summarized in Table 3.3.

\subsubsection{Role of Src in regulation of cellular processes}

c-Src is a multifunctional protein involved in the regulation of a variety of normal processes, including proliferation, differentiation, survival, motility, angiogenesis, and functions of fully 
differentiated cells (Thomas and Brugge, 1997). To carry out these activities, c-Src interacts with numerous cellular factors, including cell surface receptors (EGF family, CSF-1, PDGF, and FGF receptors, as well as integrins, cell-cell adhesion molecules, etc. [Biscardi et al., 2000; Irby and Yeatman, 2000; Owens et al., 2000; Moro et al., 2002]), steroid hormone receptors (Migliaccio et al., 1996, 2000; Boonyaratanakornkit et al., 2001), components of pathways regulated by heterotrimeric G proteins (Luttrell et al., 1999; Ma et al., 2000), STATs (Silva et al., 2003), focal adhesion kinase (FAK) (Kaplan et al., 1994), the adaptor proteins p130Cas (Burnham et al., 2000) and Shc (Sato et al., 2002), and many others. Each of these partners represents a different class of proteins and functions in unique signaling pathways for

\begin{tabular}{|c|c|c|}
\hline Protein target & Function & $\begin{array}{l}\text { Src domain } \\
\text { responsible for } \\
\text { binding }\end{array}$ \\
\hline $\begin{array}{l}\text { p85 subunit } \\
\text { of PI-3 kinase }\end{array}$ & noncatalytic PI-3 kinase subunit & $\mathrm{SH} 3, \mathrm{SH} 2$ \\
\hline RasGAP & GTPase activator Ras & \\
\hline SHPTP2/Syp & phosphotyrosine phosphatase & \\
\hline She & $\begin{array}{l}\text { binds Grb2, an adaptor protein participating in translocation of the factors } \\
\text { involved in nucleotide metabolism (GEF) to the membrane where Ras is located, } \\
\text { thus activating a signal pathway }\end{array}$ & \\
\hline $\mathrm{PLC} \gamma$ & PI-specific phospholipase C & \\
\hline p62 & RasGAP-associated protein & \\
\hline p190 & GTPase activator Rho & \\
\hline Tensin & binding to actin, integrin-dependent signal transduction mechanism & \\
\hline Vinculin & binding to actin, integrin-dependent signal transduction mechanism & \\
\hline Cortactin & binding to cortical actin & SH2 \\
\hline Talin & binding to actin and integrin, integrin-dependent signal transduction mechanism & \\
\hline Paxilline & integrin-dependent signal transduction mechanism & SH3 \\
\hline AFAP110 & associated with actin filaments & $\mathrm{SH} 3, \mathrm{SH} 2$ \\
\hline FAK & $\begin{array}{l}\text { tyrosine kinase, binding to integrin and integrin-dependent signal transduction } \\
\text { mechanism }\end{array}$ & SH2 \\
\hline$\beta 1$-Integrin & formation of adhesive complexes and signal transduction mechanism & \\
\hline $\mathrm{p} 130^{\mathrm{CAS}}$ & integrin-dependent signal transduction mechanism & $\mathrm{SH} 2$ \\
\hline $\mathrm{p} 120^{\mathrm{CAS}}$ & catenin, cell adhesion & \\
\hline$\beta$-Catenin & binding to integrin, intercellular adhesion & \\
\hline$\gamma$-Catenin & cell adhesion & \\
\hline Sam68 & RNA binding & $\mathrm{SH} 2, \mathrm{SH} 3$ \\
\hline $\begin{array}{l}\text { Calpactin I - } \\
\text { annexin II }\end{array}$ & $\mathrm{Ca}^{2+}$-phospholipid binding & \\
\hline
\end{tabular}

Table 3.3 Target proteins for Src kinases 
which the molecular nature and biological consequences of the interactions with c-Src have been investigated. The interactions between c-Src and other molecules can be found in Figure 3.5. Src is also implicated in invasion and angiogenesis, the latter property of which will be extensively discussed below (3.7).

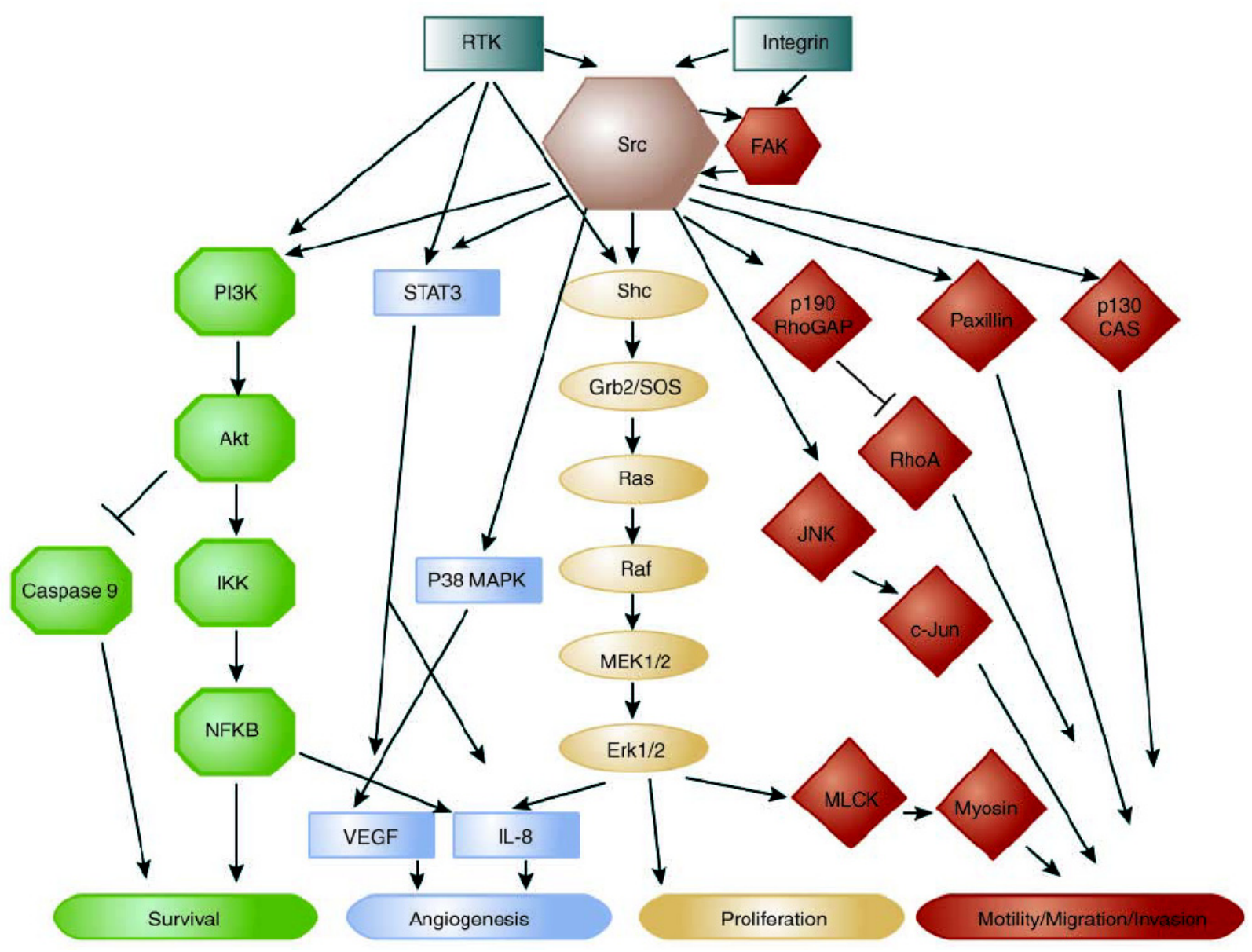

Figure $3.5 \mathrm{c}-\mathrm{Src}$ is a protein involved in the regulation of a variety of biological processes, including proliferation, differentiation, survival, motility, angiogenesis, and functions of fully differentiated cells.

RTK, receptor tyrosine kinase; PI3K, phosphatidylinositol 3-kinase; STAT3, signal transducers and activators of transcription 3; IKK, InB kinase; MAPK, mitogen-activated protein kinase; MEK, mitogen-activated protein kinase kinase; ERK, extracellular signal-regulated kinase; NF$\kappa \mathrm{B}$, nuclear factor- $\kappa \mathrm{B} ; \mathrm{FAK}$, focal adhesion kinase. 


\subsection{Src activation and tumor progression}

The likely regulators, or types of regulation, which can lead to Src's conformational "opening" and activation that might occur in cancer cells are shown in Figure 3.6.

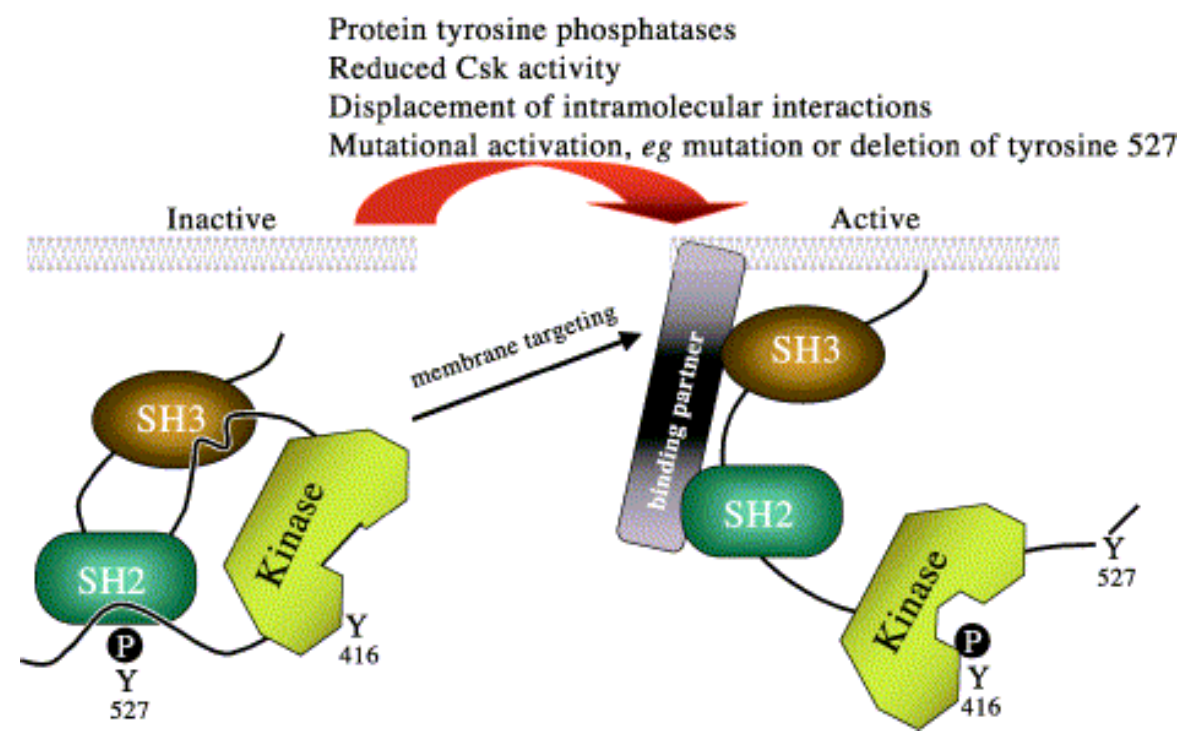

Figure 3.6 Regulation of Src activity in tumor cells

The relationship between Src activation and cancer progression appears to be significant. The evidence underlying this hypothesis is largely based on the observation that both Src protein levels and, to a greater degree, Src protein kinase activity, are frequently elevated in human neoplastic tissues when compared to adjacent normal tissues. Moreover, these levels appear to increase with the stage of disease. Similarly, increased Src protein kinase activity has been observed in numerous human cancer cell lines derived from these tumors.

Src kinase activity, from 4 - 20-fold higher than normal tissues, has been found in human mammary carcinomas (Egan et al., 1999; Jacobs and Rubsamen, 1983; Muthuswamy et al., 1994; Verbeek et al., 1996). Similarly, cell lines derived from these tumors display up to a 30 fold elevation in Src activity.

The c-Src proto-oncogene has frequently been implicated in the initiation and progression of human colon cancer (Bolen et al., 1987a; Cartwright et al., 1989, 1990, 1994; Weber et al., 1992). Src activity is increased 5 - 8-fold in the majority of colon tumors.

Elevated Src protein levels and/or kinase activity has been reported in lung (50 - 80\%) (Mazurenko et al., 1992), neural (23/27 neuroblastomas, 3/3 retinoblastomas) (Bjelfman et al., 
1990; Bolen et al., 1985), ovarian (Budde et al., 1994; Wiener et al., 1999), esophageal (3 - 4fold increases in activity in Barrett's esophagus and 6-fold elevations in adenocarcinomas) (Kumble et al., 1997) and gastric cancers (Takeshima et al., 1991), as well as melanoma (Bjorge et al., 1996) and Kaposi's sarcoma (Munshi et al., 2000).

Src activity has recently been studied in pancreatic cancer. Lutz et al. (1998) examined pancreatic ductal carcimonas as well as pancreatic cell lines for elevated Src protein levels and kinase activity. Src protein levels were elevated in 13/13 pancreatic cancers and in 14/17 pancreatic cell lines. Kinase activity was only detectable in cancer cells and this activity did not correlate with either the c-Src or Csk protein levels.

\subsection{Src and tumor angiogenesis}

There is a significant amount of data supporting the influence of Src on tumor angiogenesis and metastasis.

Src activation is required for hypoxia-mediated expression of VEGF (Mukhopadhyay et al., 1995). More recently, Trevino et al. (2005) have shown that Src regulates both constitutive and growth factor-induced VEGF and interleukin-8 expression and that Src activation up-regulates VEGF mRNA transcription by activation of signal transducers and activators of transcription 3, which forms a complex with hypoxia-inducible factor-1 and other factors on the VEGF promoter (Gray et al., 2005). The experiments by Ellis et al. (1998) demonstrated that antisense Src strategy was effective in reducing both constitutive and hypoxic-induced VEGF production in a human colon carcinoma cell line. In addition, how Src links between VEGF stimulation and the control of cell survival remains to be determined. It has been shown that receptor tyrosine kinases activate Src by autophosphorylation of tyrosine residues that function as docking sites for the SH2 domain of Src kinases on the receptor itself or by phosphorylation of docking proteins. Binding of the SH2 domain of Src to tyrosine phosphorylation site on VEGFR or on a docking protein releases Src from the autoinhibited state and enables the catalytic activity to be stimulated by autophosphorylation of a key tyrosine residue in the activation loop of the catalytic core. Once activated, Src could link VEGF-stimulation with the PDK/PKB signaling cassette leading to stimulation of endothelial cell survival and angiogenesis.

There is also evidence that Src cooperates with the EGFR in growth signaling (Roche et al., 1995; Wilson et al., 1989). Fibroblasts that overexpress Src display an enhanced mitogenic response to EGF, an effect that is independent on Src's myristylation and catalytic activity (Luttrell et al., 1988). However, the molecular understanding of synergy between Src and the 
EGFR in mitogenic signaling is much less advanced than for PDGFR (Mori et al., 1993; Broome et al., 1999; Stover et al., 1996), although it seems likely that Src and activated EGFR form a complex and that EGF induces Src activation (Biscardi et al., 1999).

Further, Karni et al. have demonstrated the ability of constitutively active Src to induce HIF1alpha under normoxic conditions (Karni et al., 2002) suggesting that Src activation, regardless of mechanism, can augment VEGF production and angiogenesis. Ongoing work from this laboratory has demonstrated a role for Src in regulating VEGF expression in other tumor types including pancreatic cancer, where Src activation of the PI3kinase/Akt signaling pathway is required (Summy et al., 2006). As Src is a regulator of multiple signal transduction pathways, it should not be surprising that Src is important in regulating other pro-angiogenic factors such as bFGF, and IL-8.

In addition to regulating VEGF and bFGF expression, Src regulates responses to these factors in both tumor and endothelial cells. Elicieri and co-workers have shown both bFGF and VEGF are able to induce Src activation in avian endothelial cells (Elicieri et al., 1999). Additionally, overexpression of the dominant negative Src induces apoptotic cell death in the VEGF-treated endothelial cells suggesting a survival function for Src during VEGF-induced angiogenesis. Similar results were obtained when utilizing a virus that encodes Csk, a protein tyrosine kinase that inhibits Src activity by phosphorylating Tyr-530 in the c-terminal tail.

Overexpression of a kinase-inactive Src also resulted in reduced phosphorylation of paxillin and cortactin, suggesting a role for Src in actin cytoskeletal rearrangement and migration (Kilarski et al., 2003).

As in tumor cells, activated Src promotes a mesenchymal-like phenotype in endothelial cells, increasing migratory potential of these cells as well (Potter et al., 2005).

There is convincing evidence that the linked activities of Src and focal adhesion kinase (FAK) control cell migration. In support of a role for Src, cells expressing kinase-defective v-Src have enlarged focal adhesions and their migration is suppressed (Fincham et al., 1998). Src and FAK co-localize at integrin adhesion sites and cooperate with growth factor receptors, such as EGF and PDGF to induce signaling pathways that control diverse aspects of cell behavior, including growth, survival and migration (Figure 3.7). 


\section{Src-induced signalling from membrane/adhesions that controls cell behaviour}

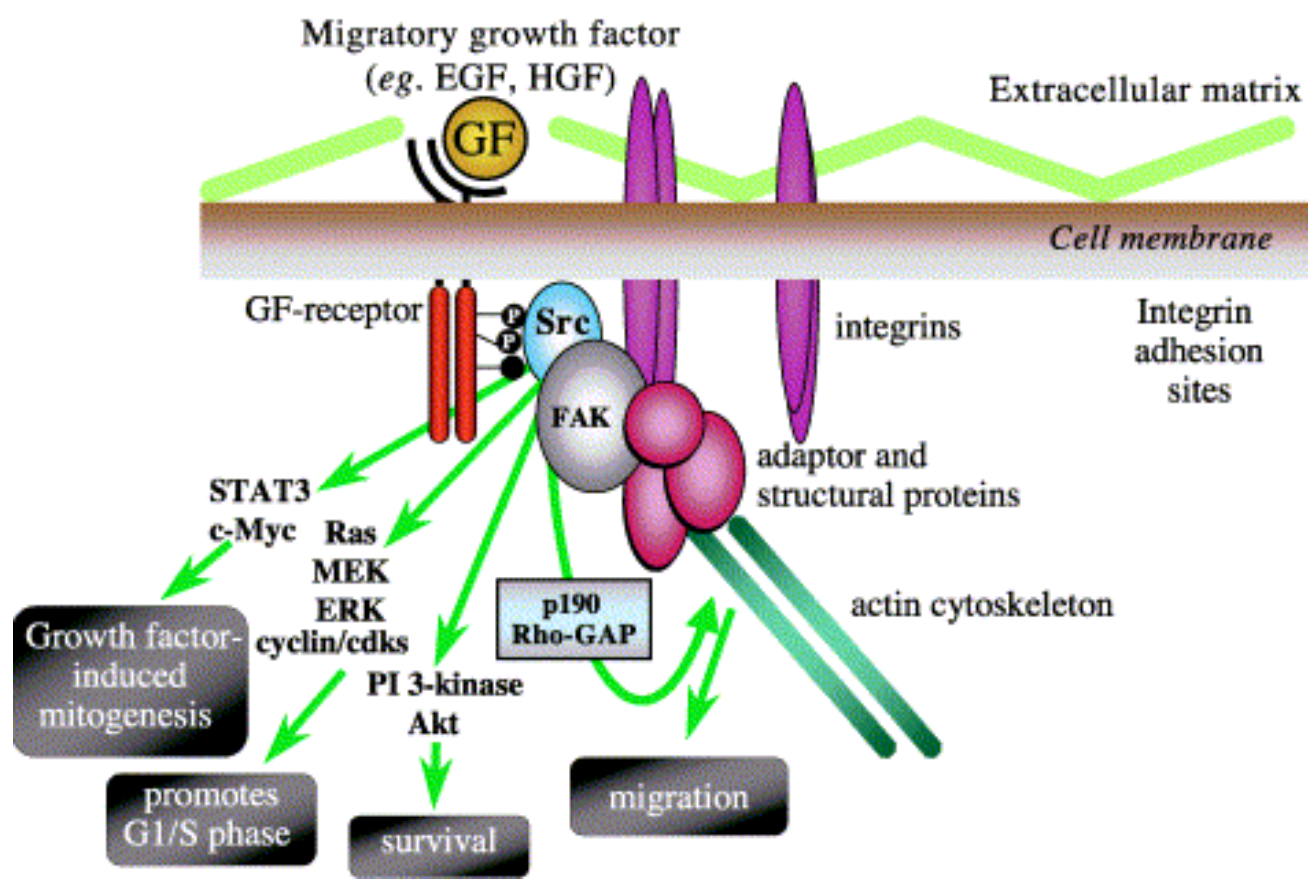

Figure 3.7 Src, FAK and adhesion turnover during fibroblast migration (Frame, 2002)

Current results suggest Src activation in tumor cells indirectly regulates Src activity in endothelial cells. Increased Src activity in the tumor cells increases VEGF expression, resulting in increased binding to VEGF receptors on endothelial cells. This process then leads to association of Src with these receptors, increasing Src activity in endothelial cells as well. This continuing cycle promotes Src-mediated increases in migratory potential and permeability of endothelial cells and facilitates tumor cell extravasation (Figure 3.8). The importance of targeting tumor-associated endothelial cells for therapeutic efficacy has been highlighted from recent work on inhibitors of receptor tyrosine kinases in clinical trial (Table 3.2) (Yokoi et al., 2005; Thaker et al., 2005; Yazici et al., 2005; Lev et al., 2005, Yigitbasi et al., 2004). Inhibitors of Src thus have the potential to interfere with this cycle by affecting biological functions in both tumor and tumor-associated endothelial cells that contribute to metastasis. 


\section{Tumor Cells}

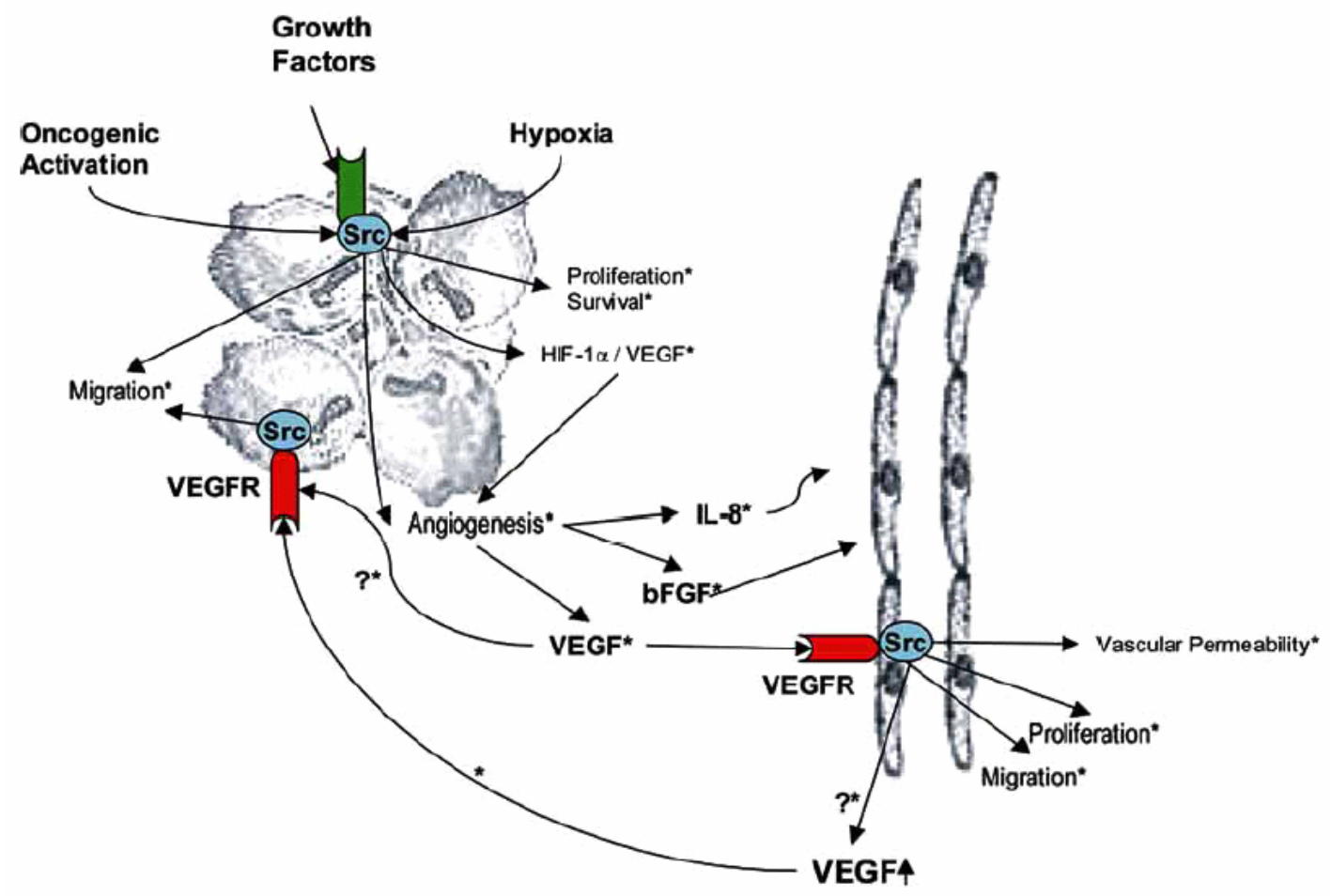

Figure 3.8 Model by which Src activity mediates biologic functioning of tumor cells and endothelial cells, and promotes intercellular signaling to promote tumor progression and metastasis. * Indicates the signaling molecules and/or cellular functions potentially affected by Src kinase inhibition. 


\section{Chapter 4}

\section{THESIS PROPOSAL}

The prevalence of activated Src in cancer indicates that this protein plays a significant role in the progression of many cancers, but since all of them (and specially pancreatic cancer) are angiogenesis dependent, the main goal of the work described in this thesis was to demonstrate the role of Src family protein kinases in pancreatic tumor progression with special emphasis on angiogenic regulation, and how Src inhibitors may affect this process (Figure 4).

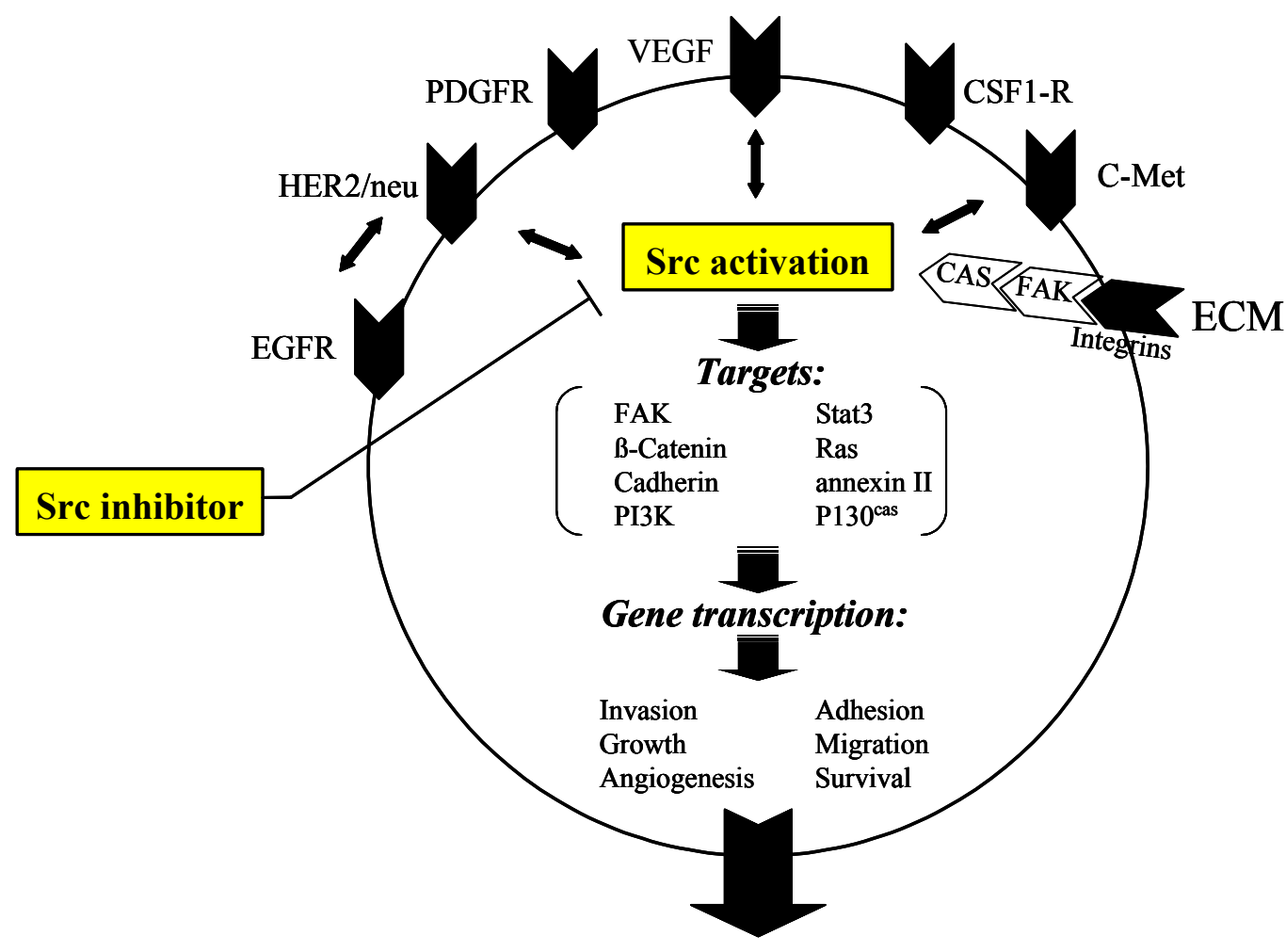

Oncogenesis

Figure 4 Thesis proposal: inhibition of Src tyrosine kinase as an anti-angiogenic therapy of human pancreatic cancer 


\section{Chapter 5}

\section{MATERIALS AND METHODS}

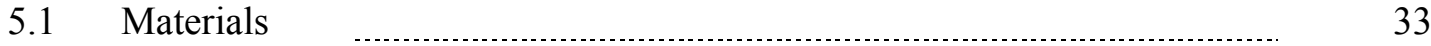

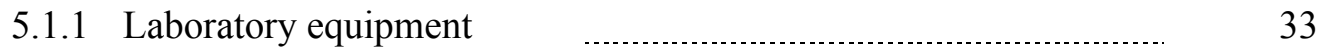

5.1.2 Chemical reagents and other research solutions

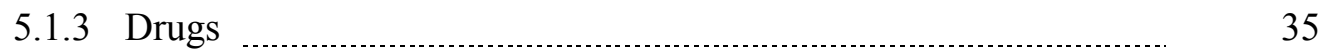

5.1 .4 Cell lines 36

5.1.5 Media and supplements

5.1.6 Growth factors

5.1.7 Kits and other research products

5.1.8 Antibodies

5.1.9 Animals for in vivo experiments $\quad$ …........................................ 40

5.1.10 Materials used for in vivo studies $\quad$ …......................................... 40

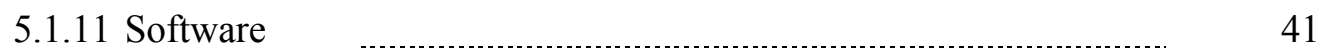

5.1.12 Buffers

5.2 Methods 45

5.2.1 Cell biological methods $\quad$............................................... 45

5.2.1.1 Cell culture techniques _....................................... 45

5.2.1.2 Cell quantification and evaluation of viability $\quad \ldots . . . . . . . . . . .46$

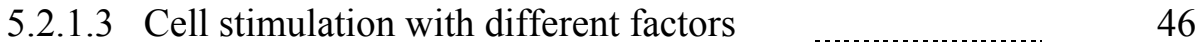

5.2.1.4 Storage of cells $\quad \ldots$

5.2.1.5 Detection of viable cells _......................................... 47

5.2.1.6 Inhibition of growth factor-mediated proliferation ............ 48

5.2.1.7 Chemotaxis assay _..................................................... 48

5.2.2 Biochemical methods $\quad$................................................. 49

5.2.2.1 Inhibition of protease activity $\ldots$

5.2.2.2 Preparation of cellular extracts using RIPA buffer ............ 49

5.2.2.3 Determination of protein concentration 


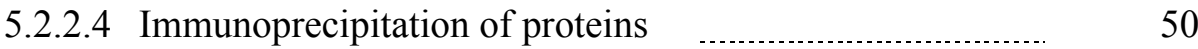

5.2.2.5 SDS-Polyacrylamidgelelectrophoresis PAGE ……...... 50

5.2.2.6 Transfer of proteins to PVDF membrane _........................ 51

5.2.2.7 Ponceau S staining of proteins on PVDF membrane .......... 52

5.2.2.8 Analysis of proteins on PVDF membrane

by immunoblotting ................................................... 52

5.2.2.9 Stripping and re-probing of western blot ……............... 53

5.2.3 Determination of apoptotic cells by FACS analysis

via propidium iodide staining 53

5.2.4 Enzyme-linked immunoassays

5.2.4.1 Determination of human vascular endothelial growth factor concentrations in cell culture supernates $\quad \ldots \ldots \ldots \ldots . . . . . \quad 53$

5.2.4.2 In vitro Src kinase inhibition test …............................... 54

5.2.5 In vitro study of angiogenesis

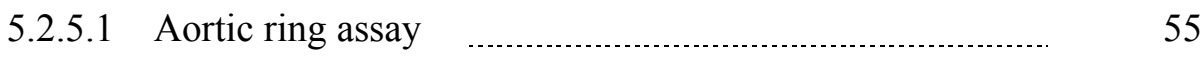

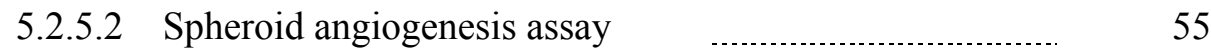

5.2.6 Orthotopic xenograft pancreatic tumor model $\ldots \ldots \ldots \ldots \ldots \ldots \ldots \ldots . . . . . . . . . . . . .56$

5.2.6.1 Tumor cell implantation _........................................... 56

5.2.6.2 Treatment of established tumors growing in the pancreas of nude mice $\quad 58$

5.2.6.3 In vivo evaluation of plasma concentration levels of AZM475271 58

5.2.6.4 Monitoring of mouse body weight and tumor volume ....... 58

5.2.6.5 Necropsy procedure and histopathological studies ............ 58

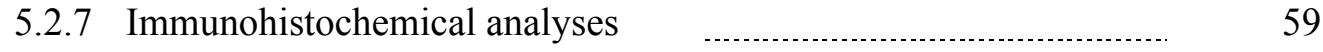

5.2.7.1 Immunohistochemistry of paraffin embedded tissues ....... 59

5.2.7.1.1 Haematoxylin and Eosin staining ..................... 59

5.2.7.1.2 Staining for Ki-67 antigen (The assessment of cell proliferation) $\quad 59$

5.2.7.2 Immunohistochemistry of snap-frozen tissues $\ldots$

5.2.7.2.1 Terminal deoxynucleotidyl transferasemediated nick end labeling (TUNEL) staining ... $\quad 60$

5.2.7.2.2 Staining for CD31

5.2.7.2.3 Immunofluorescence double staining 
for CD31 and TUNEL

5.2.8 Statistical analysis

\subsection{Materials}

\subsubsection{Laboratory equipment}

$0.45 \mu \mathrm{m}$ sterile filters

$-20^{\circ} \mathrm{C}$ Freezer

$4^{\circ} \mathrm{C}$ Fridge

$5 \mathrm{ml}$ FACS tubes

$-80^{\circ} \mathrm{C}$ Freezer

Automatic pipettes

AxioCam MRc5 camera

Blotting chamber

BD Biocoat ${ }^{\mathrm{TM}}$ Matrigel invasion chamber

Cell counting chambers

Centrifuges

$\mathrm{CO}_{2}$ Incubators

Digital Precision Scale

Embedding cassettes

Fluorescence-activated cell sorter (FACS)

Gel electrophoresis systems

Heating block

Hybond-P membrane

Hyperfilm

Kinetic microplate reader

Laminar flow hoods

Liquid nitrogen tank

Microscopes

$\mathrm{pH}$-meter

Positively-charged superfrost slides

Rocking Platforms

Rotary microtome

Semi-Dry Electrophoretic Transfer Cell
BD Falcon, France

Siemens AG, Germany

Siemens AG, Germany

BD Biosciences, Belgium

Heraeus, Hanau, Germany

Gilson, Middleton, WI, USA

Carl Zeiss GmbH, Germany

Bio-rad, Munich, Germany

BD Biosciences, Belgium

Bürker-Türk, Germany

Eppendorf, Germany

Heraeus, Rodenbach, Germany

KERN \& Sohn GmbH, Germany

Leica Microsystems GmbH, Germany

Becton Dickinson, USA

Bio-rad, Munich, Germany

Biometra, Germany

Amersham Biosciences, Germany

Amersham Biosciences, Germany

$v$ max, USA

Heraeus, Hanau, Germany

MVE, New Prague, MN, USA

Carl Zeiss GmbH, Germany

WTW, Weilheim, Germany

Menzel-Glaeser, Germany

Biometra GmbH, Göttingen, Germany

Leica Microsystems GmbH, Germany

Bio-rad, Munich, Germany 
Sterile cell scrapers

Sterile cryotube vials

Sterile tissue culture plastic flasks and plates

Sterile tissue culture plastic tubes, dishes, pipets

Tissue embedding console system

Vortex

Water bath

X-ray film developing machine
TPP, Switzerland

TPP, Switzerland

NUNC, Denmark

TPP, Switzerland

Sakura, Torrance, CA, USA

IKA Works, Wilmington, NC, USA

GFL, Burgwedel, Germany

AGFA, Germany

\subsubsection{Chemical reagents and other research solutions}

2-Mercaptoethanol

3,3',5,5'-Tetramethylbenzidine tablets (TMB)

$30 \%$ Acrylamide/Bis Solution

4',6-diamino-2-phenylindole (DAPI)

D,1-Dithiothreitol (DTT)

Acetic acid 96\%

Ammonium Persulfate

Aprotinin

ATP

Bovine serumalbumin (BSA)

Dimethylsulfoxide (DMSO)

EDTA

Protein G Sepharose 4 fast flow

Ethanol

Glycerol

Glycine for electrophoresis

HEPES

Isopropanol

Leupeptin A

Magnesium Chloride

Methanol

Nonidet P-40

Phenylmethylsulfonyl fluoride (PMSF)

Phosphate citrate buffer with Sodium Perborate
Merck, Darmstadt, Germany

Sigma-Aldrich GmbH, Germany

Roth, Karlsruhe, Germany

Molecular Probes, USA

Sigma-Aldrich GmbH, Germany

Sigma-Aldrich GmbH, Germany

Sigma-Aldrich GmbH, Germany

Roche Diagnostics GmbH, Germany

Sigma-Aldrich GmbH, Germany

Sigma-Aldrich GmbH, Germany

Sigma-Aldrich GmbH, Germany

Sigma-Aldrich GmbH, Germany

Amersham Biosciences, Germany

Merck, Darmstadt, Germany

Merck, Darmstadt, Germany

Merck, Darmstadt, Germany

NeoLab GmbH, Germany

Merck, Darmstadt, Germany

Roche Diagnostics GmbH, Germany

Merck, Darmstadt, Germany

Merck, Darmstadt, Germany

Roche Diagnostics GmbH, Germany

Sigma-Aldrich GmbH, Germany

Sigma-Aldrich GmbH, Germany 
Poly (Glu, Tyr) sodium salt

Ponceau S

Pre-stained protein ladder

Protease inhibitor cocktail tablets

Skim milk powder (blotting grade)

Sodium Chloride

Sodium Citrate

Sodium Hydroxide

Sodium Vanadate

Sodiumdodecylsulfat (SDS)

Sulphuric Acid

Tetramethylethylendiamine (TEMED)

Tris base

Triton-X100

Propidium Iodide

Human fibronectin

Trypan blue

Tween 20

Water for molecular biology

Xylene
Sigma-Aldrich GmbH, Germany

Sigma-Aldrich GmbH, Germany

Invitrogen Corporation, Germany

Roche Diagnostics GmbH, Germany

Sigma-Aldrich GmbH, Germany

Merck, Darmstadt, Germany

Sigma-Aldrich GmbH, Germany

Sigma-Aldrich GmbH, Germany

Sigma-Aldrich GmbH, Germany

Biorad, Munich, Germany

Merck, Darmstadt, Germany

ICN Biomedicals Inc, Aurora, USA

Sigma-Aldrich GmbH, Germany

Sigma-Aldrich GmbH, Germany

Sigma-Aldrich GmbH, Germany

Sigma-Aldrich GmbH, Germany

Serva, Heidelberg, Germany

Merck, Darmstadt, Germany

Maxim Biotech GmbH, Germany

Merck, Darmstadt, Germany

\subsubsection{Drugs}

AZM475271 (Scheme 5.1) is a novel anilinoquinazoline inhibitor of c-Src. AZM475271 was synthesized and kindly provided by AstraZeneca Pharmaceuticals (Macclesfield, United Kingdom). For in vivo administration, AZM475271 was dissolved in Tween 20 diluted 1:100 in $\mathrm{NaCl}$, for in vitro applications the AZM475271 stock was prepared in DMSO and stored at + $4^{\circ} \mathrm{C}$.

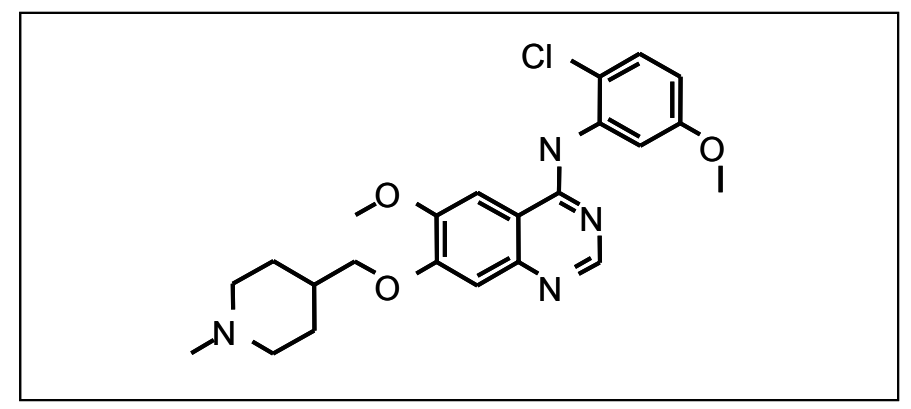

Scheme 5.1 Structure of the novel anilinoquinazoline inhibitor of c-Src AZM475271 
4-Amino-5-(4-chlorophenyl)-7-(t-butyl)pyrazolo[3,4-d]pyrimidine (PP2, Calbiochem, San Diego, CA, USA) is a potent and selective inhibitor of the Src family of tyrosine kinases that is similar to PP1. For in vitro studies PP2 (Scheme 5.2) was used as a comparable chemotherapeutic agent. PP2 was supplied as a $3.33 \mathrm{mmol} / \mathrm{L}$ stock in DMSO and stored at + $4^{\circ} \mathrm{C}$.

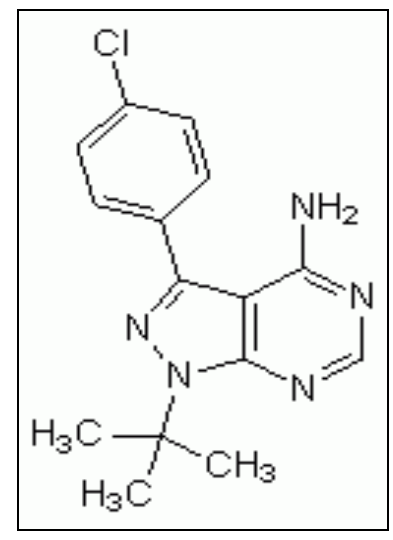

Scheme 5.2 Structure of the selective inhibitor of the Src family of protein tyrosine kinases PP2

\subsubsection{Cell lines}

\section{Human highly metastatic pancreatic carcinoma cell line L3.6pl}

For our in vivo and in vitro experiments we used variants of a human pancreatic adenocarcinoma cell line COLO 357. This cell line derived from a celiac axis lymph node that was partially replaced by neoplastic foci of well differentiated mucin-containing pancreatic ducts and it was originally isolated 1980 by a group from Colorado Morgan et al.

For in vivo selection of highly metastatic human pancreatic cancer cells, we injected cells from the original fast growing, low metastatic FG cell line derived from COLO 357 into the pancreas of nude mice. To produce liver lesions, human pancreatic cancer cells implanted into the pancreas must complete all the steps of the process. The lesions then are designated as spontaneous metastases. Spontaneous liver metastases were then harvested, established in tissue culture, and designated as L3.4pl. Cells harvested from these cultures were injected into the pancreas of another set of nude mice. Liver lesions were again isolated and cells were established in culture. After three such selection cycles, the cell line L3.6pl was established in culture (Fig. 5.1). Cytogenetic analysis confirmed the human origin of the cells. 


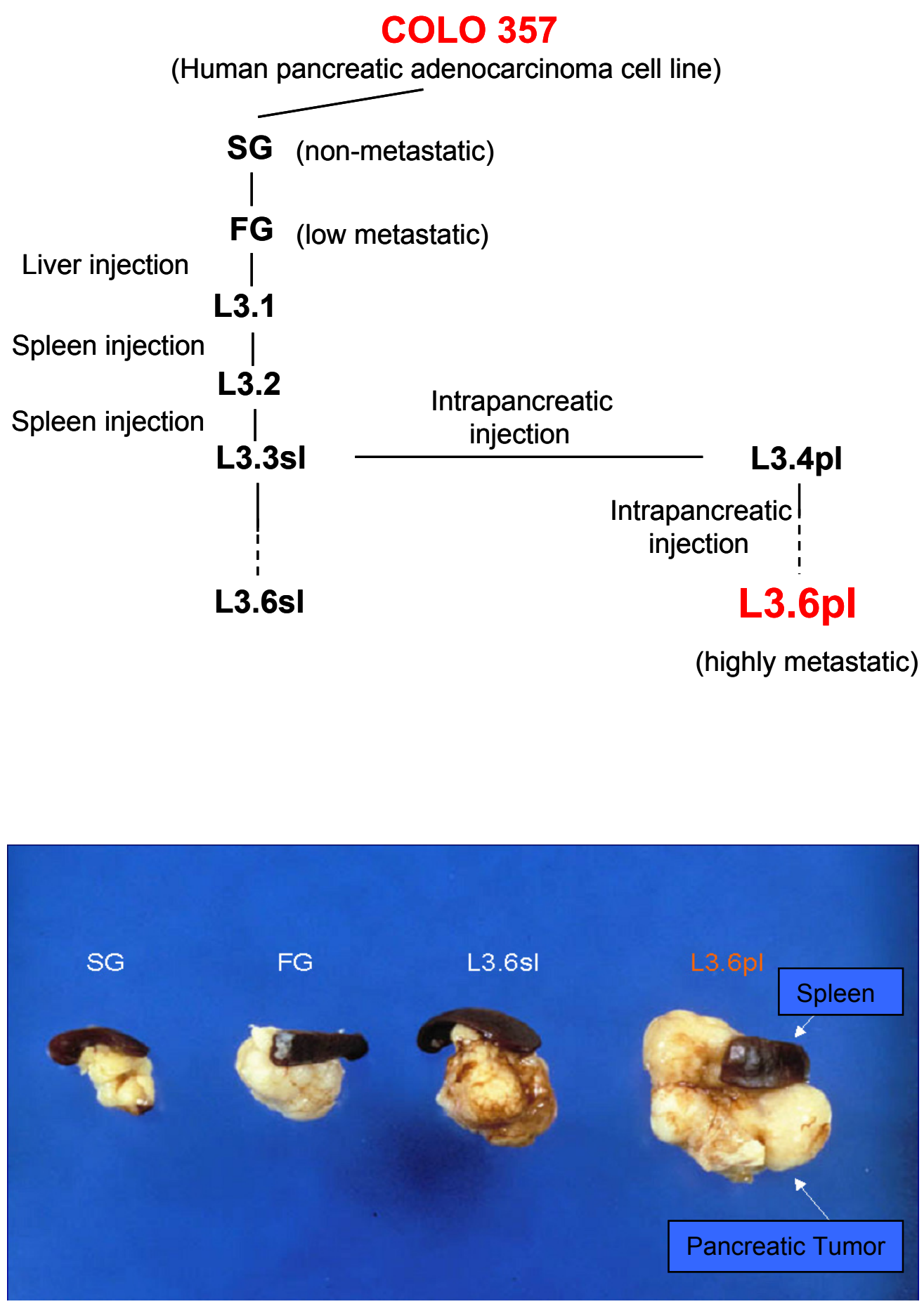

Figure 5.1 In vivo selection of metastatic human pancreatic cancer cells 
The highly metastatic cell line L3.6pl showed an aggressive primary tumor growth in nude mice with spontaneous liver metastases (50\% of animals) and spontaneous lymph nodes metastases ( $100 \%$ of animals), $50 \%$ of animals bearing L3.6pl cancer died after 36 days, whereas more then $60 \%$ of animals after the injection of parental FG cell line survived up to 100 days (Fig. 5.2). L3.6pl cells produced pro-angiogenetic factors such as VEGF, bFGF, as well as IL-8 and tumor samples presented with a high amount of microvascularisation. In vitro studies, IHC analyses and in situ hybridization of tumor samples showed a significantly low expression of E-cadherine and MMP-9/2 level in L3.6pl cells in contrast to the parental cell line (Bruns et al., 1999).

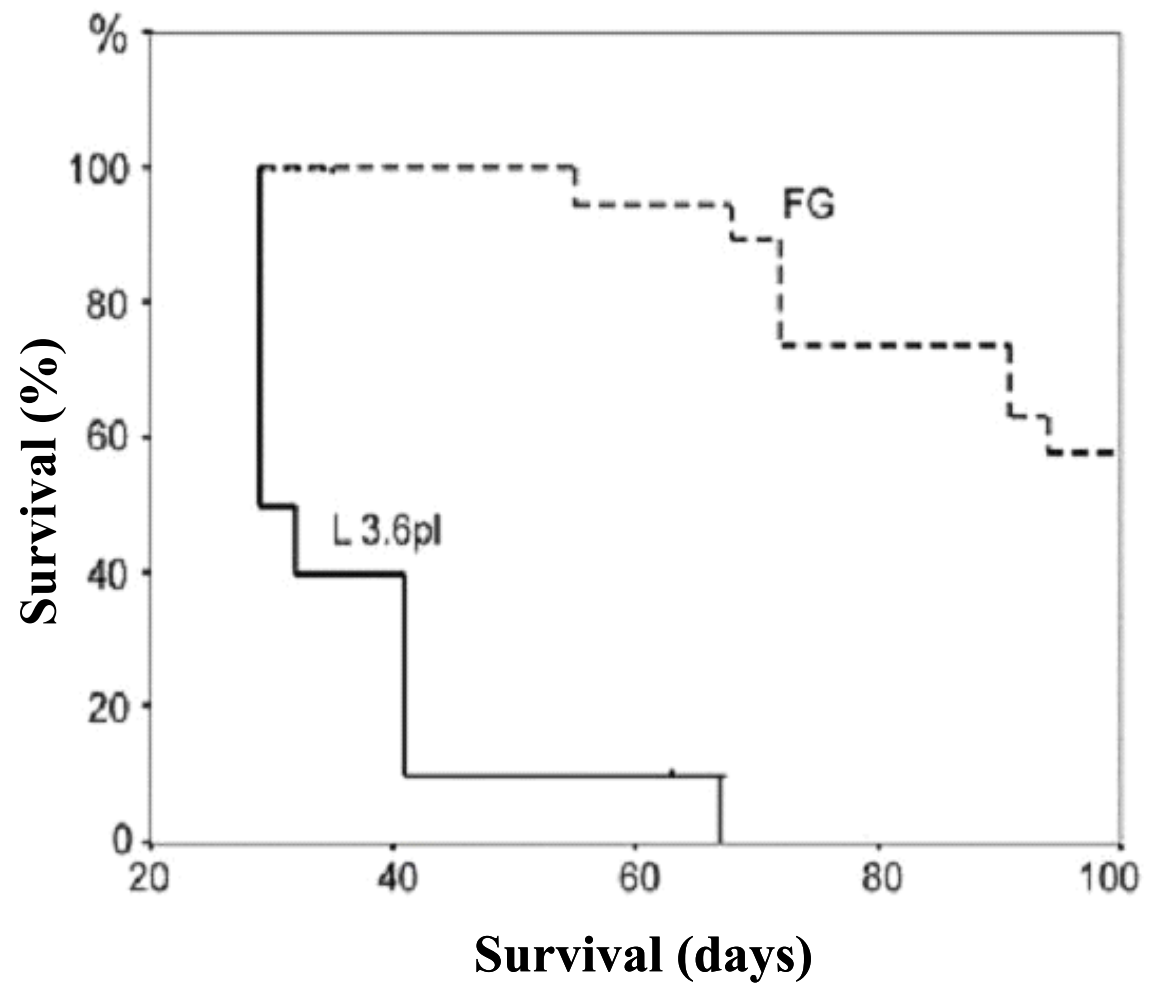

Figure 5.2 Kaplan-Meier survival test

\section{Human umbilical vein endothelial cells (HUVECs)}

HUVECs were purchased from PromoCell (PromoCell GmbH, Heidelberg, Germany).

\subsubsection{Media and supplements}


10-fold vitamin solution

Ampicillin

Dulbecco's Modified Eagle Medium (D-MEM)

Endothelial Cell Growth Medium

Fetal Bovine Serum (FBS)

Fetal Calf Serum

Human fibronectin

Kanamycin

L-Glutamin

Nonessential amino acids (10-fold solution)

Penicillin-streptomycin mixture

Sodium Pyruvate

\subsubsection{Growth factors}

bFGF

ECGS/H

Human recombinant EGF

Human recombinant $\mathrm{VEGF}_{165}$

Hydrocortison

PDGF

\subsubsection{Kits and other research products}

Avidin-biotinylated Horseradish

Peroxidase Complex (ABC Kit)

BCA $^{\text {TM }}$ Protein Assay Reagent Kit

DeadEnd ${ }^{\text {TM }}$ Fluorometric TUNEL System

ECL $^{\circledR}$ Western Blotting Detection System

Enhanced Chemiluminescence System

Human VEGF Immunoassay Kit

Immunoprecipitation Kit

Restore $^{\text {TM }}$ Western Blot Stripping Buffer

TACS MTT Cell Proliferation and
Biochrom AG, Berlin, Germany

Gibco Invitrogen, Germany

Gibco Invitrogen, Germany

PromoCell GmbH, Germany

Biochrom AG, Berlin, Germany

PromoCell GmbH, Germany

Sigma-Aldrich GmbH, Germany

Gibco Invitrogen, Germany

Biochrom AG, Berlin, Germany

Biochrom AG, Berlin, Germany

Biochrom AG, Berlin, Germany

Gibco Invitrogen, Germany

PromoCell GmbH, Germany

PromoCell GmbH, Germany

R\&D Systems, Wiesbaden, Germany

R\&D Systems, Wiesbaden, Germany

PromoCell GmbH, Germany

PromoCell GmbH, Germany

Vector Laboratories, CA, USA

Pierce, Rockford, USA

Promega, Madison, WS, USA

Amersham Biosciences, Germany

Amersham Biosciences, UK

R\&D Systems, Minneapolis, MN, USA

Sigma-Aldrich GmbH, Germany

Pierce, Rockford, IL, USA 
Viability Assay Kit

R\&D Systems, Minneapolis, MN, USA

\subsubsection{Antibodies}

Anti-FAK monoclonal

Anti-phospho-tyrosine monoclonal, HRP

Anti-pTyr 576/577 FAK monoclonal

Anti- $\beta$-actin monoclonal

Anti-v-src (Ab-1) monoclonal

CD31/PECAM-1 rat anti-mouse monoclonal

Goat anti-rabbit polyclonal, biotinylated

Goat anti-rabbit, HRP

$K i-67-$ specific rabbit anti-human polyclonal

Rabbit anti-rat polyclonal, HRP
Cell Signaling Inc., Germany

Santa Cruz Biotechnology, CA, USA

Cell Signaling Inc., Germany

Sigma-Aldrich GmbH, Germany

Oncogene, San Diego, CA, USA

Pharmingen, San Diego, CA, USA

Vector Laboratories, CA, USA

Amersham, Freiburg, Germany

Zymed GmbH, Germany

DAKO, Germany

\subsubsection{Animals for in vivo experiments}

Male immunodeficient Balb/c nu/nu mice were purchased from Charles River Laboratories (Sulzfeld, Germany). The mice were housed and maintained in laminar flow cabinets under specific-pathogen-free conditions in facilities of Institute for Surgical Research (Munich, Germany). The mice were quarantined during the acclimatization period of at least a week. Food (Standard 1320 and 1430; Altromin, Lange, Germany) and acidified water (pH 2.5-3.0) were available ad libitum. Regular health checks were done. The mice were used in accordance with institutional guidelines when they were 8-12 week of age.

Male ACI rats were purchased from Harlan Winkelmann GmbH (Borchen, Germany). The rats were kept at two per cage under climatized conditions and were given standard food (Standard 1320 and 1430; Altromin, Lange, Germany) and water ad libitum. The rats were used in accordance with institutional guidelines when they were 6-8 weeks old.

All procedures were performed in accordance with current regulations and standards of the animal protect orders.

\subsubsection{Materials used for in vivo studies}


Atropine Sulfate

Cotton applicators

Cutasept $^{\circledR} \mathrm{F}$

Disposable scalpels

Gauze swabs

Ketavet

Mouse gavage feeding needle

Pushbutton-controlled dispensing device

Sodium Chloride Solution

Suture material

Syringes, needles

Xylazin (Rompun), 2\%
Braun AG, Germany

NOBA Verbandmittel GmbH, Germany

Bode Chemie, Hamburg, Germany

Feather Safety Razor Co., Japan

NOBA Verbandmittel GmbH, Germany

Pfizer Pharmacia GmbH, Germany

Kent Scientific, Torrington, USA

Hamilton Syringe Company, USA

Braun AG, Germany

Braun AG, Germany

BD Biosciences, Spain

Bayer HealthCare, Germany

\title{
5.1.11 Software
}

Adobe Acrobat 5.0

Adobe Acrobat Distiller 5.0

Adobe Photoshop 5.0

AxioVision 4.4

SOFTmax 2.32

Cellquest Pro

Image2PDF 1.4.5

Image J $1.33 \mathrm{u}$

InStat 3.0

Microsoft Office 2002

Origin 6.0

SPSS 8.0

Windows XP Professional

WinMDI 2.8
Adobe Systems Inc., USA

Adobe Systems Inc., USA

Adobe Systems Inc., USA

Carl Zeiss GmbH, Germany

Molecular Devices Corp., USA

Beckton Dickinson, USA

Verypdf.com Inc., USA

$\mathrm{NIH}$

Graphpad Software, USA

Microsoft Corporation, USA

Microcal Software Inc., USA

SPSS STATISTICS Inc., USA

Microsoft Corporation, USA

Joseph Trotter

\subsubsection{Buffers}

\section{PBS Wash Buffer, 1X}

\author{
$140 \mathrm{mM} \quad \mathrm{NaCl}$
}




$\begin{array}{ll}2.7 \mathrm{mM} & \mathrm{KCl} \\ 10 \mathrm{mM} & \mathrm{Na}_{2} \mathrm{HPO}_{4} \\ 1.8 \mathrm{mM} & \mathrm{KH}_{2} \mathrm{PO}_{4}\end{array}$

High purity $\mathrm{dH}_{2} \mathrm{O}, \mathrm{pH} 7.4$

\section{PBS-T}

$1 X P B S$

$0.1 \% \quad$ Tween-20

\section{Kinase Buffer, 1X}

$\begin{array}{ll}25 \mathrm{mM} & \text { Tris-HCl, } \mathrm{pH} 7.5 \\ 5 \mathrm{mM} & \text { Beta-glycerophosphate } \\ 2 \mathrm{mM} & \text { Dithiothreitol } \\ 0.1 \mathrm{mM} & \mathrm{Na}_{3} \mathrm{VO}_{4} \\ 10 \mathrm{mM} & \mathrm{MgCl}_{2}\end{array}$

Src Kinase Dilution Buffer, 1X

$\begin{array}{ll}100 \mathrm{mM} & \text { HEPES } \\ 2 \mathrm{mM} & \text { Dithiothreitol } \\ 0.2 \mathrm{mM} & \text { activated } \mathrm{Na}_{3} \mathrm{VO}_{4} \\ 0.02 \% & \text { BSA } \\ 3 \text { Unit/ml } & \text { Src Kinase }\end{array}$

\section{RIPA Lysis Buffer, 1X}

\begin{tabular}{ll}
$50 \mathrm{mM}$ & Tris- $\mathrm{HCl}, \mathrm{pH} 7.4$ \\
$150 \mathrm{mM}$ & $\mathrm{NaCl}$ \\
$1 \%$ & Nonidet $\mathrm{P}-40$ \\
$1 \mathrm{mM}$ & activated $\mathrm{Na}_{3} \mathrm{VO}_{4}$ \\
$1 \mathrm{mM}$ & PMSF \\
$5 \mathrm{mM}$ & EDTA, $\mathrm{pH} 8.0$ \\
$1 \mu \mathrm{g} / \mathrm{ml}$ & Aprotinin \\
$1 \mu \mathrm{g} / \mathrm{ml}$ & Leupeptin \\
\multicolumn{2}{c}{ Filter sterilized }
\end{tabular}


Protease and phosphatase inhibitors were added freshly before cell lysis.

\section{Laemmli Buffer, 2X}

$\begin{array}{ll}0.5 \mathrm{M} & \text { Tris-HCl, } \mathrm{pH} 6.8 \\ 5 \% & \text { B-Mercaptoethanol } \\ 0.1 \% & \text { Bromophenol Blue } \\ 20 \% & \text { Glycerol } \\ 4 \% & \text { SDS }\end{array}$

Towbin Transfer Buffer, 1X

$\begin{array}{ll}25 \mathrm{mM} & \text { Tris- } \mathrm{HCl}, \mathrm{pH} 8.3 \\ 192 \mathrm{mM} & \text { Glycine } \\ 20 \% & \text { Methanol }\end{array}$

High purity $\mathrm{dH}_{2} \mathrm{O}$

Tris Buffered Saline (TBS) Buffer, 10X

$\begin{array}{ll}1 \mathrm{M} & \text { Tris- } \mathrm{HCl}, \mathrm{pH} 7.4 \\ 1.5 \mathrm{M} & \mathrm{NaCl}\end{array}$

\section{TBS-T Buffer}

$1 X T B S$

0.1\% Tween-20

\section{SDS Electrophoresis Buffer, 10X}

$\begin{array}{ll}0.25 \mathrm{M} & \text { Tris } \\ 1.92 \mathrm{M} & \text { Glycine } \\ 1 \% & \text { SDS }\end{array}$

High purity $\mathrm{dH}_{2} \mathrm{O}, \mathrm{pH} 8.3$ to $1000 \mathrm{ml}$ 
Solutions for Casting One 10\% Separating and One Stacking Gel

\begin{tabular}{lcc} 
& Separating gel, 10\% & Stacking gel \\
\hline $\mathrm{H}_{2} \mathrm{O}$ & $1.9 \mathrm{ml}$ & $1.4 \mathrm{ml}$ \\
$30 \%$ Acrylamide/Bis Solution & $1.7 \mathrm{ml}$ & $0.33 \mathrm{ml}$ \\
$1.5 \mathrm{M}$ Tris- $\mathrm{HCl}(\mathrm{pH} 8.8)$ & $1.3 \mathrm{ml}$ & - \\
$1 \mathrm{M}$ Tris- $\mathrm{HCl}(\mathrm{pH} 6.8)$ & - & $0.25 \mathrm{ml}$ \\
$10 \%$ SDS & $0.05 \mathrm{ml}$ & $0.02 \mathrm{ml}$ \\
$10 \%$ Ammonium Persulfate & $0.05 \mathrm{ml}$ & $0.02 \mathrm{ml}$ \\
TEMED & $0.002 \mathrm{ml}$ & $0.002 \mathrm{ml}$ \\
\hline
\end{tabular}

\section{Milk Blocking Solution}

$5 \%$ w/v nonfat dry milk dissolved in TBS-T buffer

\section{Ponceau S Staining Solution}

$0.5 \mathrm{~g}$ of Ponceau $S$ was dissolved in $1 \mathrm{ml}$ of glacial acetic acid and the volume was adjusted to $100 \mathrm{ml}$ with $\mathrm{H}_{2} \mathrm{O}$.

\section{TMB Substrate Solution}

One tablet of the HRP substrate TMB was dissolved in $100 \mu$ l of DMSO and added per $10 \mathrm{ml}$ of phosphate citrate buffer with Sodium Perborate.

\section{Nicoletti buffer (Propidium Iodide Staining)}

0.1\% Sodium Citrate, $\mathrm{pH} 7.4$

$0.1 \% \quad$ Triton $X-100$

$50 \mu \mathrm{g} / \mathrm{ml} \quad$ Propidium Iodide 


\section{$5.2 \quad$ Methods}

\subsubsection{Cell biological methods}

\subsubsection{Cell culture techniques}

The cells were cultivated under aseptic conditions in $75-\mathrm{cm}^{2}$ tissue culture flasks. All tissue culture flasks have caps with filters which allow gaseous exchange, allowing maintenance of correct $\mathrm{pH}$ (which is monitored by the colour of the phenol red present in the medium) and the right percentage of $\mathrm{CO}_{2}(5 \%)$. The optimal atmosphere conditions are allowed by $\mathrm{CO}_{2}$ incubator, which automatically control temperature and $\mathrm{pCO}_{2}$; it operates with a try of water on the base in an attempt to maintain more than $98 \%$ relative humidity. Temperature of the incubator was set at $37^{\circ} \mathrm{C}$ and regularly controlled.

Human highly metastatic pancreatic carcinoma cells L3.6pl were maintained as monolayer cultures in Dulbecco's Modified Eagle Medium (D-MEM) supplemented with 10\% FBS, Lglutamine, sodium pyruvate, nonessential amino acids, vitamins, and penicillin-streptomycin mixture. The cultures were tested and found to be free of Mycoplasma and the following pathogenic murine viruses: reovirus type 3, pneumonia virus, $\mathrm{K}$ virus, Theiler's encephalitis virus, Sendai virus, minute virus, mouse adenovirus, mouse hepatitis virus, lymphocytic choriomeningitis virus, ectromelia virus, and lactate dehydrogenase virus (assayed by M. A. Bioproducts, Walkersville, MD). The cultures were maintained for no longer than 12 weeks after recovery from frozen stocks.

Human umbilical vein endothelial cells were grown in Falcon "surface-modified", polystyrene flasks with complete Endothelial Cell Growth Medium. After adding the "SupplementMix" the concentrations of growth factors in the complete medium were as follows:

$\begin{array}{ll}\text { Fetal Calf Serum } & 2 \% \\ \text { ECGS/H } & 0.4 \% \\ \text { Epidermal Growth Factor } & 0.1 \mathrm{ng} / \mathrm{ml} \\ \text { Hydrocortison } & 1 \mu \mathrm{g} / \mathrm{ml} \\ \text { Basic Fibroblast Factor } & 1 \mathrm{ng} / \mathrm{ml}\end{array}$

The cells cultured in Endothelial Cell Growth Medium were checked regarding their morphology, the adherence rate and the population doubling time. All experiments were performed with cells passaged three to seven times after their receipt from the supplier. 
Growth medium was changed every 2-3 days. The cells were split into the new culture flasks when they reached $80-90 \%$ confluence. Old medium was removed and the cells were washed twice with sterile PBS buffer. Then $1 \mathrm{ml}$ of trypsin-EDTA solution was added, the culture flask was incubated at $37^{\circ} \mathrm{C}$ and observed under the microscope until cells detached from the surface of the flask. Then $10 \mathrm{ml}$ of complete fresh medium was added to inactivate the activity of trypsin. Cells were centrifuged (except for HUVE cells) at $1000 \mathrm{~g}$ for $4 \mathrm{~min}$ at room temperature. Medium was discarded and the cells were resuspended in fresh growth medium.

\subsubsection{Cell quantification and evaluation of viability}

An efficient way of counting cells and at the same time the evaluation of percentage of viable cells is the technique of "dye exclusion". This test is based on the concept that viable cells do not take up some dyes, whereas dead cells are permeable to these dyes. Trypan blue is the most commonly used dye. In the cell culture some misleading situations such as recent trypsinization and freezing and thawing in presence of dymethylsulphoxide (DMSO) may lead to membrane leakeness. From each suspension cells an aliquot of $10 \mu \mathrm{l}$ was harvested, mixed with $10 \mu 1$ of tryplan blue and counted on a counting chamber under the microscope. The mean of at least three counts of viable cells (not stained with trypan blue)/quadrant was considered and multiplied to the magnitude $\left(10^{4}\right)$ and the dilution factor.

\subsubsection{Cell stimulation with different factors}

For cytokine induction HUVE cells were maintained overnight $(16 \mathrm{~h})$ in the appropriate medium with $0.5 \%$ fetal calf serum (reduced medium) in order to synchronize the cell culture. The factors were diluted to the stock concentrations recommended by the manufacture in BSA $0.1 \%$ in sterile PBS. For further use the cytokines were diluted directly in the cell culture reduced medium at the indicated concentrations for desired period of time.

\subsubsection{Storage of cells}

In order to minimize the cellular injury induced by freezing and thawing procedures (intracellular ice crystals and osmotic effects), a cryoprotective agent DMSO was added. A

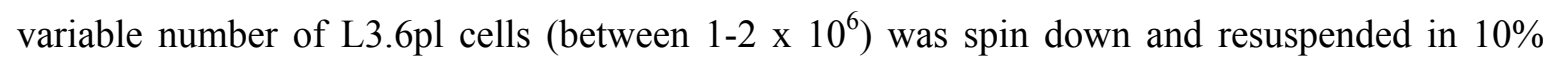
DMSO solution (DMSO diluted in FBS). Afterwards, $1 \mathrm{ml}$ aliquots of cell suspension were 
dispensed into criotubes $(1.8 \mathrm{ml})$. The tubes were placed into wells of a brass block pre-cooled at $4^{\circ} \mathrm{C}$. The block was then kept at $-70^{\circ} \mathrm{C}$ for $24 \mathrm{~h}$ after which the ampoules of cells were transferred to liquid nitrogen for long-term storage.

For revival of cells a frozen ampoule was thawed rapidly in a $37^{\circ} \mathrm{C}$ water bath, disinfected and the content was put in a cell culture flask with pre-warmed medium. After 6 hours the medium was discarded and fresh pre-warmed medium was added.

\subsubsection{Detection of viable cells}

Measurement of cell viability forms the basis for in vitro assays of a cell population's response to external factors. The reduction of tetrazolium salts is now widely accepted as a reliable way to examine cell proliferation. The yellow tetrazolium MTT (3-[4, 5-dimethylthiazolyl-2]-2, 5diphenyltetrazolium bromide) is reduced by metabolically active cells, in part by the action of dehydrogenase enzymes, to generate reducing equivalents such as NADH and NADPH. The resulting intracellular purple formazan can be solubilized and quantified by spectrophotometric means.

For an assessment of AZM475271 activity directed against cultured L3.6pl and HUVE cells, we used an in vitro TACS MTT Cell Proliferation and Viability Assay Kit. Cells were removed from subconfluent cultures by treatment with trypsin-EDTA. Trypsinization was stopped with complete medium. Cell suspension was harvested by centrifugation (400 g for $4 \mathrm{~min}$ at room temperature), $15 \times 10^{3}$ cells/well were plated in 96-well plates in complete medium (amount of the cells was determined by trypan blue method, 5.2.1.2). After 24 hours of attachment, cells were treated with AZM475271 $(1-25 \mu \mathrm{mol} / \mathrm{L})$, and the plates were incubated for another 72 hours $\left(37^{\circ} \mathrm{C}, 5 \% \mathrm{CO}_{2}\right)$. Cells were washed with PBS; the MTT Reagent was added according to the manufacturer's recommendations to each well, including controls. The plates were returned to cell culture incubator for 2 to 4 hours, and when the purple precipitate was clearly visible under the microscope the MTT Detergent was added to all wells, including controls. The plates were left with cover in the dark for 2 to 4 hours at room temperature. The absorbance in each well (OD, optical density) was measured at $570 \mathrm{~nm}$ in a microplate spectrophotometer. The $\mathrm{IC}_{50}$ (the concentration of AZM475271 at which 50\% of cells were viable compared to cells grown in the absence of Src kinase inhibitor) was calculated using the following formula:

$$
I C_{50}=O D \text { of the cells treated / OD of untreated cells } \times 100 \%
$$

All experiments were replicated three times. 


\subsubsection{Inhibition of growth factor-mediated endothelial proliferation}

HUVEC proliferation in the presence and absence of growth factors was evaluated using 3-(4, 5dimethylthiazolyl-2)-2, 5-diphenyltetrazolium bromide (MTT) incorporation. Briefly, HUVE cells were plated in 96-well plates $\left(15 \times 10^{3}\right.$ cells/well $)$ in reduced medium and dosed with $\mathrm{AZM}_{475271} \pm \mathrm{VEGF}_{165}$ or EGF (both growth factors at concentration $25 \mathrm{ng} / \mathrm{ml}$ were taken). The cultures were incubated for 72 hours $\left(37^{\circ} \mathrm{C}, 5 \% \mathrm{CO}_{2}\right)$ and then assayed for the incorporation of MTT using the microplate spectrophotometer, as described above (5.2.1.5). The $\mathrm{IC}_{50}$ dose of AZM475271 was assumed as the dose which inhibited 50\% of HUVE cell proliferation.

All experiments were replicated at least three times.

\subsubsection{Chemotaxis assay}

Chemotaxis experiments were performed using BD BioCoat ${ }^{\mathrm{TM}}$ Matrigel invasion chambers. The apparatus consists of a BD Falcon TC companion plate with Falcon cell culture inserts containing an $8 \mu \mathrm{m}$ pore size PET membrane with a thin layer of MATRIGEL Basement Membrane Matrix. The Matrigel Matrix serves as a reconstituted basement membrane in vitro. The layer occludes the pores of the membrane, blocking non-invasive cells from migration through the membrane. In contrast, invasive cells (malignant and non-malignant) are able to detach themselves from and invade through the Matrigel Matrix and the $8 \mu \mathrm{m}$ membrane pores. The membrane may be processed for light and electron microscopy and can be easily removed after staining.

HUVECs $\left(10^{5}\right.$ cells/well) resuspended in reduced medium were seeded into the upper well of the chamber system on a human fibronectin-coated polyethylene terephthalate membrane with $8 \mu \mathrm{m}$ pores. Human recombinant $\mathrm{VEGF}_{165}$ diluted in the cell culture reduced medium was added as a chemo-attractant into the lower well at $20 \mathrm{ng} / \mathrm{ml}$. Inhibition of VEGF-induced chemotaxis was assessed after including AZM475271 at relevant doses to the upper compartment of the chamber. The cells were allowed to migrate for 4 hours at $37^{\circ} \mathrm{C}$, after which the filter was fixed with cold methanol and stained with haematoxylin. The non-invading cells were removed from the upper surface of the membrane by "scrubbing" with a cotton swab, and the number of migrated cells was counted in 5 random $0.159-\mathrm{mm}^{2}$ fields at X100 magnification.

The average of triplicate inserts from three representative experiments was obtained. 


\subsubsection{Biochemical methods}

\subsubsection{Inhibition of protease/phosphatase activity}

A commercially available cocktail of protease/phosphotase inhibitors (final concentrations: 0.02 $\mathrm{mg} / \mathrm{ml}$ pancreas extract, $5 \mu \mathrm{g} / \mathrm{ml}$ pronase, $0.5 \mu \mathrm{g} / \mathrm{ml}$ thermolysin, $3 \mu \mathrm{g} / \mathrm{ml}$ chymotrypsin and 0.33 $\mathrm{mg} / \mathrm{ml}$ papain) was prepared just before use and employed when needed.

\subsubsection{Preparation of cellular extracts using RIPA buffer}

During RIPA lysis intracellular and membrane proteins are solubilized due to the presence of detergent and high salt concentration in the lysis buffer. Nonsolubilized proteins are precipitated by centrifugation. Protease inhibitor cocktail is included in the lysis buffer to prevent proteolysis, phosphotase inhibitor cocktail - to maintain the phopsphorylation status of phosphoproteins, EDTA - to chelate divalent ions that are essential for metalloproteases.

Trypsinized HUVE cells (5.2.1.1) were washed twice with ice cold PBS, collected by centrifugation at $400 \mathrm{~g}$ for $4 \mathrm{~min}$ at $4^{\circ} \mathrm{C}$. Cells were than resuspended in ice cold RIPA buffer supplemented with the cocktail of protease/phosphotase inhibitors to a final concentration of about $10^{7}-10^{8}$ cells $/ \mathrm{ml}$. Cells were incubated on ice for $10 \mathrm{~min}$ and centrifuged at $14000 \mathrm{~g}$ at $4^{\circ} \mathrm{C}$ for $10 \mathrm{~min}$. The supernatant containing total cellular proteins was collected and stored at $-20^{\circ} \mathrm{C}$. Total protein concentration in the supernatant was determined as described below (5.2.2.3).

\subsubsection{Determination of protein concentration}

The BCA ${ }^{\text {TM }}$ Protein Assay Reagent Kit was used to measure protein concentration in cellular lysates. The BCA method combines the well-known reduction of $\mathrm{Cu}^{+2}$ to $\mathrm{Cu}^{+1}$ by protein in an alkaline medium and selective colorimetric detection of the cuprous cation $\left(\mathrm{Cu}^{+1}\right)$ with a reagent containing bicinchoninic acid (BCA). The purple-colored reaction product of this assay is formed by the chelation of two molecules of BCA with one cuprous cation. This complex has a strong absorbance at $562 \mathrm{~nm}$ that is nearly linear with increasing protein concentrations.

Five $\mu \mathrm{l}$ of protein lysates were diluted in $45 \mu \mathrm{l}$ of water and plated in 96-well plate. Protein standards for calibration were prepared by diluting $0,5,15$ and $30 \mu \mathrm{g}$ of bovine serum albumin (BSA) from $2 \mathrm{mg} / \mathrm{ml}$ stock solution in water to the final volume of $100 \mu \mathrm{l}$. Working BCA reagent was prepared freshly by mixing reagent A (containing bicinchoninic acid, sodium carbonate, sodium bicarbonate and sodium tartrate in $0.1 \mathrm{M}$ sodium hydroxide) and reagent $\mathrm{B}$ 
(containing 4\% cupric sulfate) from the kit at the ratio of 1:50 vol./vol.. Fifty $\mu 1 /$ well of working $\mathrm{BCA}$ reagent was added to protein samples. Plates were placed in $60^{\circ} \mathrm{C}$ for 30 minutes, and then were allowed to cool down at room temperature for about 10 minutes. The absorbance was measured at or about $562 \mathrm{~nm}$ on the microplate spectrophotometer. A standard curve was prepared by plotting the average Blank-corrected $562 \mathrm{~nm}$ measurement for each BSA standard $v s$. its concentration in $\mu \mathrm{g} / \mathrm{ml}$. The standard curve was used to determine the protein concentration of each unknown sample.

\subsubsection{Immunoprecipitation of proteins from cellular lysates}

In this approach, specific antibody is added to the cellular lysate to bind protein of interest. Antibody-protein complexes are then precipitated using solid-phase matrix. Bacterial proteins A and $\mathrm{G}$ which have specific binding sites for Fc-parts of antibodies, covalently coupled to crosslinked agarose, are usually used as solid-phase matrix to precipitate protein-antibody complexes. Cellular lysates containing $0.5-1 \mathrm{mg}$ of total protein were mixed with about $1 \mu \mathrm{g}$ of antibody in pre-chilled $1.5 \mathrm{ml}$ tubes on ice. Volumes of the mixture were adjusted to 200-300 $\mu 1$ to obtain equal protein concentrations in each sample. Tubes were incubated for 4 hours at $4^{\circ} \mathrm{C}$ with constant rotation. 20-25 $\mu \mathrm{l}$ of Protein A or G coupled agarose was added to each sample and tubes were incubated for additional 4 hours at $4^{\circ} \mathrm{C}$ with constant rotation. Following incubation with Protein A or G agarose, immuno-complexes were pelleted by centrifugation at $4500 \mathrm{~g}$ at $4^{\circ} \mathrm{C}$ for 1 minute and washed 3 times with ice-cold RIPA lysis buffer and one time with ice-cold $1 \mathrm{X}$ kinase buffer. Each time complexes were collected by centrifugation at $4500 \mathrm{~g}$ at $4^{\circ} \mathrm{C}$ for 1 minute. Five- $10 \mu \mathrm{l}$ of the kinase buffer used for the last wash were left above the agarose pellet. Ten $\mu$ of $2 \mathrm{X}$ Laemmli loading buffer were added to the samples and proteins were denatured by heating to $95^{\circ} \mathrm{C}$ for 5 minutes. Samples were cooled down on ice and analyzed immediately or frozen at $-80^{\circ} \mathrm{C}$ for later analyses. Protein A or G agarose was pelleted by centrifugation at $14000 \mathrm{~g}$ at $4^{\circ} \mathrm{C}$ for 30 minutes and supernatants, containing immunoprecipitated proteins were analyzed by SDS-PAGE electrophoresis (5.2.2.5).

\subsubsection{SDS-Polyacrylamidgelelectrophoresis PAGE}

In this approach proteins in the mixture are denatured by heating in the presence of 2mercaptoethanol and SDS. Denatured polypeptides bind SDS and become negatively charged. The amount of bound SDS is almost always proportional to the molecular weight of a 
polypeptide, and is independent of its sequence. Therefore proteins and protein subunits are separated according to their size during migration through the pores in the gel matrix in response to an electrical field.

Protein samples for electrophoresis were prepared by dissolving a mixture of proteins in SDSPAGE loading buffer and heating up the samples at $95^{\circ} \mathrm{C}$ for 5 minutes (5.2.2.4).

Separation gels with the following dimensions were used: thickness $1.0 \mathrm{~mm}$, length $7.3 \mathrm{~cm}$ and width $8.3 \mathrm{~cm}$. One $\mu 1$ TEMED per $1 \mathrm{ml}$ of gel mix was used for the catalysis of the polymerization reaction, which was initiated by adding APS to a final concentration of $0.1 \%$. The stacking gel was composed similar to the running gel, only Tris- $\mathrm{HCl}$ with $\mathrm{pH} 6.8$ was used and the acrylamid had a final concentration of $3 \%$. Proteins were separated at $250 \mathrm{~V}$ and $30 \mathrm{~mA}$ until the dye front has left the separation gel.

\subsubsection{Transfer of proteins to PVDF membrane}

Proteins separated by SDS-PAGE were transfered to a PVDF membrane Hybond P. The transfer was done in a semi-dry TRANS-BLOT SD cell (Fig. 5.3) applying 25V and 100mA for 90 minutes. In semi-dry blotting the electrodes are placed directly in contact with the gel/nitrocellulose membrane sandwich to provide a fast, efficient transfer. Because of this direct contact there is a minimum of transfer buffer required for this process.

PVDF membrane was soaked in methanol for a few minutes and then transferred to a container with Towbin transfer buffer. Gel and attached PVDF membrane were sandwiched between two pieces of Whatman paper and soaked in the transfer buffer.

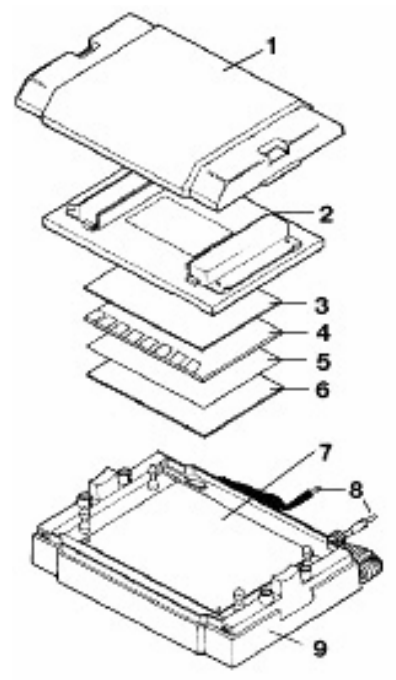


Figure 5.3 An exploded view of the Trans-Blot SD cell: 1, safety lid; 2, cathode assembly with latches; 3, filter paper; 4, gel; 5, membrane; 6, filter paper; 7, spring-loaded anode platform, mounted on four guide posts; 8 , power cables; 9 , base.

The prestained protein ladder served as a control for the transfer.

\subsubsection{Ponceau S staining of proteins on PVDF membrane}

Staining with Ponceau S was used to provide visiual evidence that electrophoretic transfer of proteins has taken place. Ponceau $\mathrm{S}$ is a negative stain which binds to the positively charged amino groups of the protein.

PVDF membrane was incubated for 5-10 seconds in Ponceau S staining solution and then washed with water until the protein bands became visible.

\subsubsection{Analysis of proteins on PVDF membrane by immunoblotting}

In this method, specific antibodies are used to identify proteins transferred to PVDF membrane. First, membrane is immersed in blocking buffer to fill all protein binding sites with non-reactive protein. Then membrane is incubated in a solution containing antibody directed against the antigen(s) in the protein to be detected. Primary antibody bound to the protein of interest are recognized by secondary antobody conjugated with horseradish peroxidase (HRP). The complex containing the antigen, primary antibody and secondary antibody-HRP conjugate is detected by chem luminescent visualization using ECL detection system.

PVDF membranes were blocked in the blocking solution either for 1-3 hours at room temperature or overnight at $4^{\circ} \mathrm{C}$. After blocking, membranes were then washed once for 15 minutes and twice for 5 minutes in TBS-T buffer with agitation. After the washes membranes were incubated with antibodies appropriately diluted in 5\% BSA in TBS-T overnight at $4{ }^{\circ} \mathrm{C}$ with agitation. After incubation with primary antibodies, membranes were washed again as described above, then transferred to the containers with secondary antibody-HRP conjugates in 5\% BSA in TBS-T and incubated for 1 hour at room temperature shaking gently. Membranes were then rinsed twice and washed with agitation twice for 15 minutes, twice for 10 minutes, and twice for 5 minutes. For detection, membranes were incubated in a mixture of ECL Western Blotting detection reagents for 2 minutes. Remaining drops of ECL buffer were removed and membranes were placed into a transparent folder. Hyperfilm ECL was then exposed for an appropriate time and developed with an AGFA developing system. 


\subsubsection{Stripping and re-probing of western blot}

PVDF membranes were stripped and re-probed using Restore ${ }^{\mathrm{TM}}$ Western Blot Stripping Buffer. Twenty $\mathrm{ml}$ of Restore ${ }^{\mathrm{TM}}$ Western Blot Stripping Buffer were warmed to room temperature. Membranes were placed in the buffer to be stripped and incubated for 15 minutes at room temperature. After incubation, the blots were removed from the buffer and washed 3 times for 15 min in TBS-T. After determining that the membranes were properly stripped, next immunoprobing experiments were performed.

\subsubsection{Determination of apoptotic cells by FACS analysis via propidium iodide staining}

Propidium Iodide (PI) binds to double-stranded DNA, but it can only cross the plasma membrane of non-viable cells. For analysis by flow cytometry, the PI staining can be monitored in the FL2 channel.

HUVE cells were plated into T75 flasks and treated with different concentrations of AZM475271 $(0-25 \mu \mathrm{M})$. After 12 hours, cells were collected and suspended in a Nicoletti buffer and incubated for $15 \mathrm{~min}$ protected from light at room temperature. The supernatant was discarded by centrifugation of cell suspension at $1300 \mathrm{~g}$ for $4 \mathrm{~min}$. After 2 washing steps with PBS, cells were finally resuspended in sterile PBS and the DNA content present in the resulting nuclei was determined on a fluorescence-activated cell sorter (FACS). Signal height, area, and width were recorded for the PI channel. Data analysis was done using the WinMDI 2.8 software. Sub- $\mathrm{G}_{0} / \mathrm{G}_{1}$ was then quantified and used as an estimate of the amount of the cells undergoing apoptosis. The cellular debris was excluded from the analysis. Experiments were repeated three times.

\subsubsection{Enzyme-linked immunoassays}

\subsubsection{Determination of human vascular endothelial growth factor concentrations in cell culture supernates}

This assay employs the quantitative sandwich enzyme immunoassay technique. A monoclonal antibody specific for VEGF has been pre-coated onto a microplate. Standards and samples are pipetted into the wells and any VEGF present is bound by the immobilized antibody. After 
washing away any unbound substances, an enzyme-linked polyclonal antibody specific for VEGF is added to the wells. Following a wash to remove any unbound antibody-enzyme reagent, a substrate solution is added to the wells and color develops in proportion to the amount of VEGF bound in the initial step. The color development is stopped and the intensity of the color is measured.

The level of VEGF was measured in cell culture supernates collected on day 0,2 , and 4 from L3.6pl or HUVE cells following treatment with Src kinase inhibitor AZM475271 at different concentrations $(0.1,1 \mu \mathrm{M})$. The assay was performed according to the manufacturer's recommendations. Absorbance at $450 \mathrm{~nm}$ was measured and corrected using the 540-nm reading on the microplate reader. VEGF content was calculated according to the parameter of the calibration curve. Calibration curves with a correlation coefficient at least 0.998 were used. All experiments were replicated three times.

\subsubsection{In vitro Src kinase inhibition test}

A poly (Glu, Tyr) 4:1 random copolymer was used as the tyrosine-containing substrate. This is stored as a $10 \mathrm{mg} / \mathrm{ml}$ stock solution in PBS at $20^{\circ} \mathrm{C}$ and diluted 1:200 with PBS to coat 96-well plates $(100 \mu 1 /$ well). Substrate was plated the day before the assay, and the plates were covered with adhesive seals and stored overnight at $4^{\circ} \mathrm{C}$. On the day of the assay, the substrate solution was discarded, and the plates were then incubated with $120 \mu \mathrm{l} /$ well of $5 \%$ BSA in PBS for 10 minutes. The plates were then washed once with PBS-T and incubated with $50 \mathrm{mmol} / \mathrm{L}$ HEPES (pH 7.4) at $100 \mu \mathrm{l} /$ well until the next stage. Confluent HUVE or L3.6pl cells were treated with different concentrations of AZM475271 or PP2. After 12 hours cells were washed and lysed in 1 $\mathrm{ml}$ of ice-cold RIPA lysis buffer. Lysates were clarified by centrifugation at $14000 \mathrm{~g}$ for 10 minutes and active src was then precipitated using $15 \mu \mathrm{g}$ of $\mathrm{v}$-src (Ab-1) monoclonal antibody pre-adsorbed to $50 \mu \mathrm{l}$ of protein G-sepharose. The immune complexes containing precipitated src were washed 3 times with ice-cold RIPA lysis buffer, one time with ice-cold 1X kinase buffer and used in kinase reaction as an active src kinase. Solutions of $80 \mu \mathrm{mol} / \mathrm{L}$ ATP in $80 \mathrm{mmol} / \mathrm{L}$ $\mathrm{MgCl}_{2}$ and $80 \mathrm{mmol} / \mathrm{L} \mathrm{MgCl}_{2}$ alone (negative controls) were prepared. The HEPES was discarded from the substrate plates and the following additions were now made in this order: 25 $\mu \mathrm{l} /$ well $\mathrm{ATP} / \mathrm{MgCl}_{2}$ or $\mathrm{MgCl}_{2}$ alone; $50 \mu \mathrm{l} /$ well beads to start the reaction. The reaction time allowed was 30 minutes at room temperature on a plate shaker. The assay was stopped by washing the plates four times with PBS-T (150 $\mu 1 /$ well). Detection of the resultant tyrosine phosphorylation was facilitated by the addition of an anti-phospho-tyrosine monoclonal antibody 
conjugated to HRP (diluted 1:5000 in PBS-T + 0.5\% BSA + 0.1 mmol/L sodium orthovanadate), added at $100 \mu \mathrm{l} /$ well and incubated for 1 hour. The plates were again washed (six times). TMB substrate solution $(100 \mu \mathrm{l} /$ well $)$ was added. After 5 minutes of color development, the reaction was stopped by the addition of $50 \mu \mathrm{l} /$ well $0.8 \mathrm{~mol} / \mathrm{L} \mathrm{H}_{2} \mathrm{SO}_{4}$. Control and blank wells were included on all plates containing compound diluent and $\mathrm{MgCl}_{2}$ solution with and without ATP, respectively, to determine the dynamic range of the assay. The in vitro VEGF-R2 kinase inhibition assay determines the ability of AZM475271 to inhibit VEGF-R2 kinase activity and has been used as a selectivity screen. The method was performed as reported previously (Lu et al., 2003).

\subsubsection{In vitro study of angiogenesis}

\subsubsection{Aortic ring assay}

Angiogenesis was studied by culturing aortic explants in three-dimentional matrix gels according to the procedure of Nikosia and Ottineri (Nikosia et al., 1990). Thoracic aortas were removed from 6- to 8- week-old male ACI rats and immediately transferred to a culture dish containing cold serum-free Dulbecco's Minimal Essential Medium. The peri-aortic tissue was carefully removed with fine microdissecting forceps and scissors, paying special attention not to damage the aortic wall. One mm long aortic slices (approximately 15 per one aorta) were sectioned and extensively rinsed in 5 consecutive washing steps with D-MEM. Ring-shaped explants of the aorta were then embedded on Matrigel-coated 24-well plates. HEPES-buffered D-MEM containing AZM475271 in different concentrations was added and the plates were incubated at $37^{\circ} \mathrm{C}, 5 \% \mathrm{CO}_{2}$, for 4 days. Fresh medium with respective additives was reintroduced into the cultures on day 2 . The rings were examined by phase contrast microscopy with a Zeiss Axiotech Vario microscope at $\times 10$ magnification. An estimation of the length of the capillary was performed by measuring the distance from the aortic explant to the approximate mean point of capillary. The length of the capillary was measured using AxioVision software.

\subsubsection{Spheroid angiogenesis assay}

To evaluate the anti-angiogenic properties of AZM475271, we used an in vitro angiogenesis assay as described in detail, previously (Korff et al., 1998). $10^{3}$ HUVECs (passage 4 to 6) per spheroid were plated into a non-adhesive, round bottom 96-well plate. After 24 hours, the 
spheroids were harvested and half the spheroids of a 96-well plate (approximately 48 spheroids) were embedded in $1 \mathrm{ml}$ of a collagen matrix and transferred into a 24-well plate. For the next 24 hours we incubated the embedded spheroids with the allocated treatment and thereafter, the spheroids were fixed in a $4 \%$ formalin solution to prepare them for the subsequent analysis. Spheroid sprouting was stimulated with human recombinant VEGF-A Vif5 $_{2}(25 \mathrm{ng} / \mathrm{ml})$ in the presence or absence of AZM475271. The pictures of the spheroids were taken under transillumination using an Achroplan objective (n.a. =0.45) providing a 20-fold magnification.

\subsubsection{Orthotopic xenograft pancreatic tumor model}

\subsubsection{Tumor cell implantation}

For in vivo injection, L3.6pl human pancreatic carcinoma cells were harvested from culture flasks by a treatment with trypsin-EDTA and resuspended in sterile ice-cold PBS. Only singlecell suspensions of $>90 \%$ viability (trypan blue exclusion) were used for injection. Male nude mice were anesthetized with ketavet $(100 \mathrm{mg} / \mathrm{kg}$ mouse body weight) and xylazin $(5 \mathrm{mg} / \mathrm{kg}$ mouse body weight) followed premedication with atropine sulfate. A small left abdominal flank incision was made and the spleen exteriorized (Fig. 5.4a). L3.6pl tumor cells $\left(1 \times 10^{6}\right.$ in $40 \mu 1$ PBS) were injected subcapsularly in a region of the pancreas just beneath the spleen. We used a 30-gauge needle, a $1 \mathrm{ml}$ disposable syringe, and a calibrated pushbutton-controlled dispensing device to inject the tumor cell suspension (Fig. 5.4b). A successful subcapsular intrapancreatic injection of tumor cells was identified by the appearance of a fluid bleb without intraperitoneal leakage (Fig. 5.4c). To prevent such leakage, a cotton swab was held for 1 min over the site of injection. One layer of the abdominal wound was closed by suture. 


\section{A}

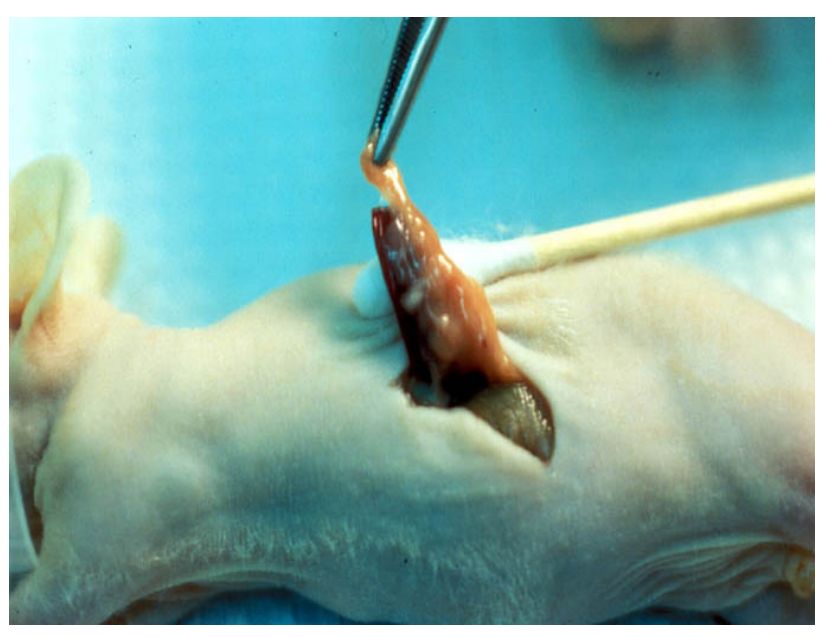

B

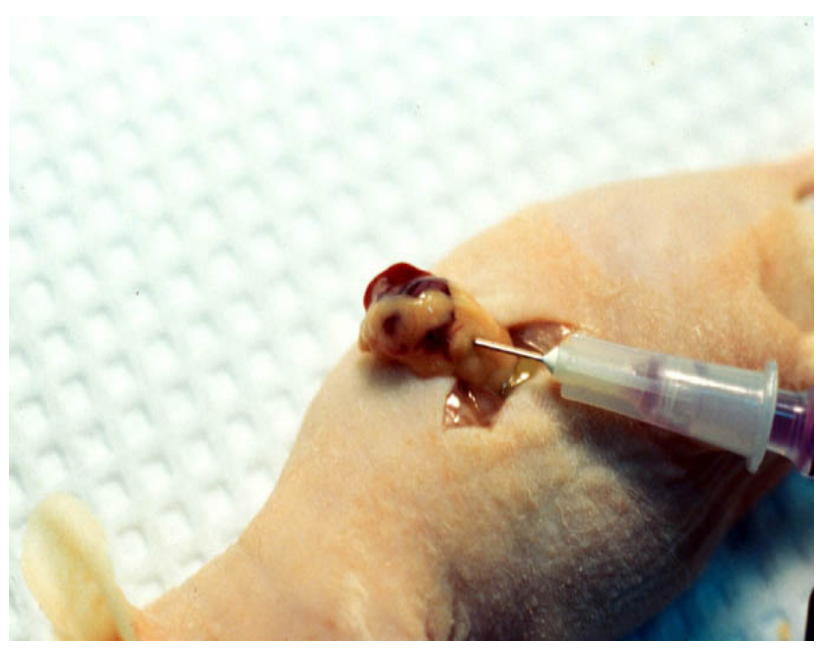

C

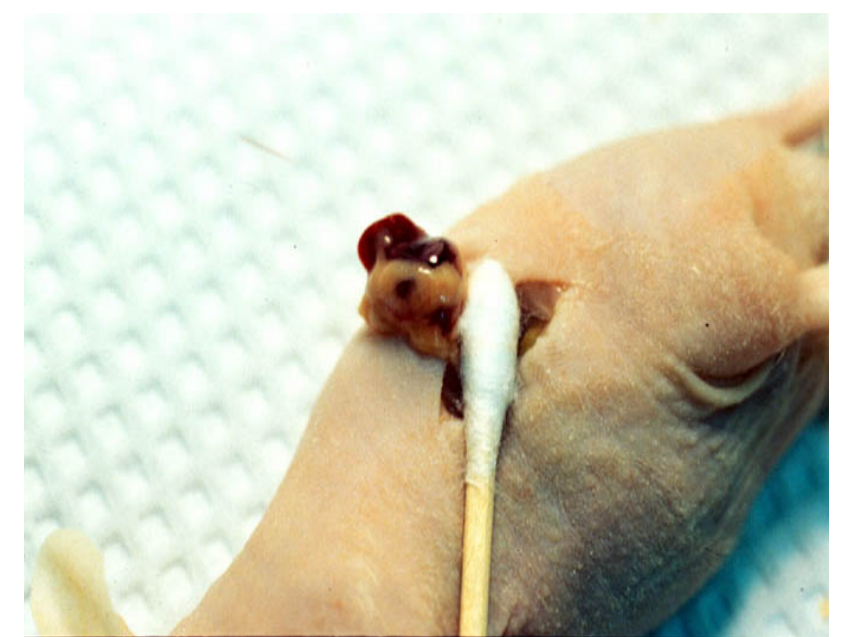

Figure 5.4 Orthotopic tumor cell injection

$-57-$ 
The animals tolerated the surgical procedure well, and no anesthesia-related deaths occurred.

\subsubsection{Treatment of established tumors growing in the pancreas of nude mice}

Seven days after implantation of tumor cells, mice were randomly assigned to one of the following groups of 5-9 mice each:

1) Daily intragastral administration of Src tyrosine kinase inhibitor AZM475271 at a dose of $25 \mathrm{mg} / \mathrm{kg}$ mouse body weight;

2) Daily intragastral vehicle solution for AZM475271 (Tween 20 diluted 1:100 in $\mathrm{NaCl})$.

\subsubsection{In vivo evaluation of plasma concentration levels of AZM475271}

Healthy nude mice were treated with a single dose of $50 \mathrm{mg} / \mathrm{kg}$ AZM475271 by oral administration. The plasma concentration of AZM475271 was measured by mass spectrometry 2,6 , and 24 hours after oral feeding of the compound.

\subsubsection{Monitoring of mouse body weight and tumor volume}

Starting 3 days after the initiation of therapy with AZM475271, the measurement of tumor volume (by transcutaneous palpation) and mouse body weight was performed.

\subsubsection{Necropsy procedure and histopathological studies}

The animals were sacrificed 32 days after the initiation of treatment, when $>50 \%$ of the control animals had become moribund. Primary pancreatic tumor size, liver and lymph node metastasis, and local peritoneal carcinosis were assessed. All palpable or visible masses in the pancreas were considered pancreatic tumors and the presence of tumor was later confirmed by Haematoxylin and Eosin (H\&E) staining. Excised pancreatic tumors were weighed. The tumor volume was then calculated using the formula $\mathrm{V}=\pi / 6(\mathrm{a} \times \mathrm{b} \times \mathrm{c})$, where $\mathrm{a}, \mathrm{b}$ and $\mathrm{c}$ represent the length, width, and height of the mass. Microscopically, tumor nodules $\geq 1 \mathrm{~mm}$ in diameter were counted on the entire liver surface. Where visible liver metastases were evident, the tissue was processed for H\&E staining to confirm the macroscopic observations. Furthermore, macroscopically-enlarged regional lymph nodes (celiac and para-aortic) were excised and H\&E staining performed to 
confirm the presence of metastases. Tumor lesions were harvested, some were fixed in $10 \%$ buffered formalin and embedded in paraffin, and some were embedded in optimum cutting temperature (OCT) compound, snap-frozen in liquid nitrogen, and stored at $-70^{\circ} \mathrm{C}$.

\subsubsection{Immunohistochemical analyses}

\subsubsection{Immunohistochemistry of paraffin embedded tissues}

\subsection{Haematoxylin and Eosin staining}

Staining of the nucleus of the cells was done with haematoxylin; eosin was used for the cytoplasm staining. Samples were deparaffinized by incubation in xylene for $20 \mathrm{~min}, 2$ minutes in $100 \%$, one minute in $96 \%$, one minute in $75 \%$ ethanol and finally washed in distilled water. The samples were then rinsed in haematoxylin for one minute, washed in distilled water and incubated with eosin for 2 minutes. After washing the slides were mounted with Mayer gel.

\subsection{Staining for Ki-67 antigen (The assessment of cell proliferation)}

Evaluation of cell proliferation was performed using $\mathrm{Ki}$-67-specific polyclonal rabbit anti-human antibody. Tissues were embedded in paraffin and 4-6 $\mu \mathrm{m}$ sections were prepared and mounted on positively-charged superfrost slides. Sections were dried overnight, deparaffinized in xylene and incubated in 100\%, 95\% and 80\% ethanol (v/v in distilled water), before rehydrating in PBS. $\mathrm{Ki}-67$ antigen retrieval was achieved by microwaving tissue sections for 15 minutes at $750 \mathrm{~W}$. After cooling down, the slides were rinsed with PBS, and nonspecific binding sites were blocked with 5\% bovine serum albumin (BSA) in PBS. After another washing step with PBS, the primary antibody (1:75, a polyclonal rabbit anti-human antibody against $\mathrm{Ki}$-67) was applied, and the slides were incubated for 2 hours at room temperature. The samples were then incubated with biotinylated goat anti-rabbit secondary antibody (1:200) for 1 hour at room temperature, followed by incubation with an avidin-biotinylated horseradish peroxidase (HRP) complex from an $\mathrm{ABC}$ kit. Sections were examined microscopically and the average number of cells staining positively for $\mathrm{Ki}-67$ per high-power field $\left(0.159 \mathrm{~mm}^{2}\right)$ was counted at $\times 100$ magnification. 


\subsubsection{Immunohistochemistry of snap-frozen tissues}

\subsection{Terminal deoxynucleotidyl transferase-mediated nick end labeling (TUNEL) staining}

Terminal deoxynucleotidyl transferase-mediated nick end labeling (TUNEL) staining was performed using a commercially available apoptosis detection kit (DeadEnd ${ }^{\mathrm{TM}}$ Fluorometric TUNEL System). In many cell types, apoptosis is characterized by the generation of DNA fragments through the action of endogenous endonucleases. The DNA of apoptotic cells is cleaved into multimers of 180-200bp fragments, corresponding to the oligonucleosomal size. Therefore, the DNA of apoptotic cells typically migrates as a ladder of 180-200bp multimers on an agarose gel. The generation of single strand breaks also has been reported. The DeadEnd ${ }^{\mathrm{TM}}$ Fluorometric TUNEL System measures the fragmented DNA of apoptotic cells by catalytically incorporating fluorescein-12-dUTP(a) at $3^{\prime}-\mathrm{OH}$ DNA ends using the enzyme Terminal Deoxynucleotidyl Transferase (TdT). TdT forms a polymeric tail using the principle of the TUNEL (TdT-mediated dUTP Nick-End Labeling) assay. The fluorescein-12-dUTP-labeled DNA can then either be visualized directly by fluorescence microscopy or quantitated by flow cytometry.

Tissue sections $(8-10 \mu \mathrm{m}$ thick) were fixed by immersing slides in freshly prepared $4 \%$ methanol-free formaldehyde solution in PBS ( $\mathrm{pH} 7.4)$ in a Coplin jar for 25 minutes at $4{ }^{\circ} \mathrm{C}$ and washed twice by immersing in fresh PBS for 5 minutes at room temperature. Then cells were premeabilized by immersing the slides in $0.2 \%$ Triton X-100 solution in PBS for 5 minutes and then rinsed twice in PBS for 5 minutes. After removing excess liquid by tapping, slides were covered with $100 \mu \mathrm{l}$ of equlibration buffer and equilibrated at room temperature for 10 minutes. Then, a sufficient TdT incubation buffer for all experimental and optional positive control reactions was prepared according to manufacture protocol. $50 \mu \mathrm{l}$ of TdT incubation buffer were added, slides were covered with plastic coverslips to ensure even distribution of the reagent and incubated at $37^{\circ} \mathrm{C}$ for 60 minutes inside the humidified chamber covered with aluminium foil to protect from direct light. After the incubation plastic coverslips were removed and reaction was terminated by immersing the slides in $2 \mathrm{X}$ SSC in a Coplin jar for 15 minutes at room temperature. Samples were washed twice by immersing the slides in PBS for 5 minutes at room temperature to remove unincorporated fluorescein-12-dUTP. Slides were mounted using glass coverslips and DEPEX gel. Samples were immediately analysed under a fluorescence microscope using a standard fluorescent filter set to view the green fluorescence of fluorescein at 
$520 \pm 20 \mathrm{~nm}$. Results were expressed as the average of apoptotic cells in 10 random fields at $\times 40$ magnification.

\subsection{Staining for CD31}

Frozen tissue sections $(8-10 \mu \mathrm{m}$ thick) were fixed with cold acetone for $5 \mathrm{~min}$, acetone and chloroform $(1: 1, \mathrm{v} / \mathrm{v})$ for $5 \mathrm{~min}$, and acetone for $5 \mathrm{~min}$, then washed in PBS. Endogenous peroxidase was blocked by incubation of slides in $3 \% \mathrm{H}_{2} \mathrm{O}_{2}$ diluted in methanol for 5 min and $3 \times 3$ min washed in PBS. Non-specific binding sites were blocked for 20 min with 5\% horse serum and $1 \%$ goat serum in PBS. After the incubation, primary antibodies dissolved in $1 \%$ blocking buffer were applied and incubated overnight at $4^{\circ} \mathrm{C}$ : CD-31, monoclonal rat anti-mouse $(1: 200)$ which reacts to a surface antigen (CD-31) presented on all endothelial cells. Next day the samples were washed $3 \times 3 \mathrm{~min}$ in PBS and the slides were incubated for 10 min with blocking buffer at room temperature. Then secondary antibodies (biotinylated polyclonal rabbit anti-rat immunoglobulin, Ig-fraction, HRP- conjugated (1: 400) dissolved in blocking buffer were applied for 1 hour at room temperature. After washing $3 \times 3 \mathrm{~min}$ in PBS the slides were rinsed with $0.2 \%$ Tween solution in PBS. Then the samples were incubated with AEC chromogen dissolved in $\mathrm{H}_{2} \mathrm{O}_{2}$ substrate, washed in distillate water and stained with haematoxylin for 1 min. After washing with distillate water the slides were mounted using glass cover slips and DEPEX gel. For the quantification of microvascular density, 10 random $0.159-\mathrm{mm}^{2}$ fields at $\times 100$ were captured for each tumor using an AxioCam camera mounted on a Carl Zeiss universal microscope and AxioVision software. Two investigators counted the microvessels independently in a blinded fashion. Tissues were examined at a low power (x40), and the three $\mathrm{x} 200$ fields of highest microvessel density were identified for vessel counts. Microvessels were quantitated according to the method described by Bruns (Bruns et al., 2000). Clusters of stained endothelial cells distinct from adjacent microvessels, tumor cells, or other stromal cells were counted as one microvessel. The results were expressed as the highest number of microvessels identified within a single $x 200$ field.

\subsection{Immunofluorescence double staining for CD31 and TUNEL}

Frozen tissue was used for CD31/TUNEL immunofluorescence double staining. The procedure used is as described previously (Baker et al., 2002). 
TUNEL assay was done with the use of a commercial apoptosis detection kit as described above (5.2.7.2.1). TUNEL-positive apoptotic cells were detected by localized green fluorescence within the cell nuclei, and endothelial cells were identified by red fluorescence. Apoptotic endothelial cells were identified by yellow fluorescence within the nuclei. The total number of apoptotic cells was quantified in 10 randomly selected microscopic fields and expressed as the ratio of apoptotic endothelial cells to the total number of endothelial cells in 5-10 random $0.011-\mathrm{mm}^{2}$ (at X400 magnification).

\subsubsection{Statistical analysis}

Pancreatic tumor weight, mouse body weight, and quantification of Ki67, TUNEL, and CD31 were compared using one-way ANOVA with a Student-Newman-Keuls multiple comparison test. The relative rates of liver and lymph node metastases within groups were compared by Fisher's exact test. Survival analysis was computed by the Kaplan-Meier method and compared by the log-rank test (Hosmer et al., 1980). Significance was taken as $p<0.05$. Results of the ELISA tests, proliferation assays, migration and aortic ring assays were analyzed using the paired Student's t-test with $p<0.05$ considered to be significant. 


\section{Chapter 6}

\section{RESULTS}

6.1 In vitro enzyme inhibition in HUVE and L3.6pl cells

6.2 In vitro selectivity profile of AZM475271 _...................................... 64

6.3 AZM475271 inhibits tumor growth and metastasis in an orthotopic nude mouse model _................................................. 67

6.4 In vivo evaluation of plasma concentration levels

6.5 Histological analysis of tissue sections ……..................................... 72

6.5.1 In vivo effect of AZM475271 on tumor cell proliferation

6.5.2 In vivo effect of AZM475271 on tumor cell apoptosis $\quad . . . . . . . . . . . . \quad 72$

6.5.3 Quantification of microvessel density in primary pancreatic tumors

6.5.4 In vivo effect of AZM475271 on endothelial cell survival ........... 75

6.6 In vitro antiproliferative activity of AZM475271

in L3.6pl and HUVE cells

6.7 In vitro effects of AZM475271 on VEGF- and EGF- dependent

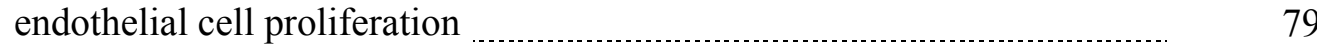

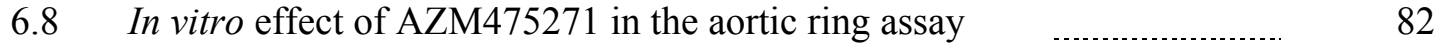

6.9 AZM475271 inhibits endothelial sprouting in vitro in the spheroid angiogenesis model ……............................................... 84

6.10 Inhibition of VEGF production by L3.6pl and HUVE cells following treatment with AZM475271

6.11 In vitro induction of cell death in HUVECs 88

6.12 In vitro inhibition of migration of HUVECs by AZM475271

6.13 AZM475271 abolishes VEGF-induced

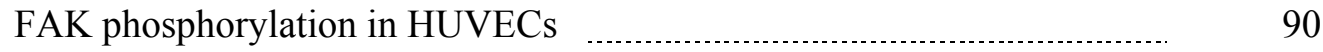


The initial goal of the work described in this thesis was to demonstrate the in vivo efficacy of the Src tyrosine kinase inhibitor AZM475271 in an orthotopic xenograft pancreatic tumor model. However, early results, which have raised questions as to the role of Src family kinases in tumor angiogenesis and metastasis, lead to a change the direction of the project.

\subsection{In vitro enzyme inhibition in HUVE and L3.6pl cells}

AZM475271 is a potent inhibitor of the Src tyrosine kinase activity in HUVE and L3.6pl cells. To demonstrate the selectivity of AZM475271, an in vitro Src inhibition ELISA was performed measuring the $\mathrm{IC}_{50}$ of AZM475271 necessary to prevent the ability (i.e. activity) of src kinase precipitated from HUVE or L3.6pl cells to phosphorylate an immobilized substrate in the presence of ATP. AZM475271 demonstrated a strong inhibition of Src kinase activity in HUVE and L3.6pl cells in a dose-dependent manner. The $\mathrm{IC}_{50}$ concentration of AZM475271 to inhibit the phosphorylation of Src in HUVE and L3.6pl cells was $0.1 \mu \mathrm{mol} / \mathrm{L}$ (Fig. 6.1, a and b, respectively). 4-Amino-5-(4-chlorophenyl)-7-(t-butyl)pyrazolo[3,4-d]pyrimidine (PP2) was used as a positive control for Src kinase inhibition.

\subsection{In vitro selectivity profile of AZM475271}

A receptor tyrosine kinase inhibitor should prevent the phosphorylation of tyrosine residues on protein substrates following stimulation of the kinase with its specific ligand. The ability of AZM475271 to inhibit receptor tyrosine kinase activity (at the Michaelis constant [Km] for adenosine triphosphate [ATP]) was examined using an ELISA with recombinant cytoplasmic domains of Src non-receptor tyrosine kinases. Table 6.1 presents the kinase inhibition and selectivity profile of AZM475271 (data were kindly provided by AstraZeneca Pharmaceuticals). AZM475271 has considerable selectivity for Src versus kinase insert domain-containing receptor $(\mathrm{KDR})\left(\mathrm{IC}_{50}=20.9 \mu \mathrm{mol} / \mathrm{L}\right)$, fms-like TK 1 (Flt-1) $\left(\mathrm{IC}_{50}>100 \mu \mathrm{mol} / \mathrm{L}\right)$, fibroblast growth factor (FGF) TK, fms-like TK 4 (Flt-4), aurora kinase (AUR-3), mitogen-activated protein kinase $(\mathrm{MAPK})$ kinase $(\mathrm{MEK})\left(\mathrm{IC}_{50}>10 \mu \mathrm{mol} / \mathrm{L}\right)$, cyclin-dependent kinase-2 $(\mathrm{CDK}-2)\left(\mathrm{IC}_{50}>9\right.$ $\mu \mathrm{mol} / \mathrm{L})$, epidermal growth factor receptor $(\mathrm{EGF}) \mathrm{TK}\left(\mathrm{IC}_{50}=2.6 \mu \mathrm{mol} / \mathrm{L}\right)$. AZM475271 has equipotent activity against Src family members c-Yes and Lck $\left(\mathrm{IC}_{50} \leq 0.004 \mu \mathrm{mol} / \mathrm{L}\right)$. Since the kinase domain is virtually identical in each member, it would be reasonable to assume that AZM475271 will inhibit the other family members with similar potency. The activities of Src kinases are normally highly regulated and AZM475271 will inhibit those that have been 
activated. AZM475271 has poor activity against Csk, a negative regulator of $\mathrm{Src}\left(\mathrm{IC}_{50}=0.84\right.$ $\mu \mathrm{mol} / \mathrm{L})$.

Kinase

$\mathrm{IC}_{50}$ $(\mu \mathrm{mol} / \mathrm{L})$

\subsection{7}

Src

KDR (kinase insert domain-containing receptor)

Csk (negative controller of Src)

Flt-1 (VEGFR1)

Flt-4 (VEGFR3)

FGF TK

EGF TK

MEK

CDK-2

c-Yes (ubiquitous Src family member)

Lck ( $T$ cell restricted Src family member)

20.9

0.843

$>100$

$>10$

$>10$

2.59

14.03

9.753

0.004

$<0.004$
Fold selectivity vs. Src

$>7700$

312

$>37000$

$>3700$

$>3700$

960

$>5000$

3612

1.48

$<1.48$

Table 6.1 AZM475271 inhibition of Src non-receptor tyrosine kinase and selectivity profile.

A

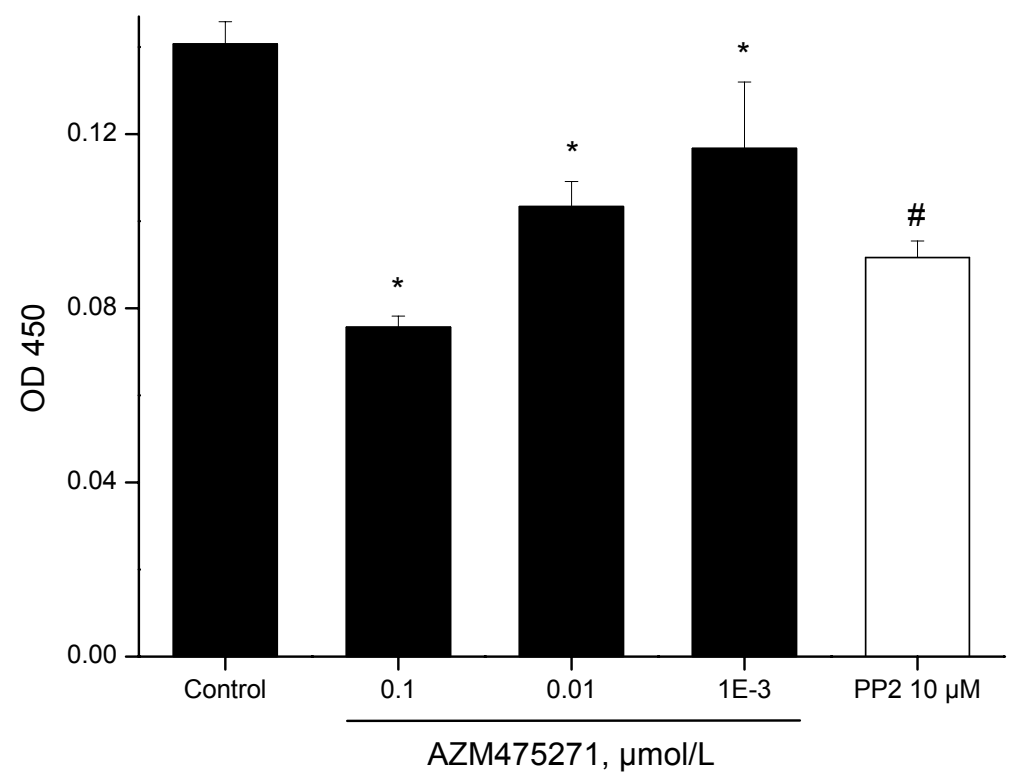




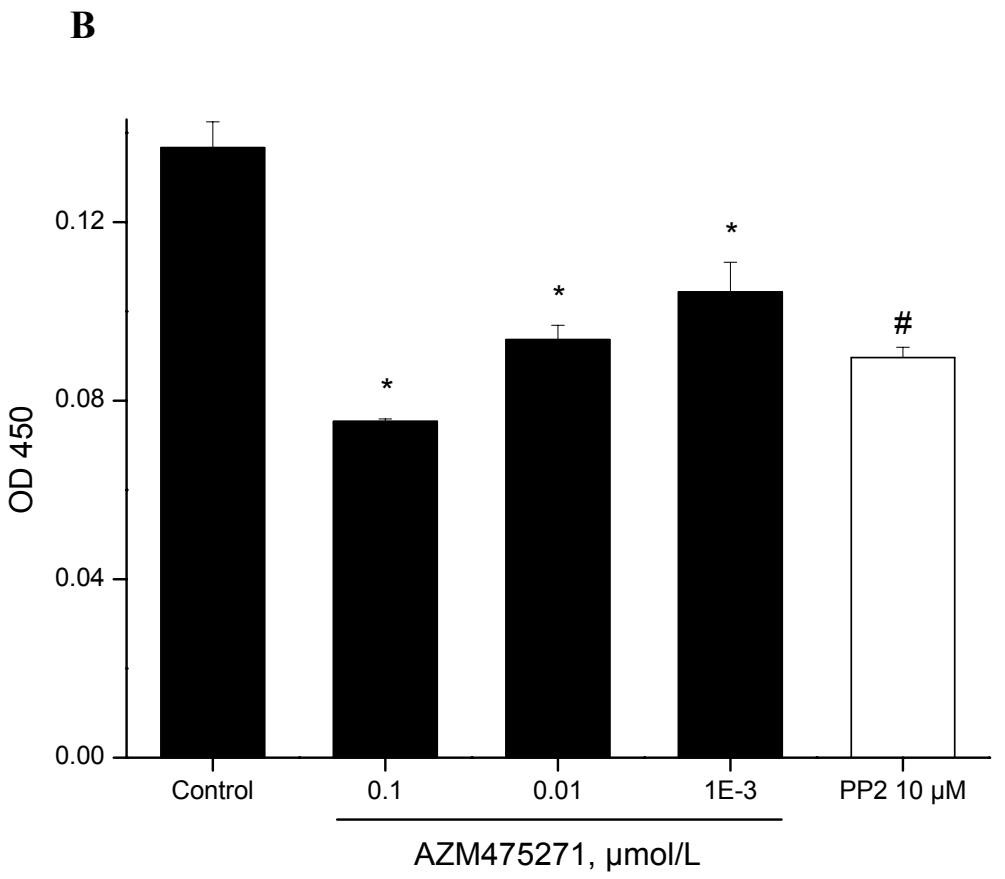

Figure 6.1 In vitro inhibition of Src Kinase.

ELISA was performed measuring the $\mathrm{IC}_{50}$ of AZM475271 necessary to inhibit the activity of src kinase, expressed in L3.6pl (A) or in HUVECs (B). 4-Amino-5-(4chlorophenyl)-7-( $t$-butyl)pyrazolo[3,4-d]pyrimidine (PP2) was used as a positive control for src kinase inhibition $\left(*, p<0.001\right.$ versus control reaction; ${ }^{*}, p<0.001$ versus control reaction).

\subsection{AZM475271 inhibits tumor growth and metastasis in an orthotopic nude mouse model}

Tumors generated by orthotopic implantation of the metastatic L3.6pl cell line were used to evaluate the effects of AZM475271 on growth, metastasis, and angiogenesis in a nude mouse model. Pancreatic tumors were allowed to become established for 7 days before initiation of treatment. Starting 3 days after the initiation of therapy with AZM475271, the measurement of mouse body weight and tumor volume (by transcutaneous palpation) was performed (Fig. 6.2, a and b). Treatment with AZM475271 did not significantly change animal weight (at the end of experiment the mean animal body weight after therapy with AZM475271 was $21.6 \mathrm{~g}$, compared to the untreated group with $22.6 \mathrm{~g}$ ) (Fig. 6.2a). Monitoring of the tumor volume over the course of experiment revealed a decrease in the tumor growth progression in all animals treated with AZM475271 (Fig. 6.2b). 
The animals were sacrificed 32 days after the initiation of treatment, when $>50 \%$ of the control animals had become moribund. At the time of necropsy, all control and treated mice had developed primary pancreatic tumors. Primary pancreatic tumor size, liver and lymph node metastasis, and local peritoneal carcinosis were assessed. Treatment with AZM475271 significantly reduced spontaneous liver metastasis (no animals had metastases) compared with treatment using vehicle solution. Mice who received AZM475271 had also a significant reduction in the incidence of lymph node metastases (five of nine animals) (Table 6.2). Tumor weight for treatment group was assessed using Fisher's Exact test. Other comparisons were made using the unpaired Student's t-test. The mean tumor volume was significantly decreased ( $40 \%$ inhibition of primary tumor growth) in all animals treated with AZM475271 (AZM475271treated animals, $817 \mathrm{~mm}^{3}$; control animals, $1359 \mathrm{~mm}^{3}$ ). Primary pancreatic tumor weight after AZM475271 therapy was also significantly less than that in control mice (mean weight 1.03 and 1.45 , respectively). Results are presented in the Figures 6.3a and 6.3b.

In addition, daily intragastral administration of AZM475271 was well tolerated.

\section{A}

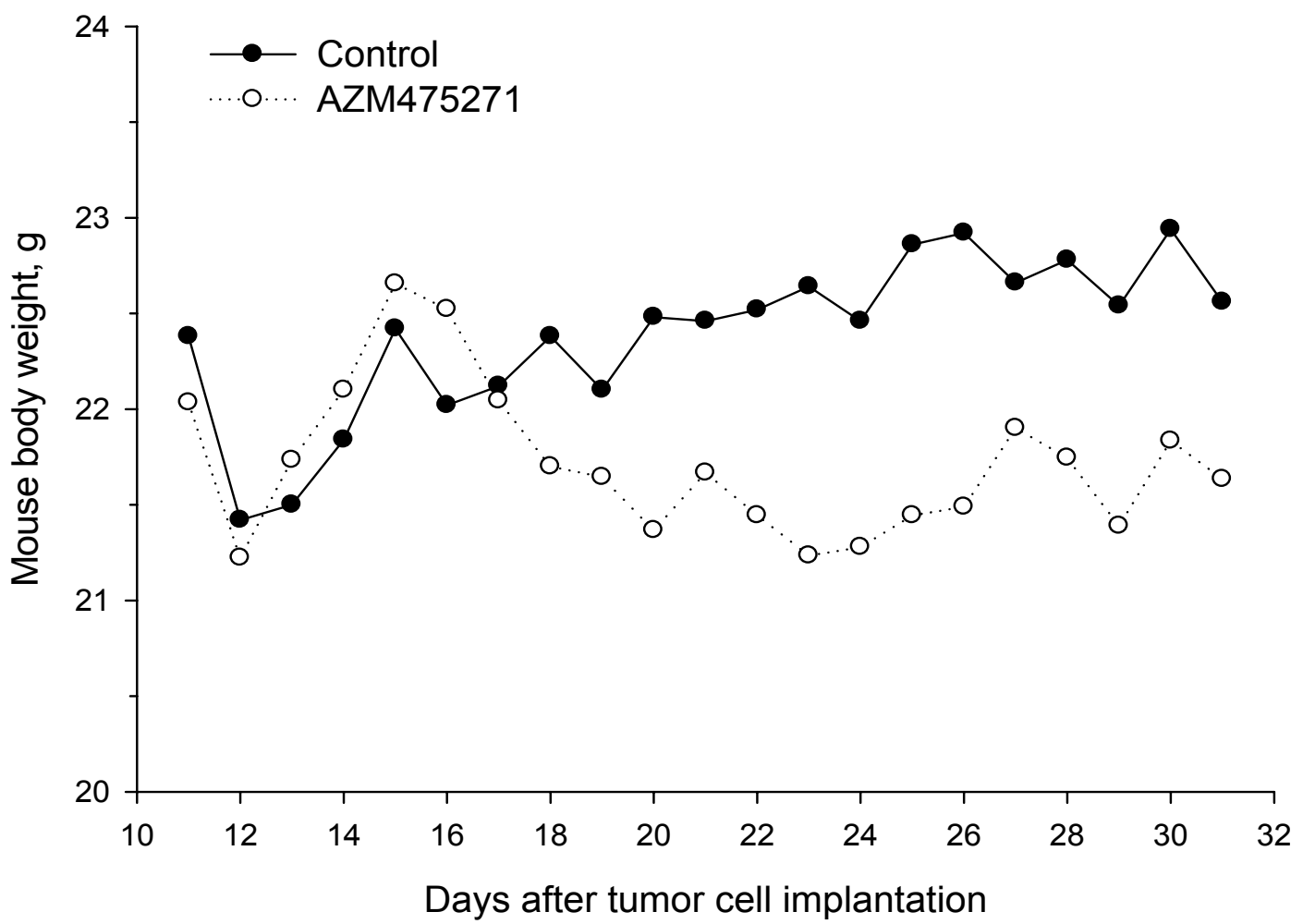


B

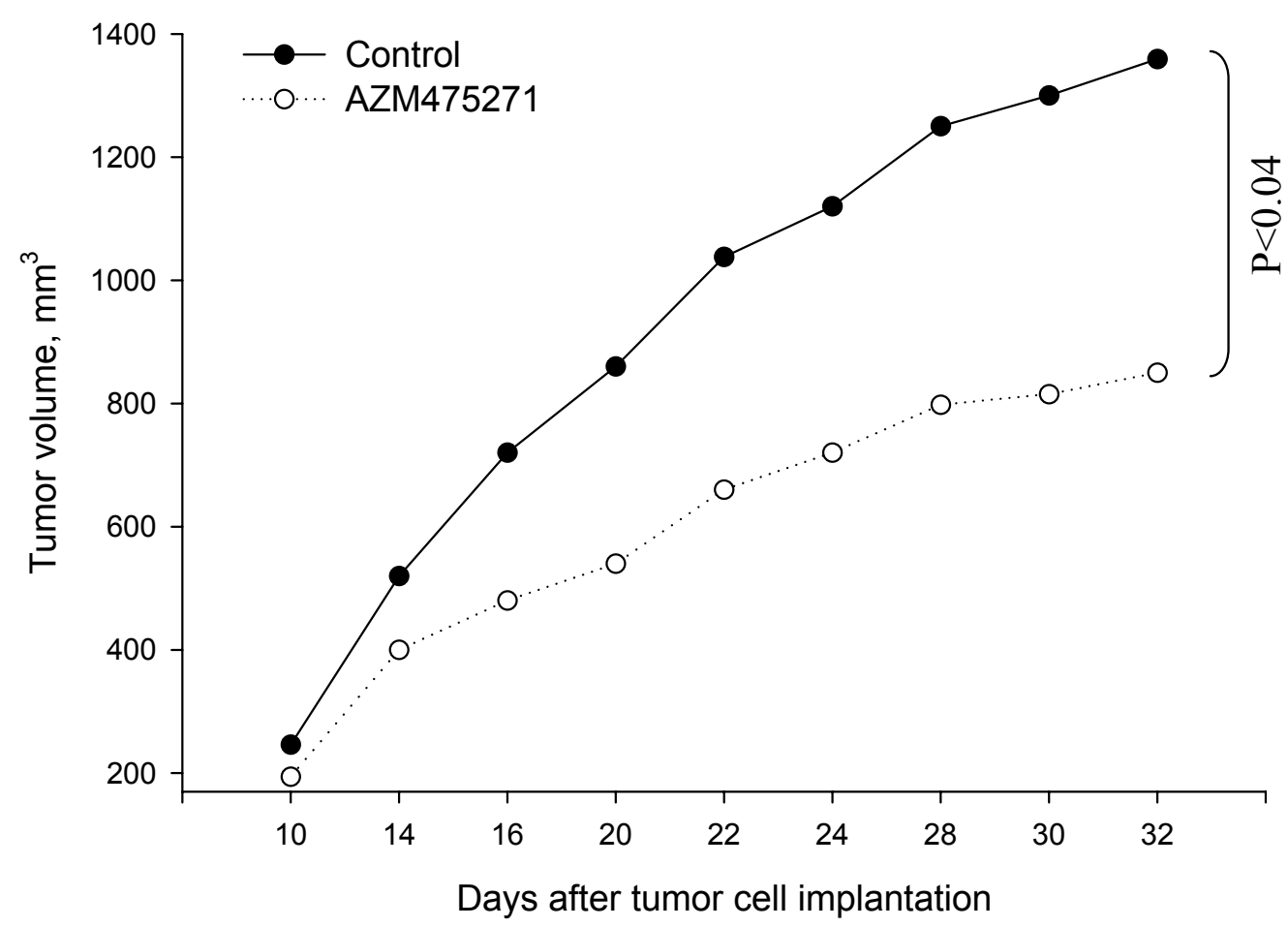

Figure 6.2 Monitoring of the mouse body weight (A) and L3.6pl tumor growth progression (B) in the orthotropic nude mouse model.

\begin{tabular}{|c|c|c|c|}
\hline \multirow{2}{*}{ Treatment group } & \multicolumn{3}{|c|}{ Incidence of macroscopic tumors $^{a}$} \\
\cline { 2 - 4 } & Pancreas tumor & Liver metastasis $^{b}$ & Regional LN metastasis $^{*}$ \\
\hline Saline control & $5 / 5$ & $3 / 5$ & $5 / 5$ \\
\hline AZM475271 & $9 / 9$ & $0 / 9^{c}$ & $5 / 9^{c}$ \\
\hline
\end{tabular}

Table 6.2 In vivo therapeutic efficacy of AZM475271 on primary pancreatic tumor growth and metastasis in the orthotopic nude mouse model

${ }^{a}$ Incidence presented as number of animals with tumor type/ number of animals in group

${ }^{b}$ Visible nodules $(\geq 1 \mathrm{~mm}$ in diameter)

${ }^{c} \mathrm{p}<0.03$ compared with control (Fisher's Exact Test) 
The photograph below shows the tumors harvested from the mice in the experiment on day 32 . Scale bar, $1 \mathrm{~cm}$.

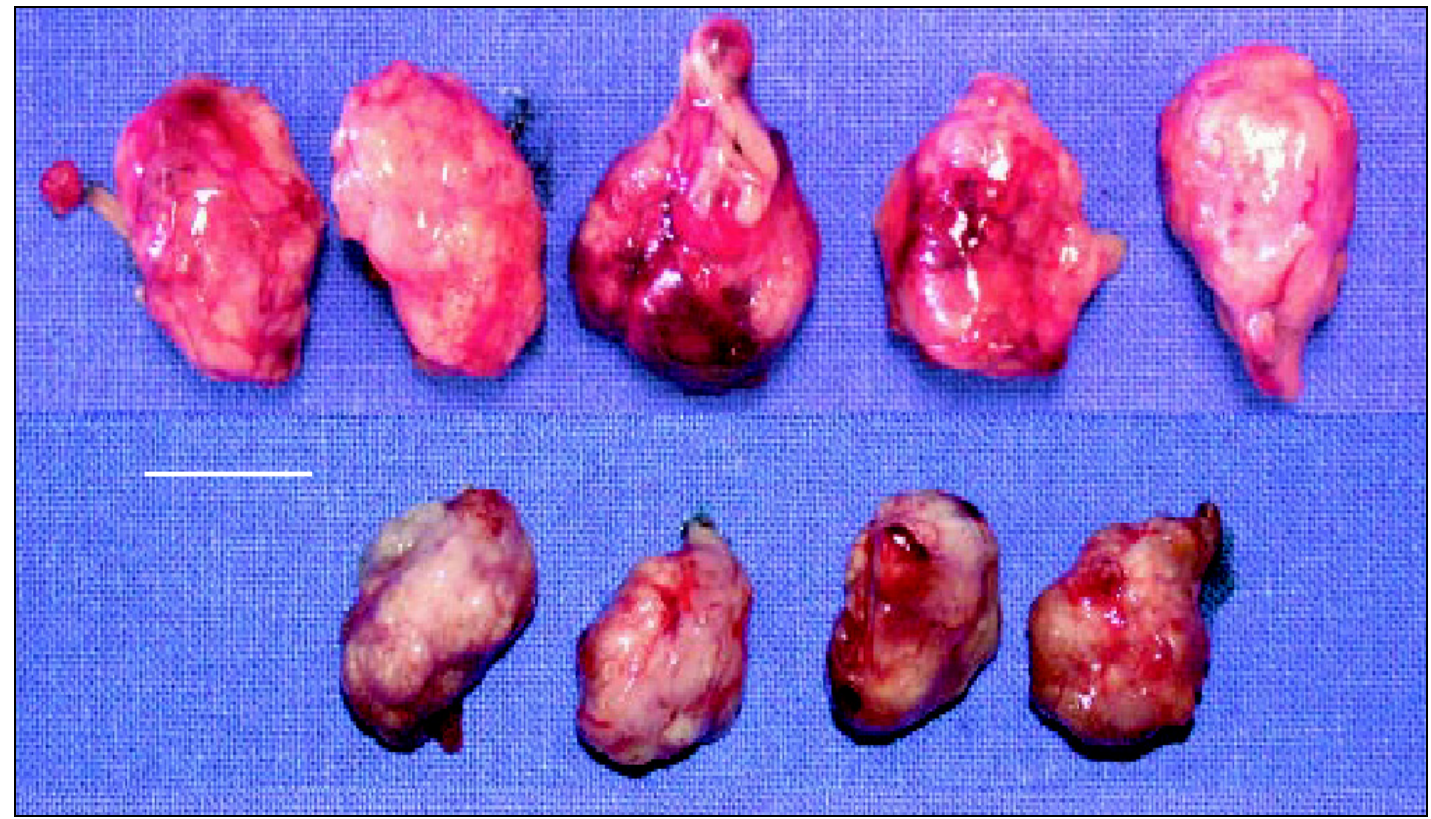

Control

AZM475271

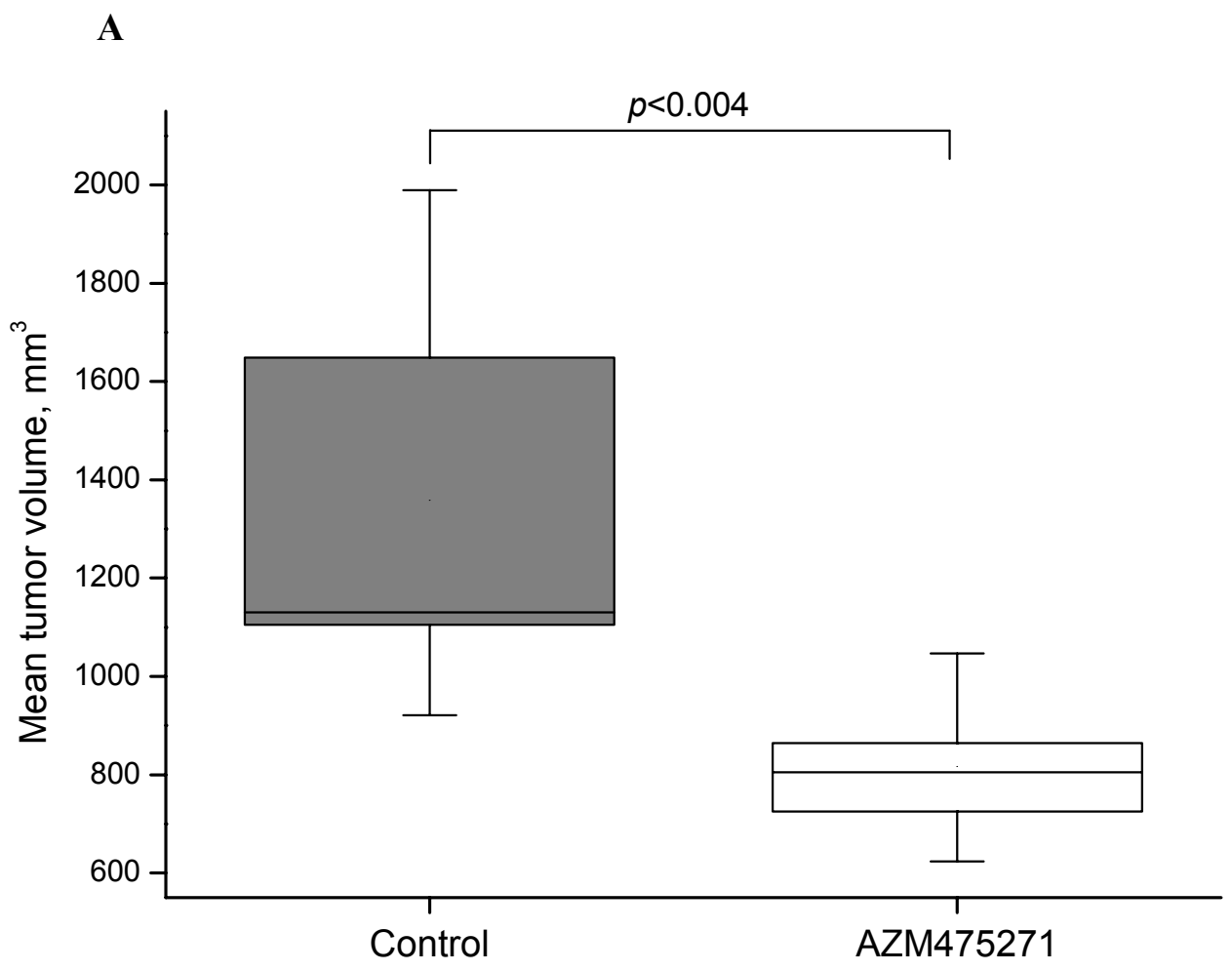




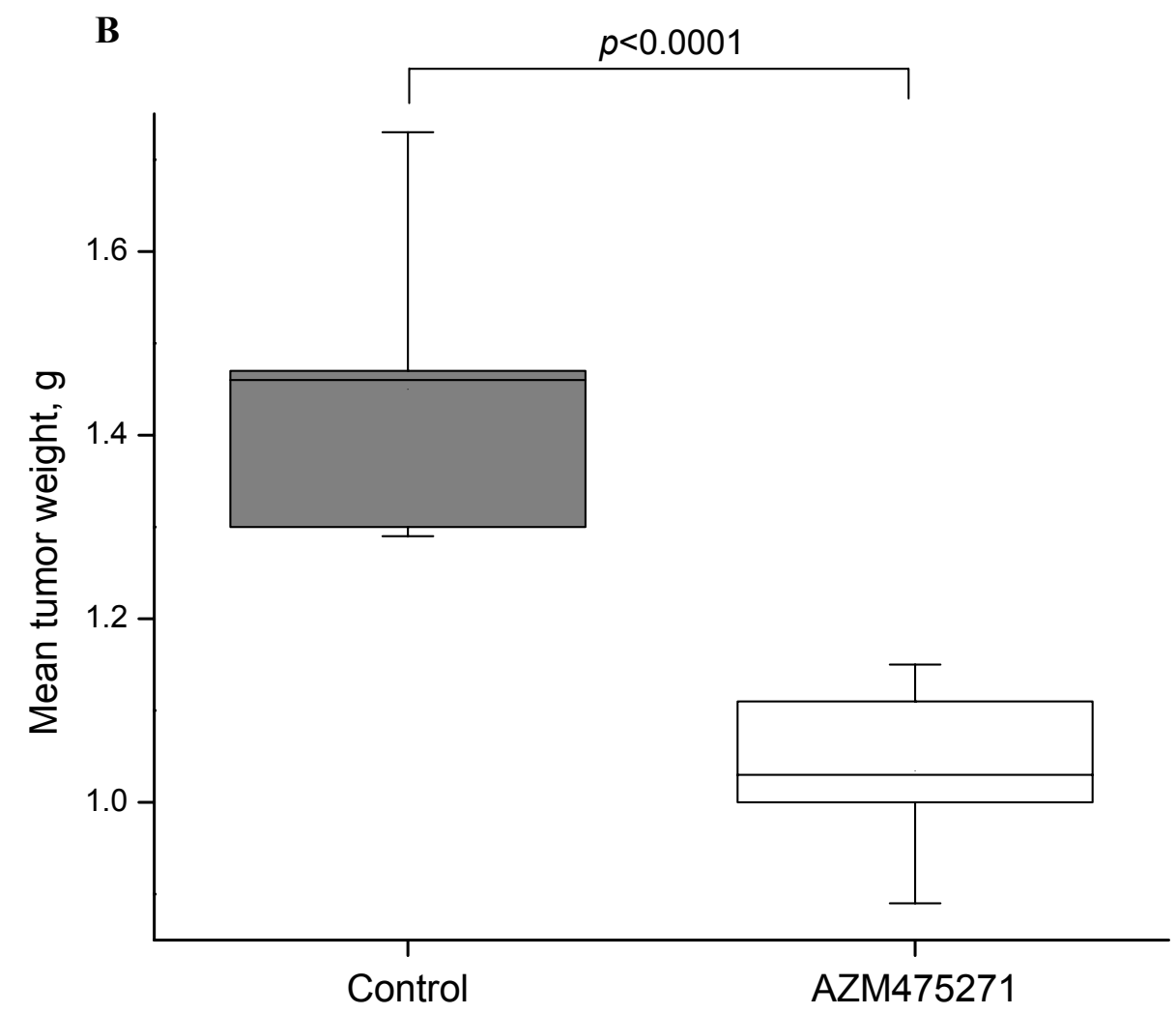

Figure 6.3 In vivo inhibition of L3.6pl pancreatic tumor volume (A) and pancreatic tumor weight (B) in the orthotopic nude mouse model.

L3.6pl human pancreatic cancer cells were injected into the pancreas of nude mice. Seven days after implantation of tumor cells, mice randomly were assigned to one of the following groups of 5-9 mice each: 1) daily intragastral administration of Src tyrosine kinase inhibitor AZM475271 at a dose of $25 \mathrm{mg} / \mathrm{kg}$; 2) daily intragastral vehicle solution for AZM475271. The animals were sacrificed 32 days after the initiation of treatment.

Box plots represent the means for each group with standard deviation of data ( $\mathrm{min}$ and $\max$ ) and standard error of the mean.

\subsection{In vivo evaluation of plasma concentration levels}

After a single oral dose (gavage) of $50 \mathrm{mg} / \mathrm{kg}$ AZM475271 to healthy nude mice, the plasma concentration was measured 2, 6, and 24 hours later. The plasma concentration of AZM475271 in nude mice was $32.1 \mu \mathrm{mol} / \mathrm{L}(14.206 \mathrm{ng} / \mathrm{ml}), 20 \mu \mathrm{mol} / \mathrm{L}(8879 \mathrm{ng} / \mathrm{ml})$, and $11.7 \mu \mathrm{mol} / \mathrm{L}(5187$ $\mathrm{ng} / \mathrm{ml}$ ) at 2, 6, and 24 hours after oral dosing with $50 \mathrm{mg} / \mathrm{kg}$ AZM475271 (Figure 6.4). 


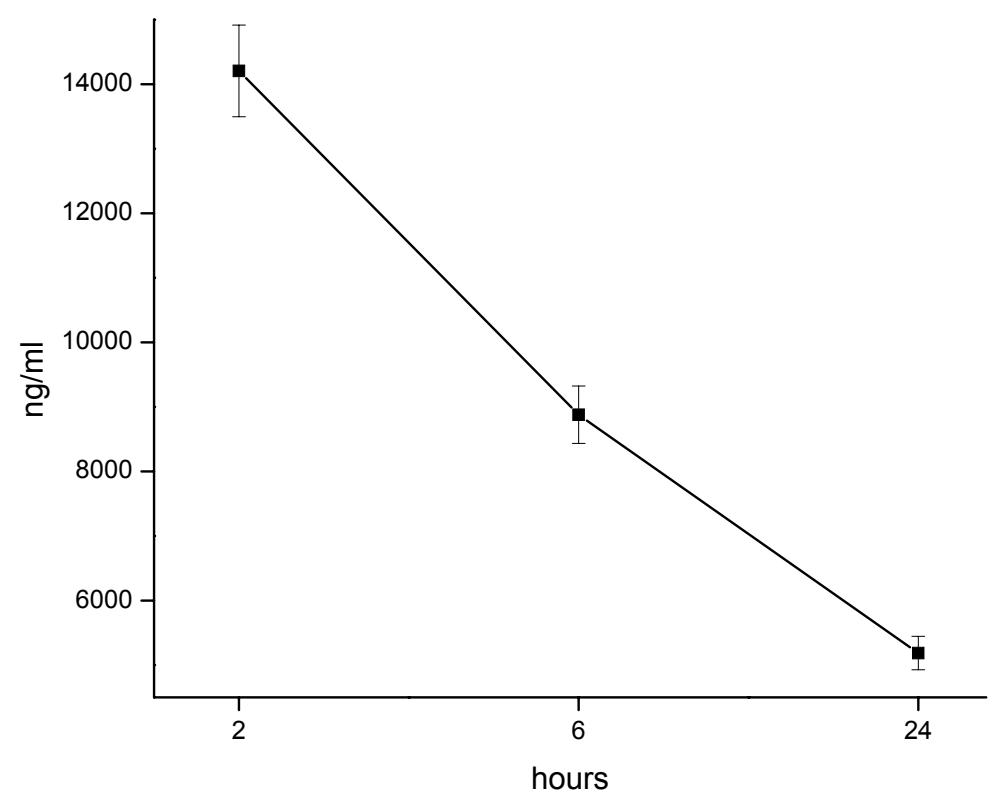

Figure 6.4 The plasma concentration of AZM475271 in nude mice after the single oral dose of $50 \mathrm{mg} / \mathrm{kg}$ AZM475271. Error bars are expressed as a 5\% average of data.

\subsection{Histological analysis of tissue sections}

\subsubsection{In vivo effect of AZM475271 on tumor cell proliferation}

We next analyzed the effect of AZM475271 on tumor cell proliferation in vivo by assessing the level of the nuclear antigen $K i-67$, which is present in all phases of the cell cycle except $\mathrm{G}_{0}$. The mean number of $\mathrm{Ki}$-67-positive tumor cells in the pancreatic tumors of control mice was $480 \pm$ 14. After therapy with AZM475271, the mean number of Ki-67-positive cells was $185 \pm 85$ (reduced over more than $50 \%$ compared to control mice) (Table 6.3; Fig. 6.5). These results indicate the in vivo antiproliferative effect of AZM475271.

\subsubsection{In vivo effect of AZM475271 on tumor cell apoptosis}

To determine the ability of AZM475271 to induce apoptosis in pancreatic carcinoma cells TUNEL staining was carried out. The mean number of TUNEL-positive cells was $8 \pm 2$ and $26 \pm$ 11 ( $\mathrm{p}<0.05$ versus control) in control and AZM475271-treated group, respectively. Results showed a significant enhancement of apoptotic tumor cells in the AZM475271 therapy group compared to control tumors. (Table 6.3; Fig. 6.5). 


\begin{tabular}{ccc}
\hline & \multicolumn{2}{c}{ Positively staining cells $($ mean \pm SD) } \\
\cline { 2 - 3 } & \multicolumn{2}{c}{ Tumor cells $^{a}$} \\
\cline { 2 - 3 } Treatment group & $K i-67$ & TUNEL \\
Saline control & $480 \pm 14$ & $8 \pm 2$ \\
\hline AZM475271 & $185 \pm 85^{b}$ & $26 \pm 11^{c}$ \\
\hline
\end{tabular}

${ }^{a}$ Positive cells per field determined from measurement of 10 random 0.159 $\mathrm{mm}^{2}$ fields at $\times 100$ magnification.

${ }^{b} \mathrm{p}<0.001$ compared with controls.

${ }^{c} \mathrm{p}<0.05$ compared with controls.

Table 6.3 Quantification of Ki-67- and TUNEL-positive cells in primary pancreatic tumors after therapy with AZM475271. 
A

Control
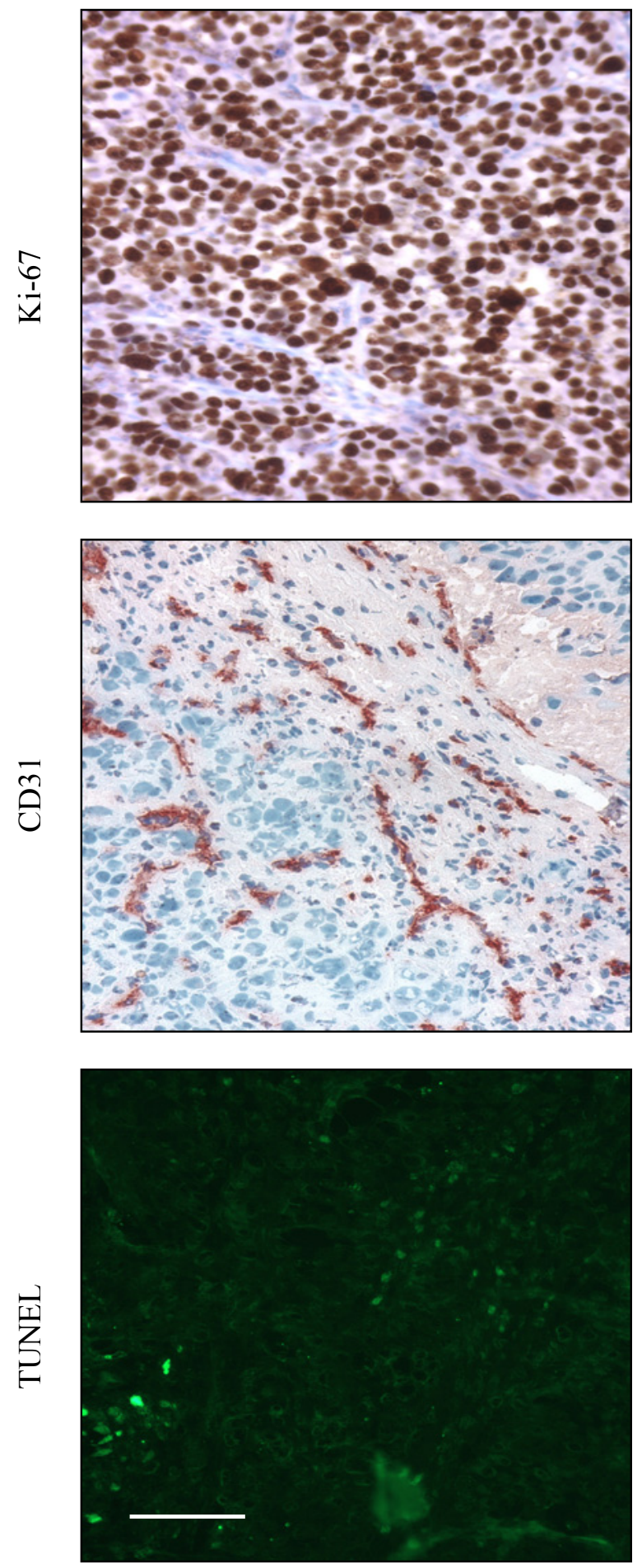

AZM475271
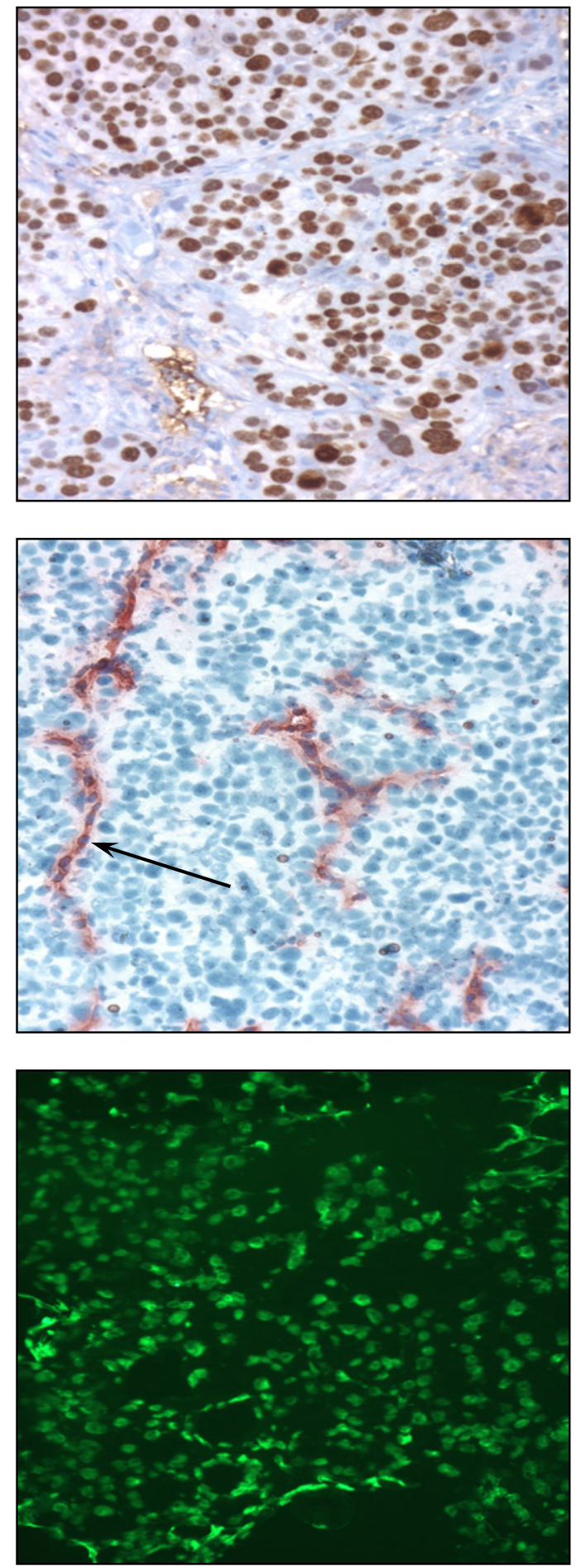


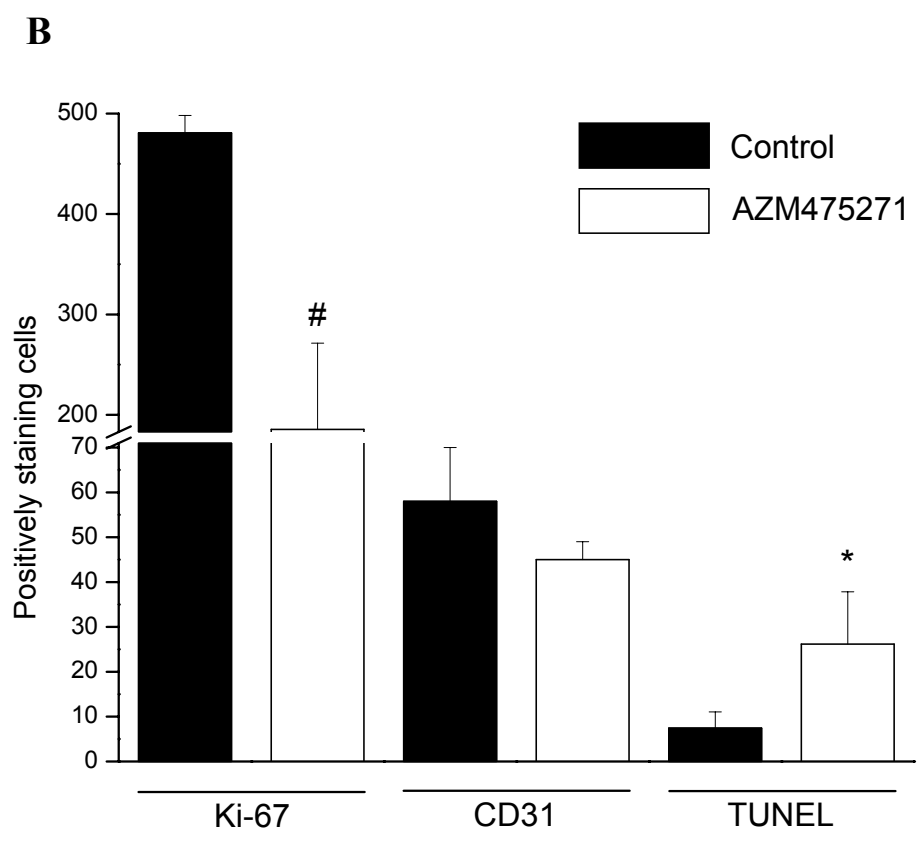

Figure 6.5 Immunohistochemical analyses of proliferation (Ki-67), microvessel density (CD31), and apoptotic cells (TUNEL) in L3.6pl pancreatic tumors growing in nude mice.

$A$, histological sections of control and AZM475271-treated tumors; $B$, mean number of positively stained cells per field (bars represent mean $\pm \mathrm{SD}$ ), ${ }^{\#} \mathrm{p}<0.001$ compared with controls; ${ }^{*} \mathrm{p}<0.05$ compared with controls.

Histopathologic evaluation of cell proliferation was performed using Ki-67 staining. Sections were examined microscopically and the average number of cells staining positive for $K i-67$ per high-power field $\left(0.159 \mathrm{~mm}^{2}\right)$ was counted at $\times 100$ magnification. The mean number of $K i-67$ positive tumor cells after therapy with AZM475271 was reduced by $>50 \%$ compared with control mice. Frozen tissues were used for the evaluation of microvessel density (CD31-positive structures). CD31 staining demonstrated no significant influence of AZM475271 on MVD of tumors compared with controls $(\mathrm{p}=0.14967$, the arrow delineates CD31-positive cells).

In contrast, terminal deoxynucleotidyl transferase-mediated nick end labeling (TUNEL) staining for apoptotic cells revealed an increase in the number of cells undergoing apoptosis in pancreatic cancer in the AZM475271 group. The number of TUNEL-positive cells was counted in 10 random fields $\left(0.159 \mathrm{~mm}^{2}\right)$ at $\times 100$ magnification $($ bars $=100 \mu \mathrm{m})$.

\subsubsection{Quantification of microvessel density in primary pancreatic tumors}

Frozen tissues were used for the evaluation of microvessel density (CD31-positive structures). Clusters of stained endothelial cells distinct from adjacent microvessels, tumor cells, or other stromal cells were counted as one microvessel. The number of CD31-positive microvessels 
counted per $\times 100$ field in the pancreatic tumors was lower in mice after therapy with AZM475271, but not significant $(\mathrm{p}=0.14967)$ (Figure 6.5, the arrow delineates CD31-positive cells).

\subsubsection{In vivo effect of AZM475271 on endothelial cell survival}

We speculated that tumor cell apoptosis may have been due to poor perfusion after endothelial cell apoptosis rather then due to decreasing in microvessel density. Therefore, we developed a technique with which we could evaluate endothelial cell apoptosis in vivo in tissue sections. Endothelial cells were detected by localized red fluorescence, whereas green fluorescence was detected within the nuclei of apoptotic cells. Double-labeling of endothelial cells undergoing apoptosis resulted in localized yellow fluorescence. The total number of apoptotic cells was quantified in 10 randomly selected microscopic fields and expressed as the ratio of apoptotic endothelial cells to the total number of endothelial cells in 5-10 random $0.011-\mathrm{mm}^{2}$ (at $\times 400$ magnification).

The number of endothelial cells undergoing apoptosis was significantly greater in pancreatic tumors from mice treated with AZM475271 compared to control tumors $(24 \pm 9.1$ for AZM475271 compared with $0.7 \pm 1.5$ for untreated control, $p=0.01$ ) (Fig. 6.7). Clusters of apoptotic tumor cells were seen surrounding apoptotic endothelial cells when treated with AZM475271 (Fig. 6.6, the arrows delineate TUNEL-positive endothelial cells).

This finding suggests that the reduced tumor size that followed therapy with Src inhibitor was not wholly a direct consequence of inhibition of tumor cell proliferation. There was a statistically significant induction of endothelial cell apoptosis in the pancreatic tumor model when AZM475271-treated tumors and control tumors were compared, suggesting that the reduction in tumor growth and metastasis in the treated group was due to endothelial cell death and not to a direct effect on the tumor cells themselves. 
Control
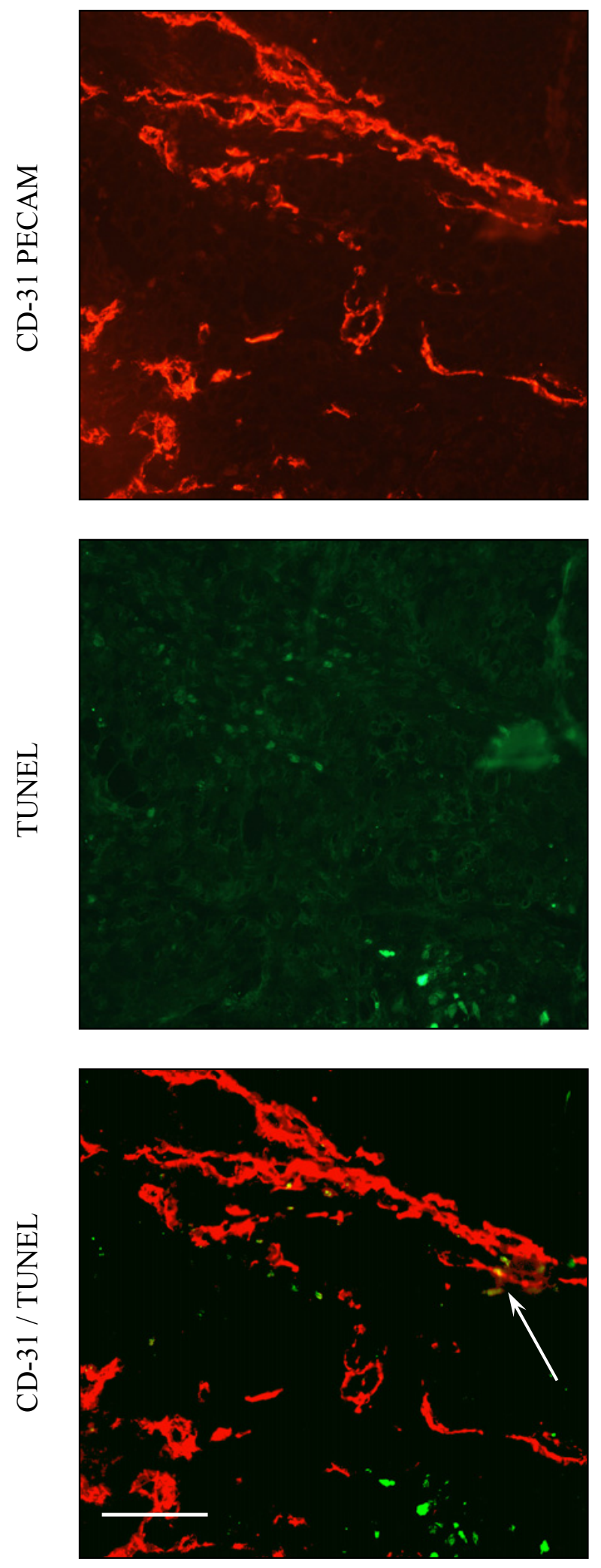

AZM475271
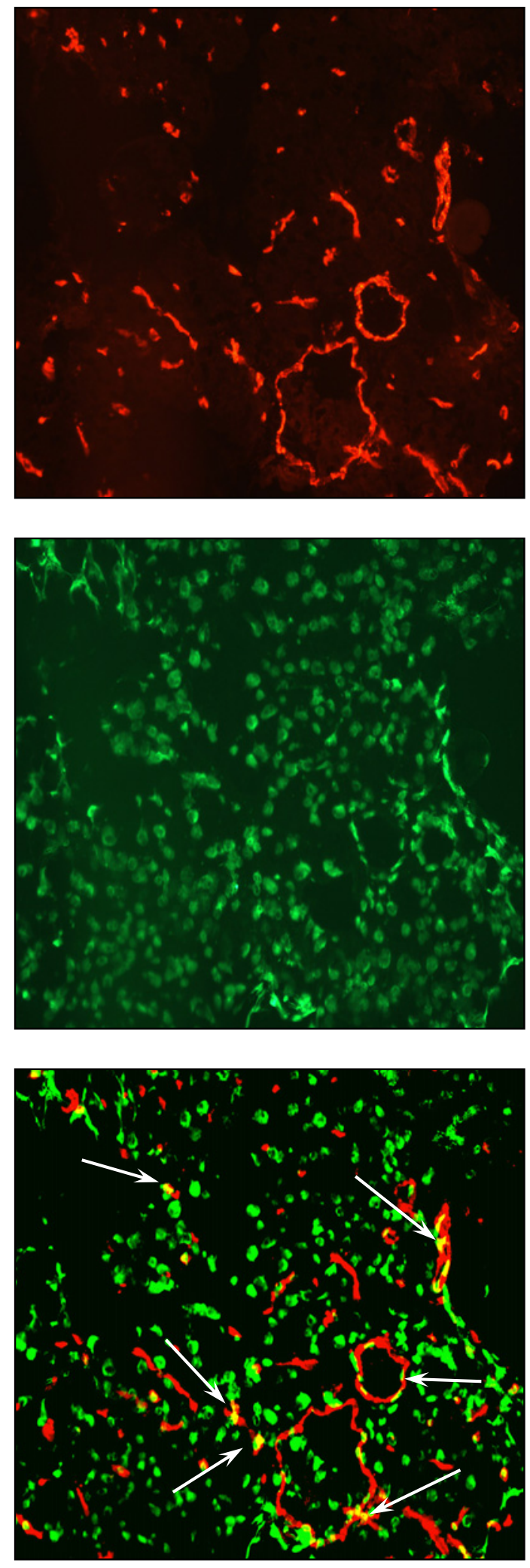
Figure 6.6 Immunofluorescent staining of L3.6pl human pancreatic tumors from mice treated with AZM475271.

Serial tissue sections were stained with the immunofluorescent endothelial cell marker (CD31) and the immunofluorescent apoptosis marker (TUNEL). A representative sample $(\times 100$ magnification) of this CD31/TUNEL fluorescent double-staining is shown. Fluorescent red, CD31-positive endothelial cells; fluorescent green, TUNEL-positive cells; fluorescent-yellow, TUNEL-positive endothelial cells; bar $=100 \mu \mathrm{m}$, the arrows delineate TUNEL-positive endothelial cells.

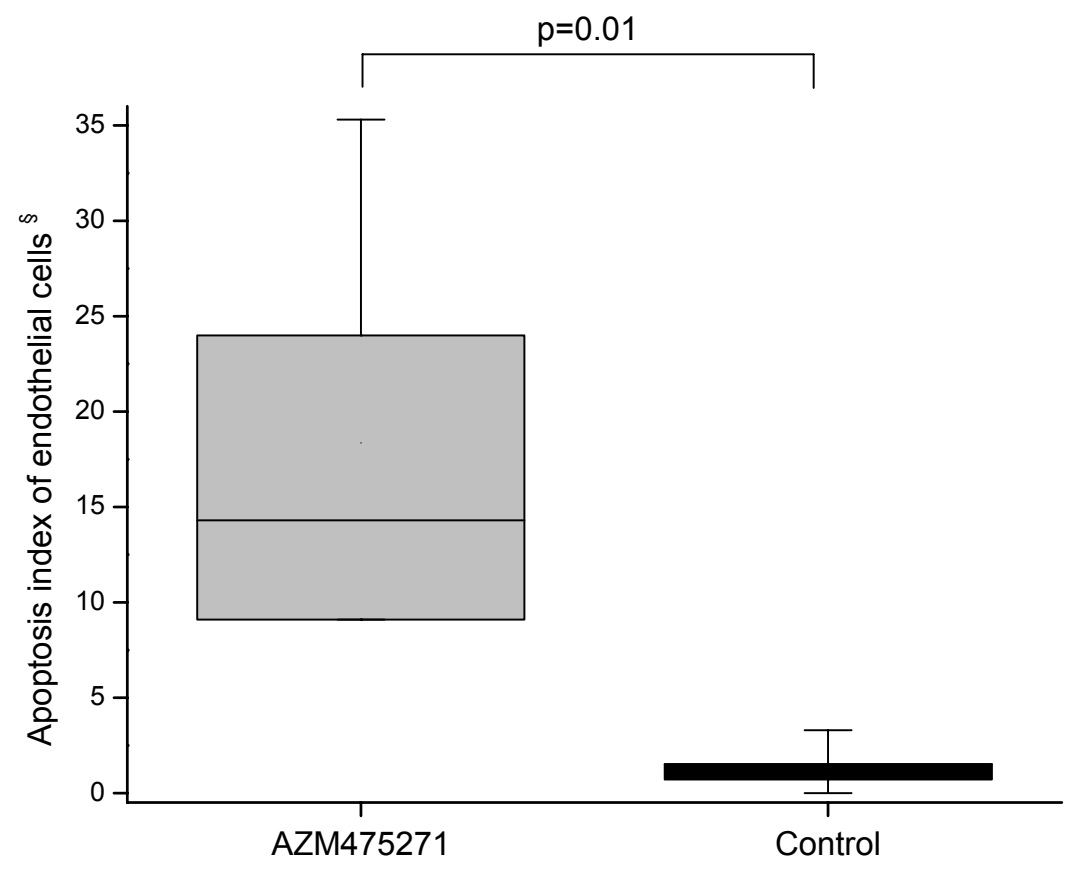

Figure 6.7 Apoptosis of endothelial cells of microvessels after therapy with AZM475271.

$\S$ The total number of apoptotic cells was quantified and expressed as the ratio of apoptotic endothelial cells to the total number of endothelial cells in 5-10 random $0.011-\mathrm{mm}^{2}$ (at $\mathrm{x} 400$ magnification).

Box plots represent the means for each group with standard deviation of data (min and max) and standard error of the mean.

\subsection{In vitro antiproliferative activity of AZM475271 in L3.6pl and HUVE cells}

Viability assays for L3.6pl and HUVE cells were performed with the TACS MTT Cell Proliferation and Viability Assay Kit. Treatment of HUVECs with AZM475271 at high concentrations $(>10 \mu \mathrm{mol} / \mathrm{L})$ caused a rapid decrease in cell proliferation that could be linked to the ability of AZM475271 to induce HUVEC death, whereas a significant antiproliferative activity of AZM475271 on HUVECs could be already observed at concentrations of $2 \mu \mathrm{mol} / \mathrm{L}$ or 
above $\left(\mathrm{IC}_{50}=6 \mu \mathrm{mol} / \mathrm{L}\right.$ ) (Fig. 6.8). Interestingly, no significant inhibition of proliferation was seen on L3.6pl cells at doses up to $5 \mu \mathrm{mol} / \mathrm{L}$. The antiproliferative effect of AZM475271 on L3.6pl was seen exclusively at very high doses $\left(\mathrm{IC}_{50}=25 \mu \mathrm{mol} / \mathrm{L}\right)$ (Fig. 6.8). These results suggest that the anti-angiogenic properties of AZM475271 might predominantly be mediated through a direct effect on the endothelial cells rather than via inhibition of tumor cells.

A

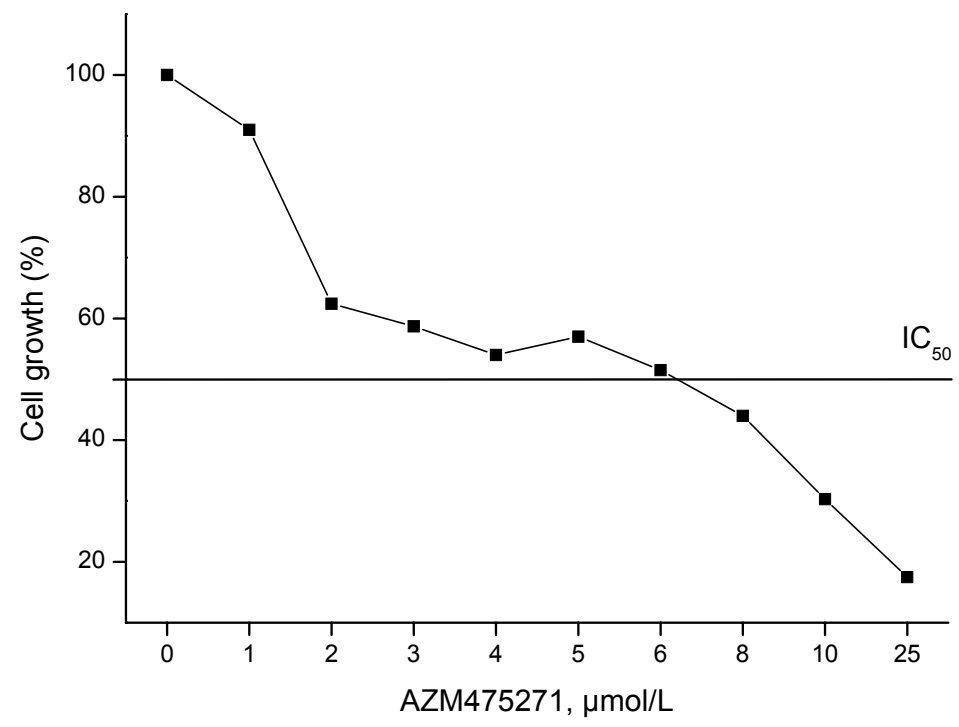

B

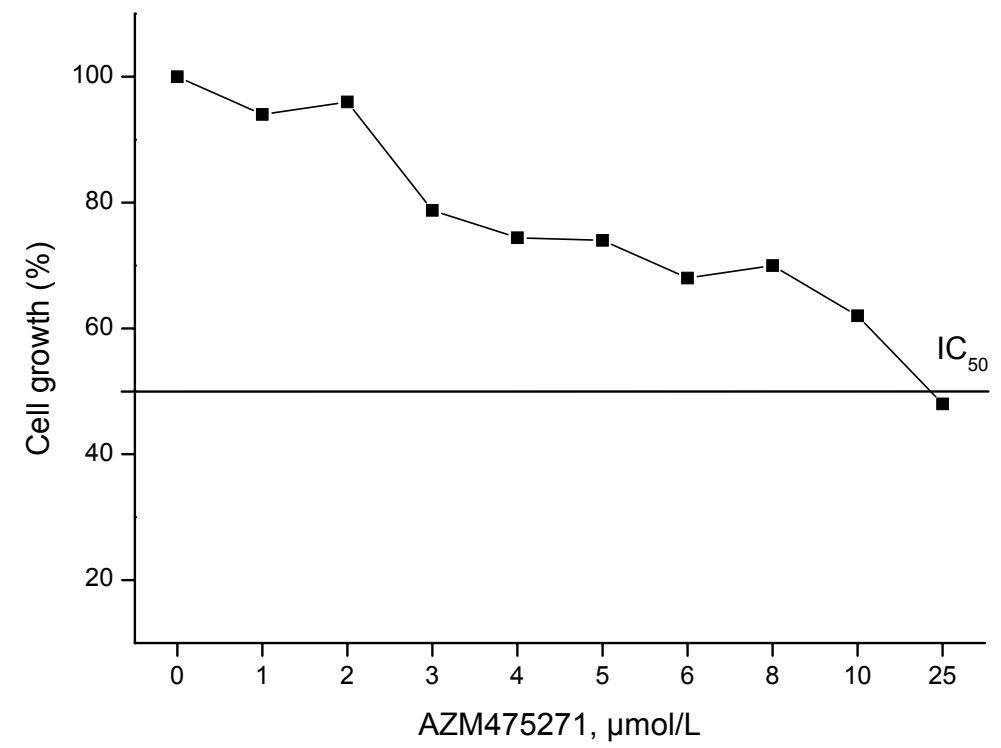


Figure 6.8 In vitro effects of AZM475271 on tumor and endothelial cell proliferation.

Viability assays for HUVE (a) and L3.6pl (b) cells with AZM475271 were performed with the TACS MTT Cell Proliferation and Viability Assay Kit. Treatment of HUVECs with AZM475271 at high concentrations $(>10 \mu \mathrm{mol} / \mathrm{L}, p<$ 0.0001 versus AZM475271 $0 \mu \mathrm{mol} / \mathrm{L}$ ) caused a rapid decrease in cell proliferation that could be linked to the ability of AZM475271 to induce HUVEC death. The $\mathrm{IC}_{50}$ concentration was reached at $6 \mu \mathrm{mol} / \mathrm{L}$ for HUVECs and at $25 \mu \mathrm{mol} / \mathrm{L}$ for L3.6pl cells, respectively.

\subsection{In vitro effects of AZM475271 on VEGF- and EGF- dependent endothelial cell proliferation}

The effects of exogenous VEGF or EGF on endothelial cell proliferation were analyzed using the TACS MTT Cell Proliferation and Viability Assay Kit.

To address the functional importance of HUVEC proliferation in response to growth factors, we incubated the cells for 48 hours in serum reduced medium $(0.5 \%$ FCS $)$ in the presence or absence of VEGF or EGF. Both growth factors at concentrations of $25 \mathrm{ng} / \mathrm{ml}$ induced endothelial cell proliferation under the starved conditions (Fig. 6.9). The results allow us to speculate that VEGF and EGF signalling pathways play a critical role in promoting endothelial cell survival under our in vitro conditions.

Cell proliferation assays were performed to examine an in vitro inhibition of VEGF and EGF induced HUVEC growth following treatment with AZM475271. Inhibition of Src kinase in HUVECs by AZM475271 showed prevention of survival signaling from VEGF - and EGF induced cell growth in a dose-dependent cytostasis. Interestingly, the $\mathrm{IC}_{50}$ concentration for AZM475271 in both VEGF- and EGF- stimulated HUVECs was significantly higher (Fig. 6.10) than that found under unstimulated conditions (Fig. 6.8a). The results allow us to speculate that VEGF and EGF signalling pathways play a critical role in promoting endothelial cell proliferation. 


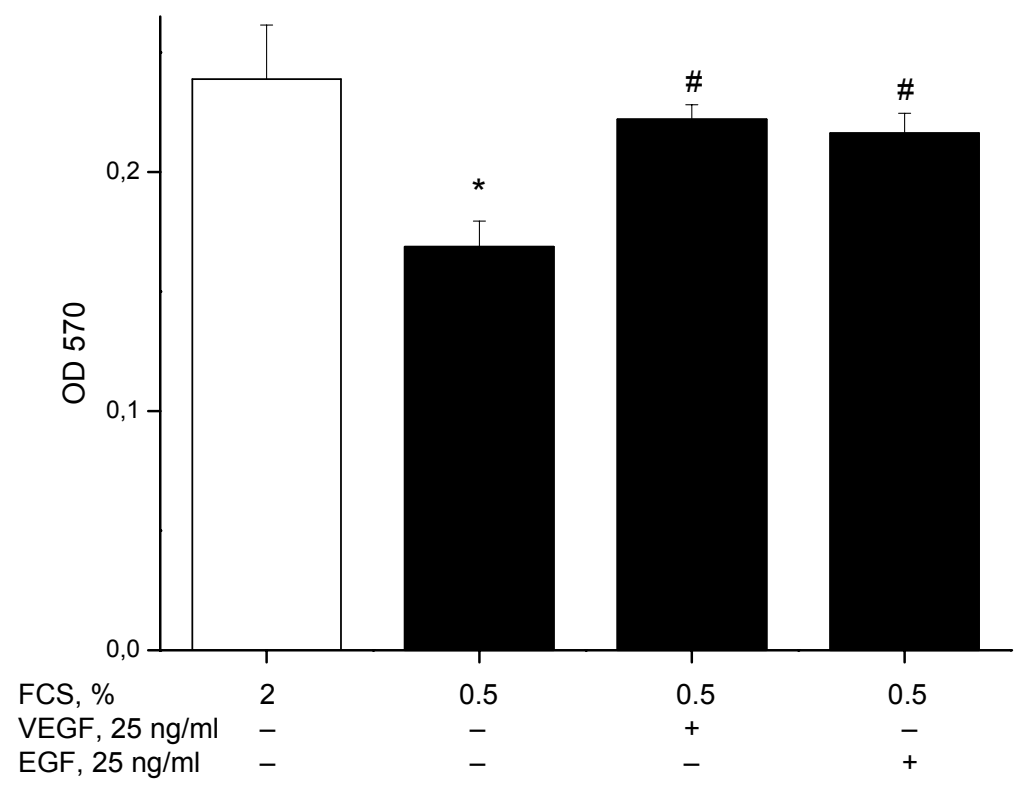

Figure 6.9 The effects of exogenous VEGF or EGF on endothelial cell proliferation.

Both growth factors at concentrations of $25 \mathrm{ng} / \mathrm{ml}$ induced endothelial cell proliferation under the starved conditions. $\left({ }^{*} \mathrm{p}<0.05\right.$ compared with $2 \%$ FCS control, ${ }^{\#} \mathrm{p}<0.05$ compared with $0.5 \%$ FCS starved control).

A

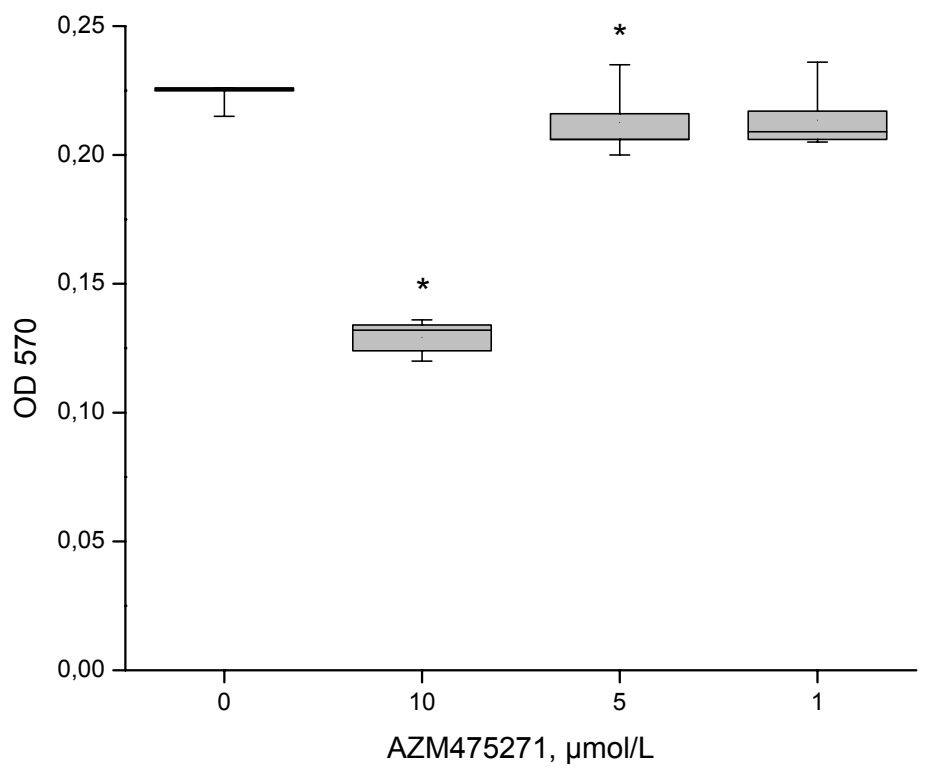


B

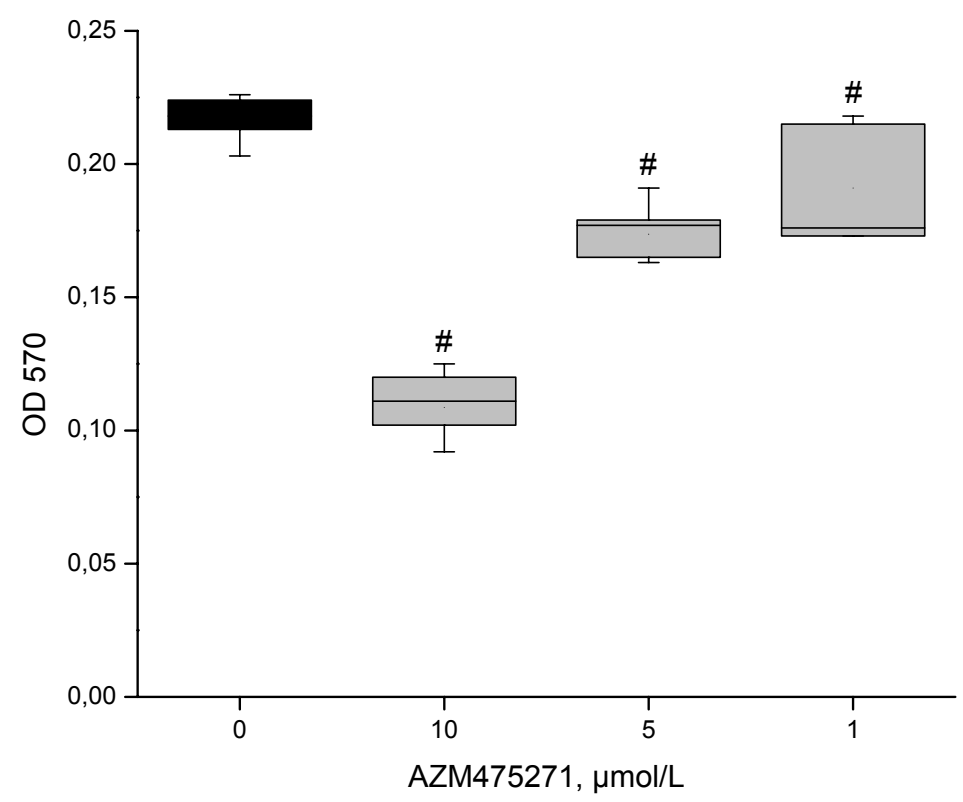

Figure 6.10 Inhibition of VEGF (A) - and EGF (B) - mediated endothelial cell proliferation.

Cells were treated with AZM475271 $(1-10 \mu \mathrm{mol} / \mathrm{L})$ in the presence of human recombinant $\mathrm{VEGF}_{165}$ or human recombinant $\mathrm{EGF}$ at concentrations of $25 \mathrm{ng} / \mathrm{ml}$ in serum reduced Endothelial Cell Basal Medium. Inhibition of Src kinase in HUVECs by AZM475271 showed prevention of survival signaling from VEGF (A) - and EGF (B) - induced cell growth in a dose-dependent cytostasis. Box plots represent the means for each group with standard deviation of data ( $m$ in and max) and standard error of the mean; *, $\mathrm{p}<0.05$ versus VEGF - stimulated cells; \#, $\mathrm{p}<0.05$ versus EGF - stimulated cells.

\subsection{In vitro effect of AZM475271 in the aortic ring assay}

Angiogenesis was studied by culturing aortic explants in three-dimensional matrix gels according to the procedure of Nikosia and Ottineri. Endothelial cell sprouting from cultured rat aortic rings was abrogated by AZM475271 at any of the concentrations tested $(1 \mu \mathrm{mol} / 1$ to 5 $\mu \mathrm{mol} / \mathrm{L}$; Fig. 6.11). At a concentration of $1 \mu \mathrm{mol} / \mathrm{L}$ endothelial migration and sprouting was 52 $\%$ relative to untreated controls $(\mathrm{p}=0.0024$ versus control). In contrast, a concentration of 5 $\mu \mathrm{mol} / \mathrm{L}$ inhibited sprouting by $93 \%$ relative to controls $(\mathrm{p}<0.0005$ versus control; Fig. 6.7). 
A

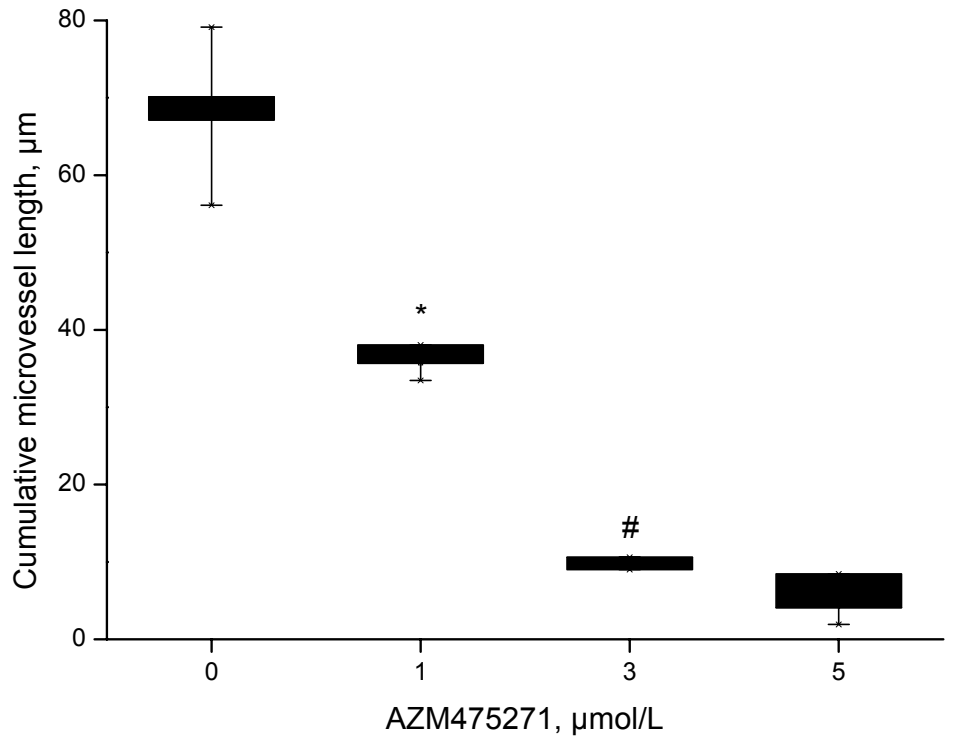


B

$\mathrm{AZM} 1 \mu \mathrm{M}$

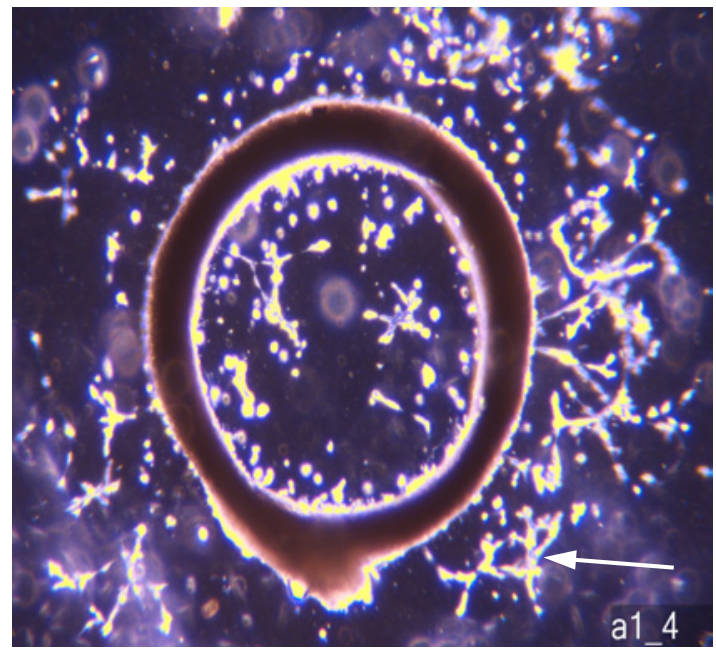

AZM $5 \mu \mathrm{M}$

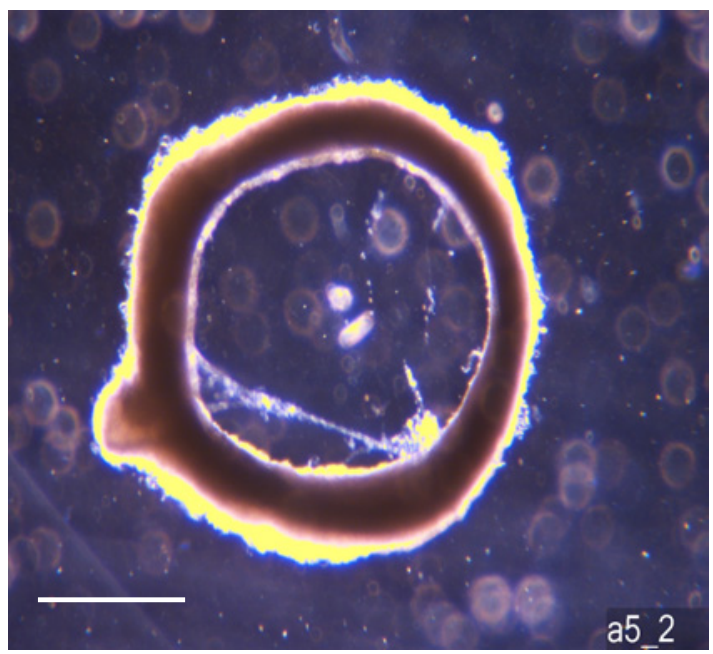

AZM $3 \mu \mathrm{M}$

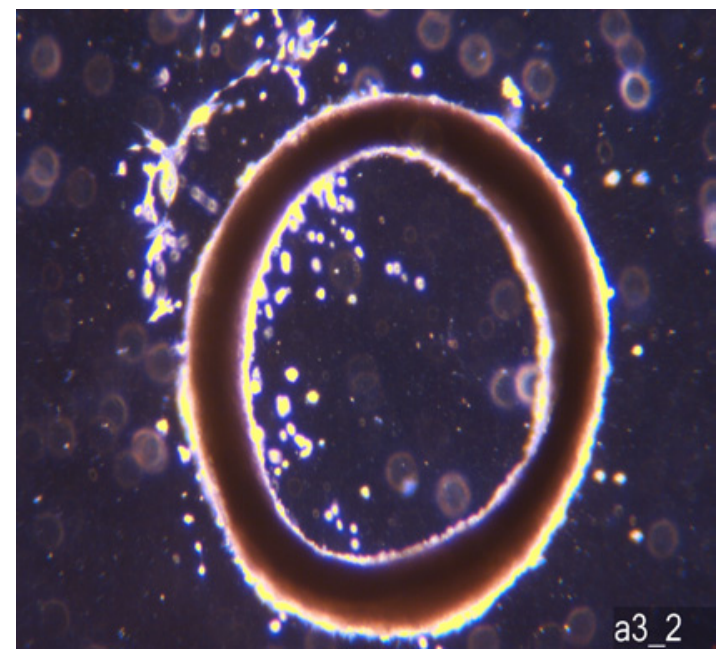

Control

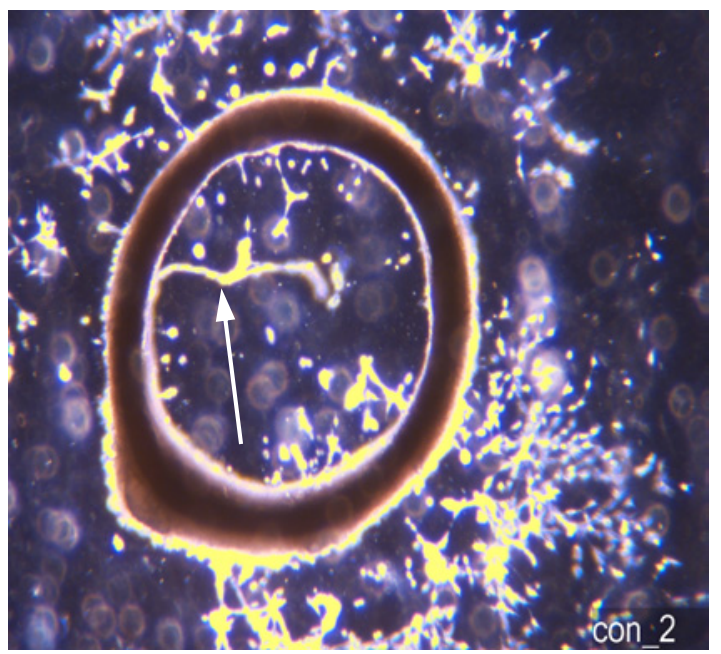

Figure 6.11 Effect of AZM475271 on rat aortic ring formation.

An estimation of the length of the capillary was performed by measuring the distance from the aortic explant to the approximate mean point of capillary. Endothelial cell sprouting from cultured rat aortic rings was abrogated by AZM475271 (a) at any of the concentrations tested ( $1 \mu \mathrm{mol} / \mathrm{L}$ to $5 \mu \mathrm{mol} / \mathrm{L})$. At a concentration of $1 \mu \mathrm{mol} / \mathrm{L}$ endothelial migration and sprouting was $52 \%$ relative to untreated controls. By contrast, a concentration of $5 \mu \mathrm{mol} / \mathrm{L}$ inhibited sprouting by $93 \%$ relative to controls $\left({ }^{\#}, p<0.0004\right.$ versus AZM475271 $0 \mu \mathrm{mol} / \mathrm{L} ;{ }^{*}, p=$ 0.0024 versus AZM475271 $0 \mu \mathrm{mol} / \mathrm{L}$ ). Representative photographs (b) showing the in vitro anti-angiogenic activity of the Src kinase inhibitor (the rings were examined by phase contrast microscopy with a Zeiss Axiotech Vario microscope at $\times 10$ magnification, bar $=10 \mu \mathrm{m}$, the arrows delineate capillary outgrowth). 


\subsection{AZM475271 inhibits endothelial sprouting in vitro in the spheroid angiogenesis model}

To investigate the complex processes of angiogenesis in vitro, we used the spheroid assay. We measured the ability of the endothelial cells to form sprouts in the spheroid model as a result of angiogenic stimulation, a prerequisite for an engagement of these cells in the formation of blood vessels.

Interestingly, AZM475271 inhibited sprouting of HUVEC at lower concentrations than suggested by the MTT proliferation assay $(1 \mu \mathrm{mol} / \mathrm{L}$ for the sprouting assay versus $6 \mu \mathrm{mol} / \mathrm{L}$ for the MTT assay). At concentrations higher than the $\mathrm{IC}_{50}$, sprouting of the endothelial cell spheroids was completely prevented (Fig. 6.12). 
Unstimulated

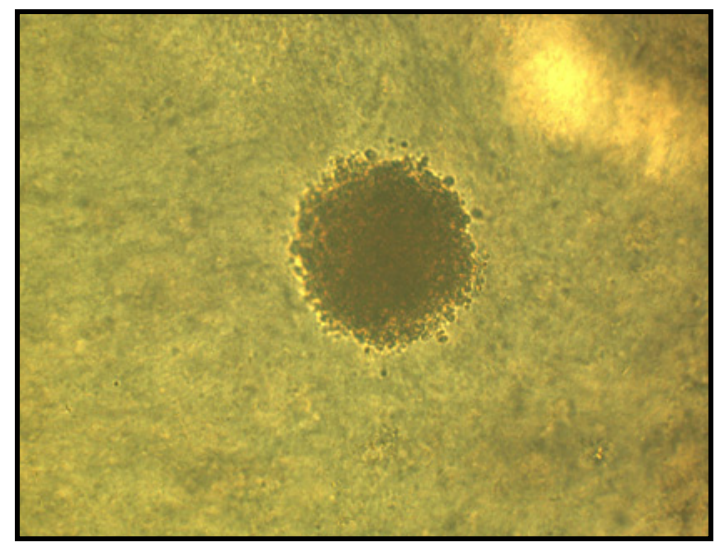

AZM $10 \mu \mathrm{mol} / \mathrm{L}$

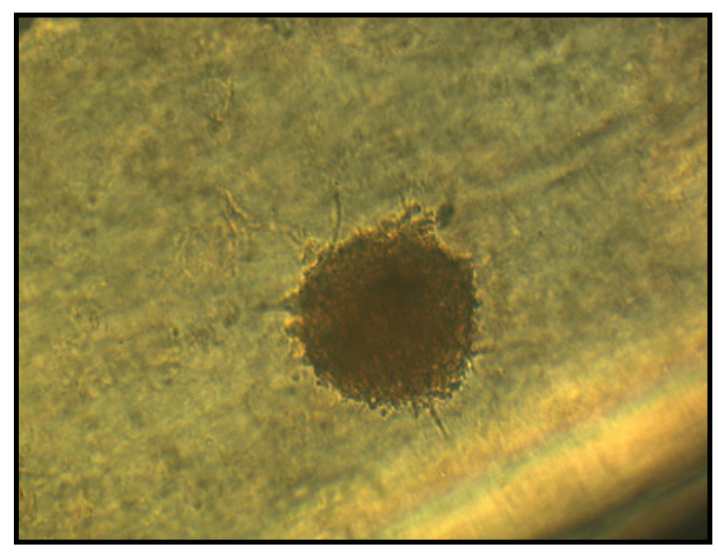

$\mathrm{AZM} 1 \mu \mathrm{mol} / \mathrm{L}$

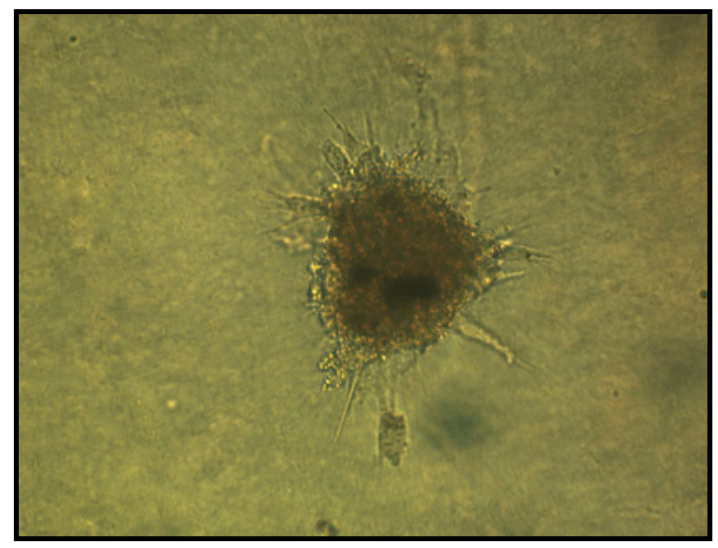

VEGF $25 \mathrm{ng} / \mathrm{ml}$

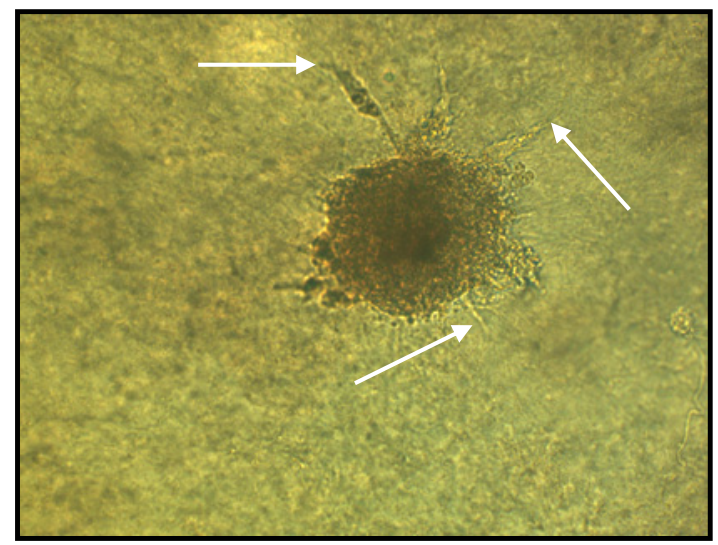

AZM $5 \mu \mathrm{mol} / \mathrm{L}$

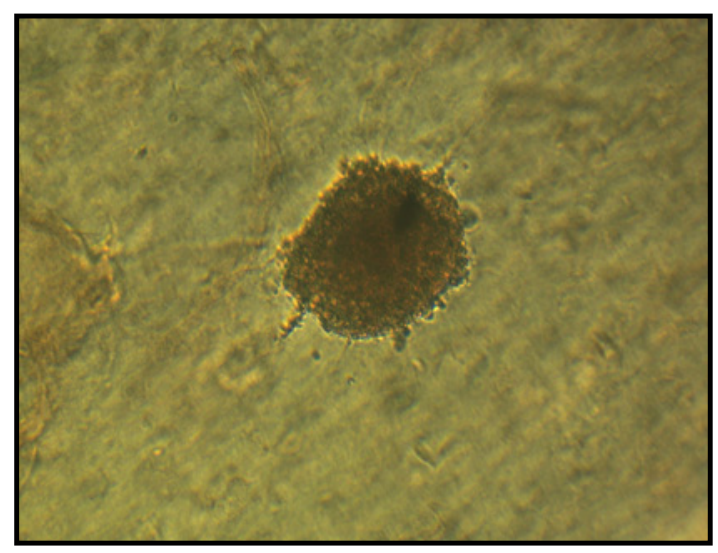

AZM $0.1 \mu \mathrm{mol} / \mathrm{L}$

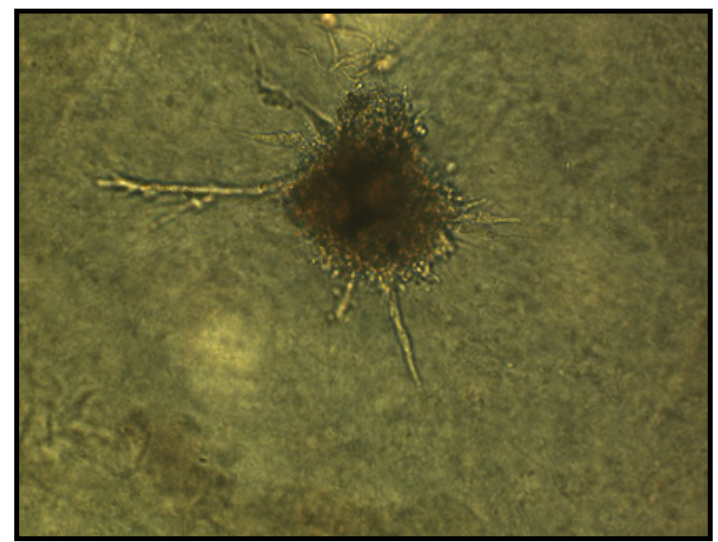

Figure 6.12 AZM475271 inhibits endothelial sprouting in vitro in the spheroid angiogenesis model

Spheroids were stimulated with $25 \mathrm{ng} / \mathrm{ml}$ VEGF-A 165 and the inhibiting properties of AZM475271 were investigated. AZM475271 was able to overcome the stimulating effect of VEGF- $\mathrm{A}_{165}$ at micromolar concentrations. Representative 
pictures of spheroids are presented (the pictures of the spheroids were taken under trans-illumination using an Achroplan objective providing a 20-fold magnification; the arrows delineate spheroid sprouting).

\subsection{Inhibition of VEGF production by L3.6pl and HUVE cells following treatment with} AZM475271

The level of VEGF was measured in cell culture supernates collected on day 0,2 , and 4 from L3.6pl or HUVE cells at one passage during treatment with Src kinase inhibitor AZM475271 at different concentrations $(0.1$ and $1 \mu \mathrm{mol} / \mathrm{L})$. The assay was performed according to the manufacturer's recommendations. Absorbance at $450 \mathrm{~nm}$ was measured and corrected using the $540-\mathrm{nm}$ reading on the microplate reader. VEGF content was calculated according to the parameter of the calibration curve. Calibration curves with a correlation coefficient at least 0.998 were used and data are expressed as picograms per millilitre per $10^{6}$ cells. All experiments were replicated three times.

The concentrations of AZM475271 below or equal $1 \mu \mathrm{mol} / \mathrm{L}$ (the concentrations with a maximum of inhibitory effect against Src tyrosine kinase [Fig. 6.1] without antiproliferative activity on tumor or endothelial cells [Fig. 6.8]) were taken to show that the production of VEGF by tumor or endothelial cells is "Src-dependent". We found that the level of VEGF in HUVE cell supernate on Day 0 (the beginning of experiment) as well as the level of VEGF in Endothelial Cell Basal Medium completed with supplemented growth factors was mostly non-detectable. The level of VEGF in HUVE cell supernate increased on Day 4, although this difference did not reach a significant level (Fig. 6.13a).

The level of VEGF in supernate taken from L3.6pl cells was significantly higher ( $>50$-fold) compare to those found in the HUVE cell supernate on Day 2. The amount of VEGF expressing by L3.6pl cells on Day 4 after the beginning of experiment increased significantly (Fig. 6.13b).

Most interestingly, the blockade of Src kinase by AZM475271 dramatically reduced the level of VEGF in L3.6pl supernate, the effect which was found also in the cell culture supernate from HUVE cells (Fig. 6.13, a and b). The inhibition of VEGF production by L3.6pl and HUVE cells following treatment with AZM475271 was day- and dose- dependent. 
$\mathbf{A}$
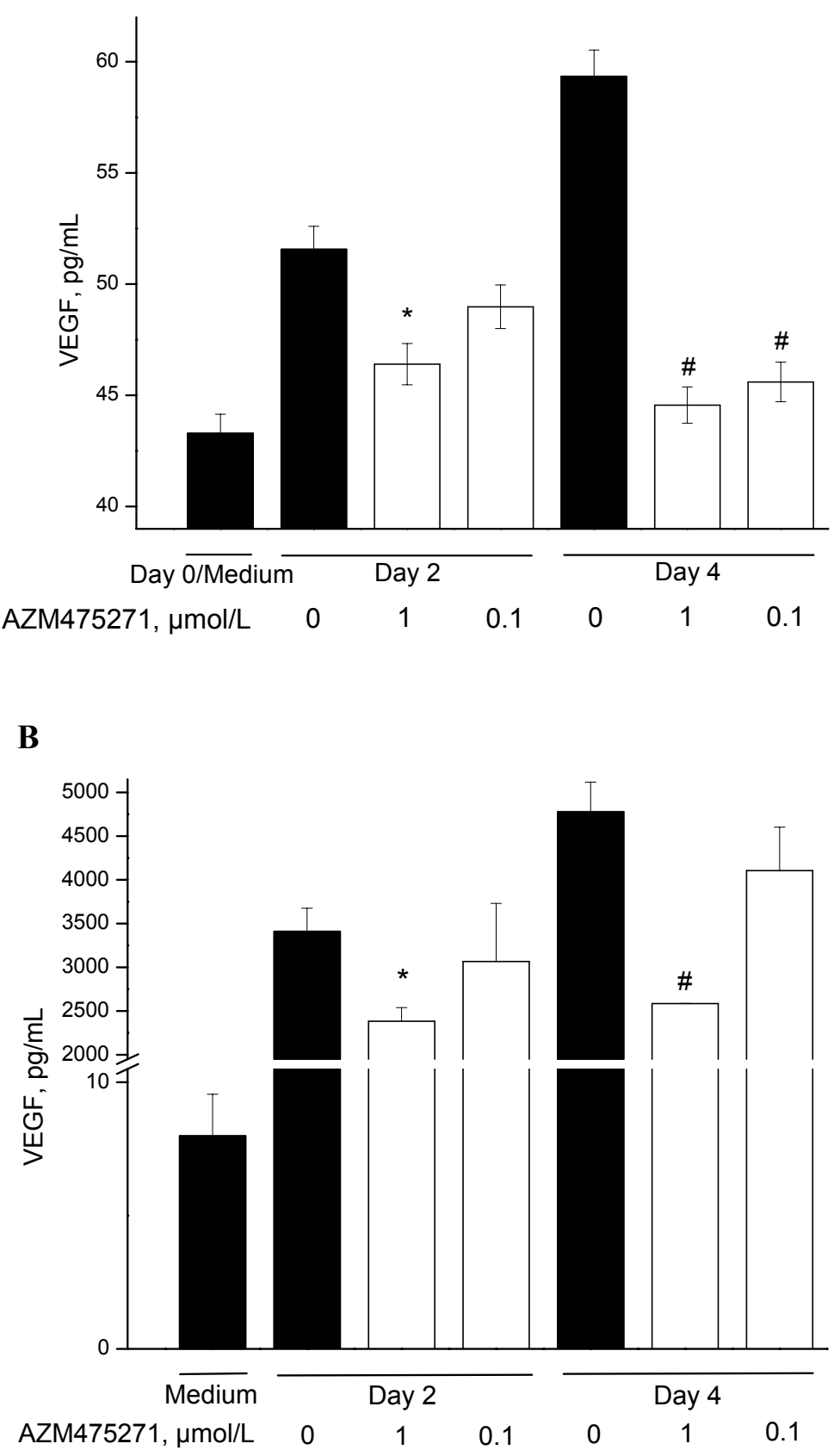

Figure 6.13 VEGF production by HUVE (a) and L3.6pl (b) cells following treatment with AZM475271.

The level of VEGF was measured in cell culture supernates collected on day 0,2 , and 4 from L3.6pl or HUVECs at one passage. The blockade of Src kinase by AZM475271 significantly reduced the level of VEGF in L3.6pl supernate in a dose-dependent manner (b), the effect which was found also in the cell culture supernate from HUVECs (a). ( ${ }^{*}, \mathrm{p}<0.05$ versus AZM475271 $0 \mu \mathrm{mol} / \mathrm{L}$, Day 2; \#, $\mathrm{p}<0.05$ versus AZM475271 $0 \mu \mathrm{mol} / \mathrm{L}$, Day 4). 


\subsection{In vitro induction of cell death in HUVECs}

FACS analysis was used to determine the effects of AZM475271 on HUVEC cell cycle progression. Quantification of apoptosis was performed using propidium iodide staining. HUVECs were treated with AZM475271 in different concentrations for 12 hours, and then cells were collected and suspended in a Nicoletti buffer. Inhibition of Src kinase in HUVECs resulted in the induction of apoptosis in $99 \%$ of the cells treated with AZM475271 at concentrations from 10 up to $25 \mu \mathrm{M}$ as compared with $6.3 \%$ of apoptotic cells present in the untreated control (Fig. 6.14, b). Interestingly, at the more physiologically relevant submicromolar doses of AZM475271 (5, 1 and $0.1 \mu \mathrm{mol} / \mathrm{L})$ the level of apoptotic fraction was also significantly higher $(60 \%, 40 \%$ and $15 \%$, respectively) when compared with untreated cells (6\%; Fig. 6.14, a).

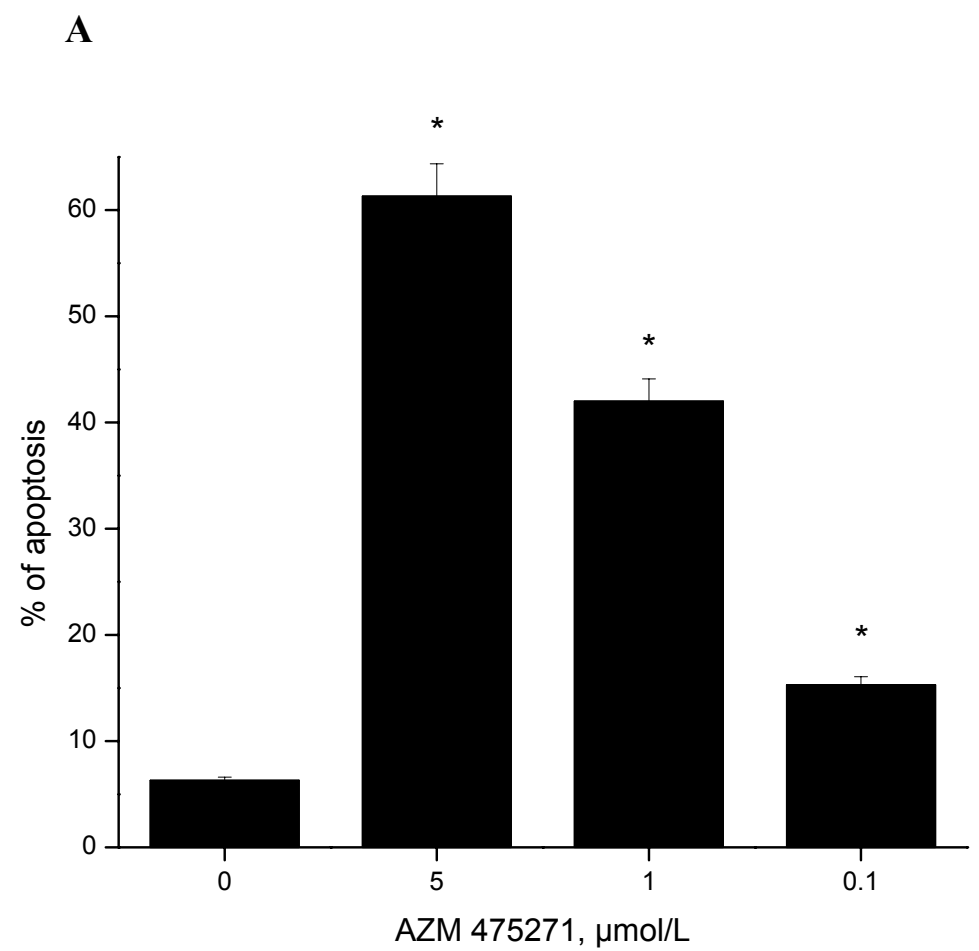


B
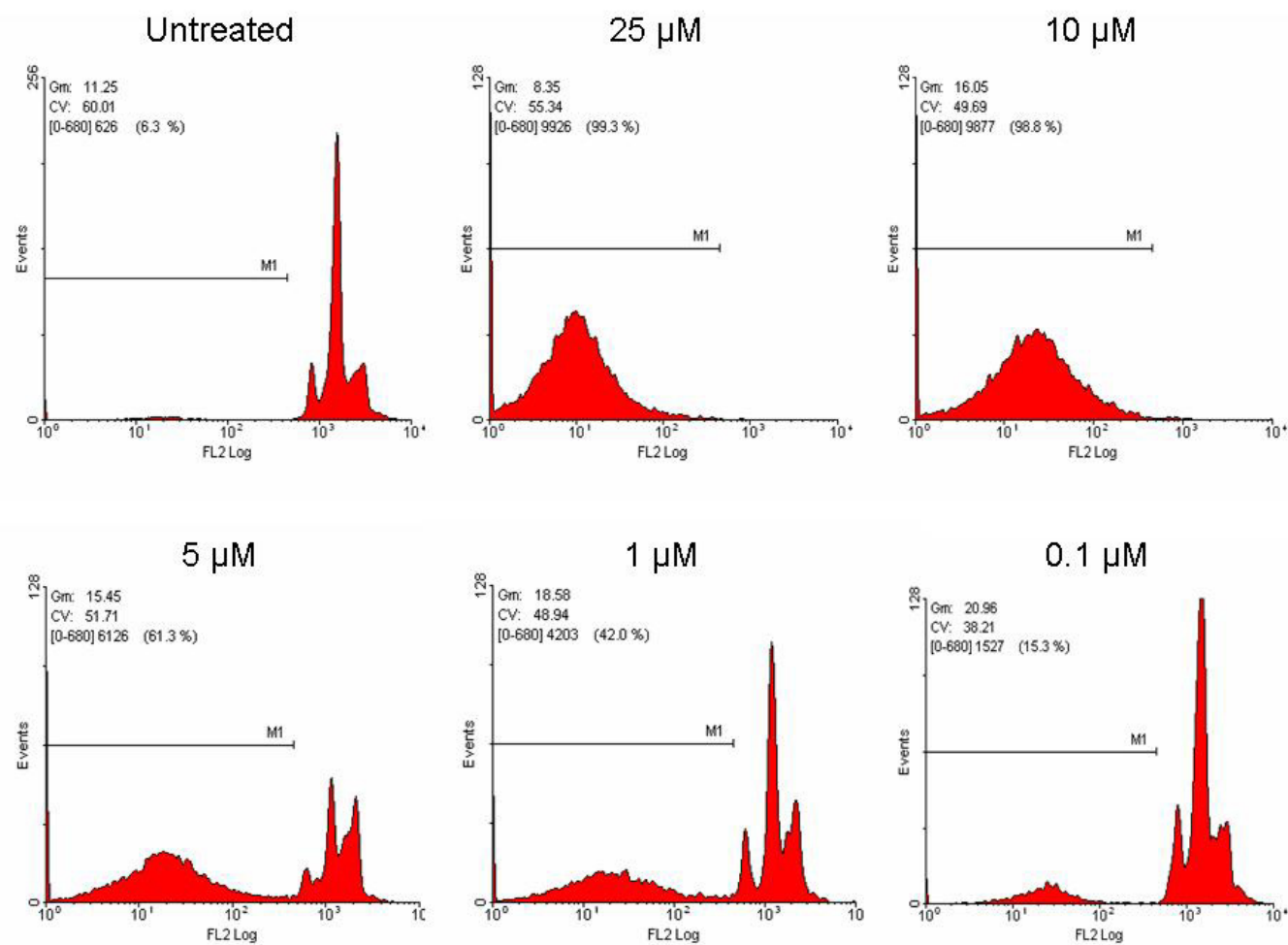

Figure 6.14 In vitro effect of AZM475271 on endothelial cell survival. Quantification of apoptosis was performed using propidium iodide staining for cell cycle analysis by FACS. AZM475271 promotes HUVEC apoptosis in a dosedependent manner (a), $\left(^{*}, \mathrm{p}<0.05\right.$ versus AZM475271 $\left.0 \mu \mathrm{mol} / \mathrm{L}\right)$. Histograms (b) show one representative of three independent experiments.

\subsection{In vitro inhibition of migration of HUVECs by AZM475271}

To investigate the anti-migratory effects of AZM475271 on endothelial cells we demonstrated whether Src inhibition in HUVECs prevented cell migration in a modified Boyden chamber assay. Inhibition of Src kinase resulted in a dose depended decrease of HUVEC migration. ( $\mathrm{p}<$ 0.05; Fig. 6.15). 


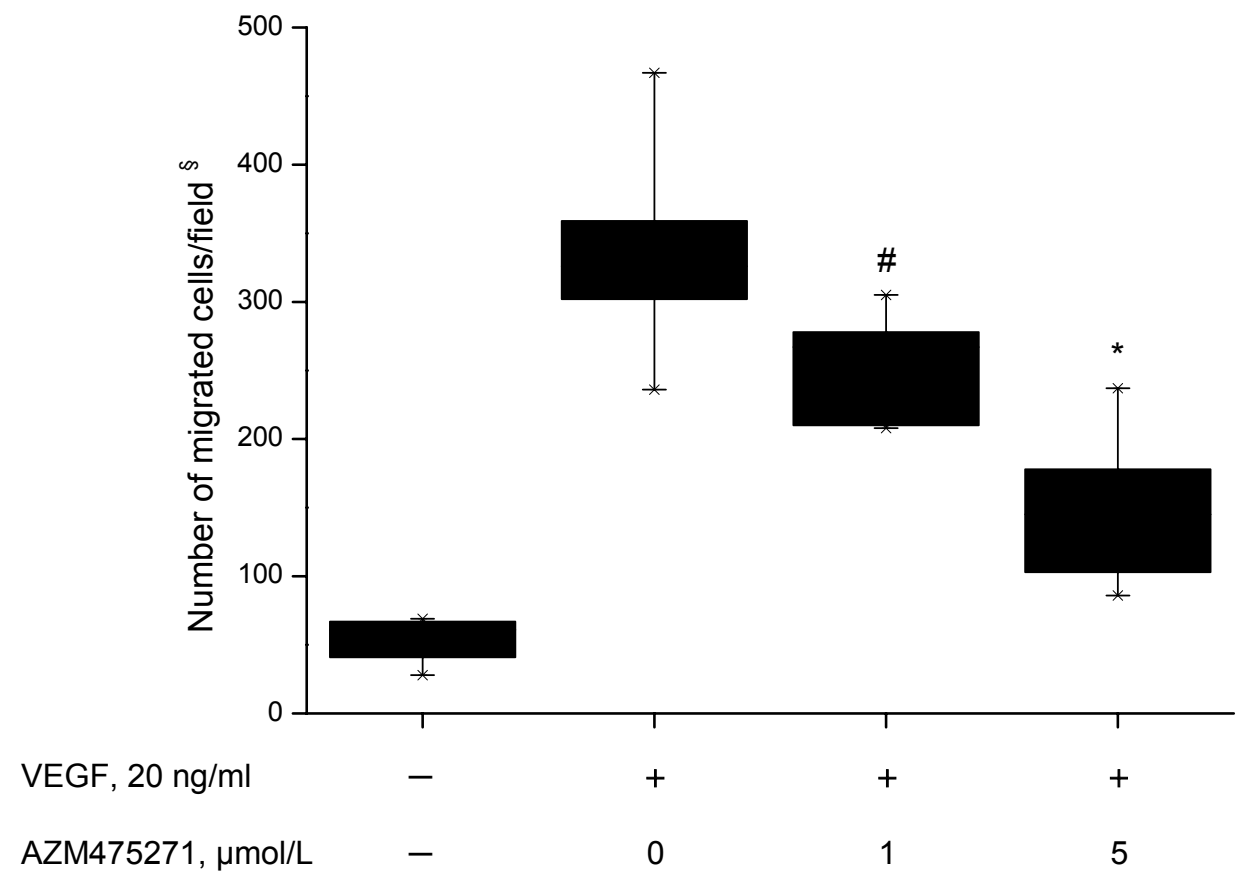

Figure 6.15 In vitro inhibition of migration of HUVECs by AZM475271. Migration of HUVECs was demonstrated using a modified Boyden chamber assay. Inhibition of VEGF-induced chemotaxis was assessed after including AZM475271 at relevant doses. Migration through the membrane was determined after 4 hours of incubation at $37^{\circ} \mathrm{C}$ by fixing, staining with hematoxylin and eosin, and counting the migrated cells in five random fields at $\times 100$ magnification. The average of triplicate inserts from three representative experiments was obtained. Bars, $\mathrm{SD} ;{ }^{*}, \mathrm{p}<0.001 ;{ }^{\#}, \mathrm{p}<0.0004$ (both versus VEGF stimulation); ${ }^{\S}$, positive cells in 5 random $0.159-\mathrm{mm}^{2}$ fields at x100 magnification.

\subsection{AZM475271 abolishes VEGF-induced FAK phosphorylation in HUVECs}

Src tyrosine kinase has been shown to mediate the tyrosine phosphorylation signal from VEGFR to FAK. Focal adhesion kinase is involved in integrin-mediated signal transduction. It plays an important role in the control of several biological processes, including cell spreading, migration and survival (Parsons et al., 2000). The recruitment of Src family kinases results in the phosphorylation of tyrosine residues 576 and 577 in the catalytic domain. Phosphorylation of tyrosines 576 and 577 is significantly elevated in the presence of c-Src in vitro and v-Src in vivo (Calalb et al., 1995). Furthermore, the maximal kinase activity of FAK immune complexes requires phosphorylation of both tyrosines 576 and 577. 
Here, we test the possibility that AZM475271 could affect VEGF-induced FAK kinase activity in HUVECs. Using Western Blots, we found src-dependent up-regulation of FAK phosphorylation (Fig. 6.16). Treatment of HUVECs with $10 \mu \mathrm{mol} / \mathrm{L}$ of AZM475271 resulted in the significant inhibition of VEGF-activated pTyr 576/577 FAK phosphorylation, indicating that VEGF mediates its effect in HUVECs at least in part via Src kinase.
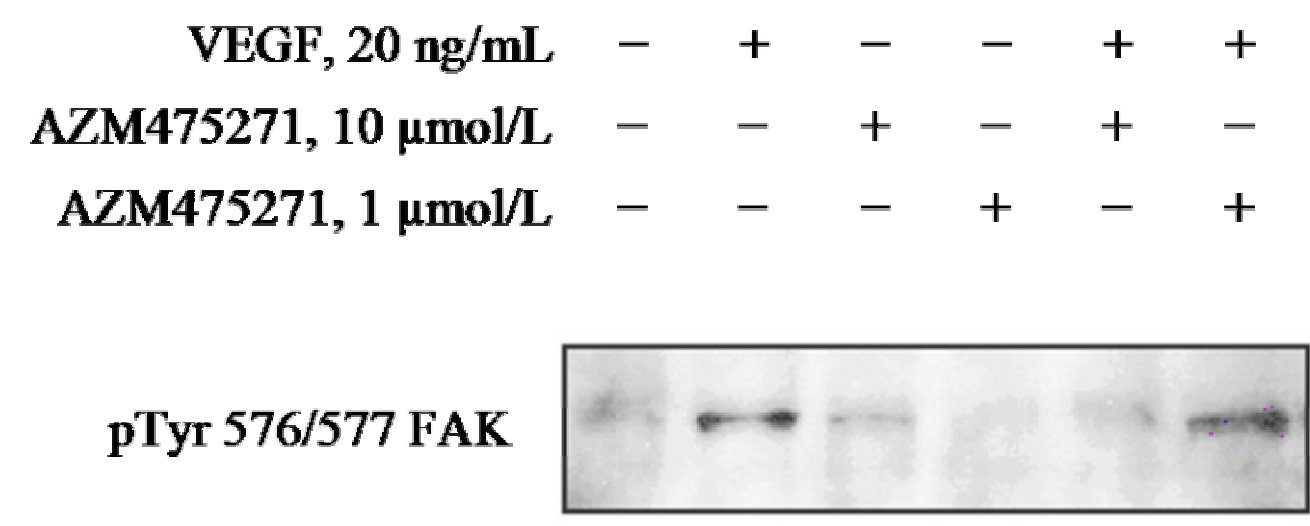

FAK

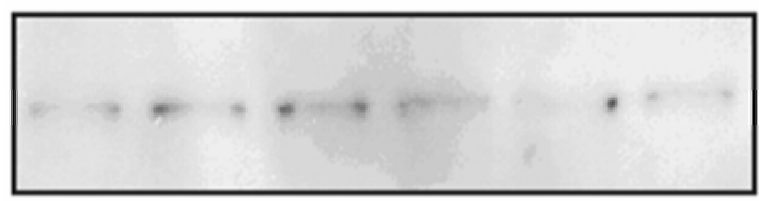

Figure 6.16 VEGF-induced HUVEC FAK phosphorylation is inhibited by AZM475271.

Lysates of VEGF-stimulated HUVECs were prepared as described in Materials and Methods and subjected to immunoblotting with anti-phosphotyrosine antibody specific for 576/577 within FAK. 


\section{Chapter 7}

\section{DISCUSSION}

Currently, a large variety of chemotherapeutic drugs is being used to treat pancreatic cancer, but, unfortunately, many compounds show only limited efficacy due to problems of delivery and development of drug resistance in tumor cells. Tumor cells are rapidly changing targets because of their genetic instability, heterogeneity, and high rate of mutation, leading to selection and outgrowth of drug-resistant tumor cell populations (Gasparini et al., 1999; Kerbel, 1997).

Anti-angiogenic therapy offers several advantages over therapy directed against tumor cells. First, endothelial cells are a genetically more stable, diploid, and spontaneous mutations rarely occur. Second, the turnover of tumor endothelial cells is approximately 50 times higher than of endothelial cells in normal quiescent tissues. Third, tumor endothelial cells as target are easily accessible by systemic administration. Finally, a high number of tumor cells is sustained by a single capillary, that means, inhibition of a small number of tumor vessels may affect the growth of many tumor cells (Kerbel, 1997). It has been shown, that the intratumoral blood vessel density is a prognostic marker in a variety of solid tumors, including invasive breast (Kumar et al., 1999), lung (Fontanini et al., 1996), malignant melanoma, gastrointestinal, (Tanigawa et al., 1997) and genitourinary cancers (Pepper, 1997). The progressive growth of pancreatic neoplasms also depends on the induction of angiogenesis, in these tumors a positive correlation was found between tumor angiogenesis and the risk of metastasis, tumor recurrence, and death (Kumar et al., 1999; Fontanini et al., 1996; Tanigawa et al., 1997). However, as tumors grow, they begin to produce a wider array of angiogenic molecules. Therefore, if only one molecule (for example, VEGF) is blocked, tumors may switch to another molecule (for example, bFGF or IL-8). Thus we may require a cocktail of antibodies/inhibitors. In this respect, targeting intracellular proteins might be a promising approach in angiogenesis therapy of pancreatic cancer. Indeed, our results support the theory that the inhibition of intracellular transducers of receptor tyrosine kinase signaling can avoid these disadvantages. 
The purpose of the current study was to determine whether the intracellular tyrosine kinase Src might play a role in angiogenesis of pancreatic cancer. c-Src is a multifunctional protein involved in the regulation of a variety of normal processes, including proliferation, differentiation, survival, motility, and functions of fully differentiated cells (Thomas and Brugge, 1997). There are several recent reports that Src contributes to the control of tumor angiogenesis. Specifically, Src is needed for hypoxia-induced vascular endothelial growth factor (VEGF) production in a number of cell types (Mukhadopathyay et al., 1995). Furthermore, it has been shown, that suppression of Src in HT29 colon cancer cells by an antisense approach, led to a reduction of VEGF expression (Ellis et al., 1998). Thus, it appears that Src cannot only regulate the production of VEGF, but also control the consecutive endothelial cell response (see Chapter $3)$.

To investigate the hypothesis, that Src inhibitory drugs do not only affect tumor cell proliferation and survival, but also angiogenesis and migration, we conducted an in vivo experiment using a novel orally available Src kinase inhibitor AZM475271 (AstraZeneca) in nude mice bearing L3.6pl human pancreatic cancer implanted orthotopically in the pancreas. Treatment with AZM475271 did not significantly change animal weight (at the end of experiment the mean animal body weight after therapy with AZM475271 was $21.6 \mathrm{~g}$, compared to the untreated group with $22.6 \mathrm{~g}$ ). Monitoring of the tumor volume over the time of experiment revealed a decrease in the tumor growth progression in all animals treated with AZM475271. The animals were sacrificed 32 days after the initiation of treatment, when $>50 \%$ of the control animals had become moribund. At the time of sacrifice, all animals developed primary pancreatic tumors, however the mean tumor volume was significantly decreased ( $40 \%$ inhibition of primary tumor growth) from $1125 \pm 460 \mathrm{~mm}^{3}$ (control animals) to $508 \pm 205 \mathrm{~mm}^{3}$ in animals treated with AZM475271. Furthemore, treatment with AZM475271 significantly reduced spontaneous liver metastasis (no animals had metastases) compared with treatment using vehicle solution. Mice who received AZM475271 had also a significant reduction in the incidence of lymph node metastases (five of nine animals). In addition, daily intragastral administration of AZM475271 was well tolerated. IHC analyses of primary pancreatic tumors demonstrated a significant decrease in proliferating tumor cells, the mean number of $\mathrm{Ki}-67$ positive tumor cells after therapy with AZM475271 was reduced by $>50 \%$ compared to control mice. The mean number of apoptotic cells in the tumors treated with AZM475271 was significantly elevated compared to control tumors ( $26 \pm 11$ versus $8 \pm 2$, respectively). The number of CD31-positive microvessels counted per $\times 100$ field in the pancreatic tumors was lower in mice after therapy with AZM475271, but not significant $(\mathrm{p}=0.14967)$. We speculated that tumor cell apoptosis may 
have been due to poor perfusion after endothelial cell apoptosis rather then due to decreasing in microvessel density. Indeed, double staining of endothelial cells with antibodies against CD31 and TUNEL revealed that the reduction in MVD was attributable to a significant increase of apoptosis in endothelial cells $(24 \pm 9.1$ for AZM475271 compared with $0.7 \pm 1.5$ for untreated control, $\mathrm{p}=0.01$ ) and not to a direct effect on the tumor cells themselves (clusters of apoptotic tumor cells were seen surrounding apoptotic endothelial cells when treated with AZM475271). This finding suggests that the reduced tumor size that followed therapy with Src inhibitor was not wholly a direct consequence of inhibition of tumor cell proliferation. There was a statistically significant induction of endothelial cell apoptosis in the pancreatic tumor model when AZM475271-treated tumors and control tumors were compared. This is the first report to our knowledge demonstrating that therapy with AZM475271 leads to apoptosis of endothelial cells within pancreatic tumors as determined by a double-labeling immunofluorescence procedure. Moreover, the antiangiogenic activity of the Src kinase inhibitor was also evident in vitro, where proliferation, invasion, and migration of the endothelial cells were significantly reduced by AZM475271.

In vitro, AZM475271 was shown to inhibit proliferation and to induce apoptosis of human umbilical vein endothelial cells (HUVECs) in a dose dependent manner. Treatment of HUVECs with AZM475271 at high concentrations $(>10 \mu \mathrm{mol} / \mathrm{L})$ caused a rapid decrease in cell proliferation that could be linked to the ability of AZM475271 to induce HUVEC death, whereas a significant antiproliferative activity of AZM475271 on HUVECs could be already observed at concentrations of $2 \mu \mathrm{mol} / \mathrm{L}$ or above $\left(\mathrm{IC}_{50}=6 \mu \mathrm{mol} / \mathrm{L}\right)$. Interestingly, no significant inhibition of proliferation was seen on $\mathrm{L} 3.6 \mathrm{pl}$ cells at doses up to $5 \mu \mathrm{mol} / \mathrm{L}$. The antiproliferative effect of AZM475271 on L3.6pl was seen exclusively at very high doses $\left(\mathrm{IC}_{50}=25 \mu \mathrm{mol} / \mathrm{L}\right)$. These in vitro findings support our theory that the anti-tumor properties of AZM475271 might predominantly be mediated through a direct effect on the endothelial cells rather that on the tumor cells.

Inhibition of Src kinase in HUVECs also showed prevention of survival signaling from VEGF and EGF. The $\mathrm{IC}_{50}$ concentration for AZM475271 in both VEGF- and EGF- stimulated HUVECs was higher $\left(\mathrm{IC}_{50}=10 \mu \mathrm{mol} / \mathrm{L}\right)$ than that found in HUVECs under unstimulated conditions. The results allow us to speculate that VEGF and EGF signalling pathways play a critical role in promoting endothelial cell proliferation and survival. Indeed, it has been shown that receptor tyrosine kinases activate Src by autophosphorylation of tyrosine residues that function as docking sites for the $\mathrm{SH} 2$ domain of Src kinase on the receptor itself or by phosphorylation of docking proteins. Once activated, Src could link VEGF- or EGF-stimulation 
with the PDK/PKB signaling cassette leading to stimulation of endothelial cell survival and angiogenesis (Schlessinger et al., 2000). However, although both growth factors stimulate Src activation, it has only been shown that VEGF-induced angiogenesis can be inhibited by treatment with a retrovirus that encodes for Src-251, a dominant-negative mutant of Src. Moreover, overexpression of Src-251 in avian blood vessels induces apoptotic death, indicating that VEGF-induced activation of Src is essential for endothelial cell survival and angiogenesis. Interestingly, VEGF-induced vascular permeability is impaired in $\mathrm{Src}^{-/-}$and in $\mathrm{Yes}^{-/-}$but not in $\mathrm{Fyn}^{-/-}$mice (Eliceiri et al., 1999), suggesting that the function of Src kinases in endothelial cells is not comparable to the function of other family members.

Furthemore, we found that in addition to regulating the VEGF response of HUVE cells, Src also regulates the expression of VEGF in both tumor and endothelial cells. The level of VEGF was measured in cell culture supernates collected on day 0, 2, and 4 from L3.6pl or HUVE cells at one passage during treatment with Src kinase inhibitor AZM475271 at different concentrations $(0.1$ and $1 \mu \mathrm{mol} / \mathrm{L})$. The concentrations of AZM475271 below or equal $1 \mu \mathrm{mol} / \mathrm{L}$ (the concentrations with a maximum of inhibitory effect against Src tyrosine kinase without antiproliferative activity on tumor or endothelial cells) were taken to show that the production of VEGF by tumor or endothelial cells is "Src-dependent". We found that the level of VEGF in HUVE cell supernate on Day 0 (the beginning of experiment) as well as the level of VEGF in Endothelial Cell Basal Medium completed with supplemented growth factors was mostly nondetectable. The level of VEGF in HUVE cell supernate increased on Day 4, although this difference did not reach a significant level. The level of VEGF in supernate taken from L3.6pl cells was significantly higher ( $>50$-fold) compare to those found in the HUVE cell supernate on Day 2. The amount of VEGF expressing by L3.6pl cells on Day 4 after the beginning of experiment increased significantly. Most interestingly, the blockade of Src kinase by AZM475271 dramatically reduced the level of VEGF in L3.6pl supernate, the effect which was found also in the cell culture supernate from HUVE cells.

To gain more relevant information in terms of angiogenic processes, we measured the ability of the endothelial cells to form sprouts in the spheroid assay as a result of angiogenic stimulation, a prerequisite for an engagement of these cells in the formation of blood vessels. Cells organized in a spheroid that is embedded in a collagen matrix, are much more sensitive to pro-angiogenic as well as anti-angiogenic stimuli as compared to the same cells in a monolayer culture. This finding was also apparent in our experiments and is rationalized by the fact that proliferation is only one of the features of angiogenic processes. Additional processes such as cell plasticity and mobility are also pivotal features of angiogenesis. Therefore, our finding that AZM475271 
abrogated the stimulating effect of VEGF-A $\mathrm{A}_{165}$ even at submicromolar concentrations demonstrates the high susceptibility of sprouting endothelial cells to AZM475271.

Image analysis was also used to quantify angiogenesis on the rat aortic ring model by culturing aortic explants in three-dimensional matrix gels according to the procedure of Nikosia and Ottineri. This model bridges the gap between in vivo and in vitro models and is suitable to quantify spontaneous angiogenesis as well as to analyze a complex microvascular network induced by VEGF. Interestingly, endothelial cell sprouting from cultured rat aortic rings was abrogated by AZM475271 at any of the concentrations tested $(1 \mu \mathrm{mol} / 1$ to $5 \mu \mathrm{mol} / \mathrm{L})$. At a concentration of $1 \mu \mathrm{mol} / \mathrm{L}$ endothelial migration and sprouting was $52 \%$ relative to untreated controls. In contrast, a concentration of $5 \mu \mathrm{mol} / \mathrm{L}$ inhibited sprouting by $93 \%$ relative to controls.

Recent reports have demonstrated a major role for Src activity in the control of cell adhesion and cytoskeletal changes, which in turn regulate cell invasion and migration (Frame, 2002). To produce new vessels, endothelial cells must migrate, degrade extracellular matrix, divide, form tubes, and survive (Fidler et al., 1994; Folkman, 1995). Evidence is provided that VEGF activates Src kinase, which induces the phosphorylation of tyrosines 576/577 within FAK, facilitating the association of FAK with integrin $\alpha_{\mathrm{v}} \beta_{3}$. Blockade of Src activity by AZM475271 inhibits the formation of a VEGF-induced FAK/ $\alpha_{\mathrm{v}} \beta_{3}$ complex. Integrin $\alpha_{\mathrm{v}} \beta_{3}$ is known to bind a number of ECM proteins, among them vitronectin, fibrinogen, von Willebrand factor, fibronectin and denatured collagen. More recent studies show that integrin $\alpha_{\mathrm{v}} \beta_{3}$ can also bind directly to matrix metalloproteinase 2, thereby localizing the MMP-2-mediated matrixdegradation capacity to the invasive/migratory site of vascular cells during angiogenesis (Brooks et al., 1996). This enables endothelial cells to degrade and remodel the ECM during their invasion.

We confirmed the antimigratory effect of AZM475271 by analysis of endothelial cell migration using a modified Boyden chamber assay revealing a strong inhibition of HUVEC migration. These findings suggest that one major role of Src activity is to cooperate with activated growth factor receptors to induce adhesion and cytoskeletal changes that are associated with invasion and metastasis. Therefore, it is possible, that Src-specific inhibitory drugs, such as AZM475271, might primarily affect these pathways in endothelial cells, and so be useful in preventing further tumor spread, while not necessarily having such a strong influence on cancer cell growth. 


\section{Chapter 8}

\section{SUMMARY}

The results of all experiments can be summarized as follows:

- AZM475271 is the selective inhibitor of the Src tyrosine kinase activity in HUVE and L3.6pl cells with the $\mathrm{IC}_{50}=0.1 \mu \mathrm{mol} / \mathrm{L}$;

- Monitoring of the tumor volume in mice bearing human pancreatic cancer revealed a decrease in the tumor growth progression in all animals treated with AZM475271;

- Daily intragastral administration of AZM475271 was well tolerated;

- At the time of necropsy, the mean tumor volume was significantly decreased $(\sim 40 \%$ inhibition of primary tumor growth) in all mice treated with AZM475271;

- Treatment with AZM475271 significantly reduced spontaneous liver metastasis (no animals had metastases) compared with treatment using vehicle solution. Mice who received AZM475271 had also a significant reduction in the incidence of lymph node metastases (five of nine animals);

- The mean number of proliferating tumor cells ( $\mathrm{Ki}$-67-positive) in harvested tumors was reduced over than $50 \%$ in the AZM475271 therapy group compared to the control group;

- The mean number of apoptotic cells (measured by TUNEL staining) was significantly higher in the AZM475271 therapy group;

- The number of endothelial cells undergoing apoptosis (determined by a double CD31 and TUNEL staining) was significantly greater in pancreatic tumors from mice treated with AZM475271 compared to control tumors;

- A significant antiproliferative activity of AZM475271 on HUVECs can be already observed at concentrations of $2 \mu \mathrm{mol} / \mathrm{L}$ or above $\left(\mathrm{IC}_{50}=6 \mu \mathrm{mol} / \mathrm{L}\right)$;

- Treatment of HUVECs with AZM475271 at high concentrations ( $>10 \mu \mathrm{mol} / \mathrm{L})$ caused a rapid decrease in cell proliferation that could be linked to the ability of AZM475271 to induce HUVEC death (measured by MTT proliferation assay); 
- Inhibition of Src kinase in HUVECs by AZM475271 showed prevention of survival signaling from VEGF - and EGF - induced cell growth in a dose-dependent manner (measured by MTT proliferation assay);

- Endothelial cell sprouting from cultured rat aortic rings was abrogated by AZM475271 at any of the concentrations tested $(1 \mu \mathrm{mol} / 1$ to $5 \mu \mathrm{mol} / \mathrm{L})$;

- AZM475271 inhibited sprouting of HUVEC in the spheroid angiogenesis model at lower concentrations than suggested by the MTT proliferation assay $(1 \mu \mathrm{mol} / \mathrm{L}$ for the spheroid assay versus $6 \mu \mathrm{mol} / \mathrm{L}$ for the MTT assay).

- The blockade of Src kinase by AZM475271 dramatically reduced the level of VEGF in L3.6pl and HUVEC supernates;

- Src inhibition in HUVECs prevented VEGF - induced cell migration in the modified Boyden chamber assay;

- Treatment of HUVECs with AZM475271 resulted in the significant inhibition of VEGFactivated pTyr 576/577 FAK phosphorylation.

Taken together, our results suggest that the Src kinase inhibitor AZM475271, in addition to its antiproliferative effects on pancreatic tumor cells, suppresses tumor growth in vivo potentially by anti-angiogenic mechanisms by inducing intratumoral endothelial cell apoptosis and finally reducing the MVD. It is an exciting prospect that Src inhibitory drugs might not only affect more traditional Src activities, such as cell growth, migration, and invasion, but could also induce endothelial cell death in regions of pancreatic tumors where neovascularisation is occurring. These findings are consistent with our in vitro studies, where AZM475271 was shown to significantly inhibit VEGF-induced endothelial cell proliferation, migration, spreading, and survival. VEGF production by L3.6pl cells was also inhibited following treatment with AZM475271, so angiogenesis inhibition found in vivo may be mediated, at least in part, by paracrine effects.

Since AZM475271 is well tolerated when given to animals, we believe that the findings of the present study may shed light on the pharmacological basis for the clinical application of Src kinase inhibitors for suppression of angiogenesis, which plays a crucial role in pancreatic tumor growth and metastasis. 


\section{Chapter 9}

\section{ZUSAMMENFASSUNG}

Die Ergebnisse der Doktorarbeit können wie folgt zusammengefasst werden:

- AZM475271 ist ein selektiver inhibitor der Scr Tyrosinkinase-Aktivität in humanen vasklären Endothelzellen undin humanen Pankreaskarzinomzellen L3.6pl mit einem $\mathrm{IC}_{50}$ $=0,1 \mu \mathrm{mol} / 1$

- Durch regelmäßiges Monitring konnte im Tierexperiment eine Abnahme des Pankreastumorwachstums nach Behandlung mit AZM475271 festgestellt werden

- Die tägliche intragastrale Verabreichung von AZM475271 wurde von allen Tieren gut vertragen

- Zum Zeitpunkt der Tötung war das Tumorvolumen nach Behnadlung mit AZM475271 signifikant niedriger $(\sim 40 \%$ niedriger $)$

- Die Behandlung mit AZM475271 führte zu einer signifikanten Reduktion der Inzidenz von Leber- und Lymphknotenmetastasen

- Die Anzahl der proliferierenden Zellen (Ki67 positiv) in den Pankreastumoren war nach Behandlung mit AZM475271 bis zu 50\% im Vergelich zu den Kontrolltieren reduziert

- Die mittlere Anzahl apoptotischer Zellen (TUNEL-Färbung) in den Pankreastumoren war signifikant höher nach Therapie mit AZM475271 als in den Kontrolltumoren

- Die mitlere Anzahl apoptotischer Endothelzellen (TUNEL/CD31-Doppelfärbung) in den Pankreastumoren war signifikant höher nach Therapie mit AZM475271 als in Kontrolltumoren

- In HUVECs zeigt sich bereits ab einer Konzentration von $2 \mu \mathrm{mol} / 1\left(\mathrm{IC}_{50}=6 \mu \mathrm{mol} / \mathrm{l}\right)$ ein signifikant anti-prolferativer Effekt im MTT-Assay

- Die Behandlung von HUVECs mit hohen Dosen von AZM475271 (>10 $\mu \mathrm{mol} / \mathrm{l})$ führt zum Zelltod

- Die Blockade der Src Kinase in HUVECs durch AZM475271 zeigte eine dosisabhängige Inhibition des VEGF- und EGF induzierten Zellwachstums 
- Das endotheliale „Sprouting“ kultivierter Rattenaortenringe konnte mit AZM475271 in Dosieurungen von 1-5 $\mu \mathrm{mol} / 1$ unterbunden werden.

- AZM475271 führte zur Hemmung des „Sproutings“ im Spheroid-Angiogenese-Assay

- Die Blockade der Src Kinase mit AZM475271 führte zur deutlichen Reduktion der VEGF-Konzentrationen in Überständen von kultivierten L3.6pl und HUVE-Zellen

- Src Inhibition in HUVECs verhindert VEGF-induzierte Zellmigration in eine modifizieren Boyden Chamber Assay

- Die Behandlung von HUVECs mit AZM475271 resultierte in einer signifikanten Inhibition der VEGF-aktivierten pTyr576/577 FAK-Phosphorylierung

Schlußfolgernd lassen diese Ergebnisse vermuten, daß die Reduktion des Pankreastumorwachstums durch den Src Kinase inhibitor AZM475271 zum einen durch den anti-proliferativen Effekt auf die Pankreastumorzellen bedingt ist, desweiteren allerdings durch einen potentiell anti-angiogenetischen Mechanismus durch Induktion der intratumoralen Apoptose von Endothelzellen und damit Reduktion der Mikrogefäßdichte im Tumor. Das Spektrum Src-inhibierender Substanzen beschränkt sich daher nicht nur auf ihre antimigratorische, anti-invasive oder anti-proliferative Wirkunsgweisen, sondern kann auch auf antiangiogenetische Effekte erweitert werden.

Die in vivo Ergebnisse im orthotopen Pankreastumor-Mausmodell sind in den in vitro Experimenten nachvollziehbar: der Src Kinase Inhibitor AZM475271 führte zur signifikanten Reduktion des VEGF-induzierten Überlebens, der Proliferation, Migration und des „Sproutings“. Die tumorzelleigene VEGF-Produktion konnte durch den Src Kinase Inhibitor AZM475271 deutlich reduziert werden, so daß anzunehmen ist, daß die Angiogenese-Inhibition auch zum Teil durch parakrine Effekte vermittelt wird.

Da AZM475271 im Tierexperiment gut verträglich war, ist vorstellbar, daß Src Kinase Inhibitoren nach Kenntnis ihrer pharmakologischen Effektivität - auch als anti-angiogenetische Substanz - eine klinische Applikation insbesondere beim metastasierten Pankreaskarzinom finden könnten. 


\section{Chapter 10}

\section{REFERENCES}

1. Abram CL, Courtneidge SA: Src family tyrosine kinases and growth factor signaling. Exp Cell Res 254(1): 1-13, 2000

2. Allgayer H, Boyd DD, Heiss MM, Abdalla EK, Curley SA, Gallick GE: Activation of Src kinase in primary colorectal carcinoma: An indicator of poor clinical prognosis. Cancer 94: 344-351, 2002

3. Alonso G, Koegl M, Mazurenko $\mathrm{N}$ and Courtneidge SA: Sequence requirements for binding of Src family tyrosine kinases to activated growth factor receptors. J Biol Chem 270: 9840-8, 1995

4. Andreev J, Galisteo ML, Kranenburg O, Logan SK, Chiu ES, Okigaki M, Cary LA, Moolenaar WH and Schlessinger J: Src and Pyk2 mediate G-protein-coupled receptor activation of epidermal growth factor receptor (EGFR) but are not required for coupling to the mitogen-activated protein (MAP) kinase signaling cascade. J Biol Chem 276: 20130-5, 2001

5. Androulakis N, Kourousis C, Dimopoulos MA et al.: Treatment of pancreatic cancer with docetaxel and granulocyte colony-stimulating factor: a multicenter phase II study. J Clin Oncol 17: 1779-1785, 1999

6. Arlt A, Gehrz A, Muerkoster S, Vorndamm J, Kruse ML, Folsch UR, Schafer H: Role of NF-kappaB and Akt/PI3K in the resistance of pancreatic carcinoma cell lines against gemcitabine-induced cell death. Oncogene 22(21): 3243-51, 2003

7. Arnold SF, Vorojeikina DP, Notides AC: Phosphorylation of tyrosine 537 on the human estrogen receptor is required for binding to an estrogen response element. J Biol Chem 270: 30205-30212, 1995

8. Avizienyte E, Wyke AW, Jones RJ, McLean GW, Westhoff MA, Brunton VG, Frame $\mathrm{MC}$ : Src-induced de-regulation of E-cadherin in colon cancer cells requires integrin signaling. Nat Cell Biol 4: 632-638, 2002

9. Baker $\mathrm{CH}, \mathrm{CH}$, Bruns CJ, Killion JJ, Ellis LM, Wood J, Fidler IJ: Inhibition of growth and metastasis of human pancreatic cancer growing in nude mice by PTK 787/ZK222584, an inhibitor of the vascular endothelial growth factor receptor tyrosine kinases. Cancer Biother Radiopharm 16(5): 359-70, 2001 
10. Baker CH, Solorzano CC, Fidler IJ: Blockage of vascular endothelial growth factor receptor and epidermal growth factor receptor signaling for therapy of metastatic human pancreatic cancer. Cancer Res 62: 1996-2003, 2002

11. Belsches-Jablonski AP, Biscardi JS, Peavy DR, Tice DA, Romney DA, Parsons SJ: Src family kinases and HER2 interactions in human breast cancer cell growth and survival. Oncogene 20: 1465-1475, 2001

12. Bergman AM, Pinedo HM, Peters GJ: Determinants of resistance to $2^{\prime}, 2^{\prime}-$ difluorodeoxycytidine (gemcitabine). Drug Resist Update 5(1): 19-33, 2002

13. Biscardi JS, Belsches AP, Parsons SJ: Characterization of human epidermal growth factor receptor and c-Src interactions in human breast tumor cells. Mol Carcinog 21: 261-272, 1998

14. Biscardi JS, Ishizawar RC, Silva CM, Parsons SJ: Tyrosine kinase signaling in breast cancer: Epidermal growth factor receptor and c-Src interactions in breast cancer. Breast Cancer Res 2: 203-210, 2000

15. Bjorge JD, Pang A, Fujita DJ: Identification of protein-tyrosine phosphatase $1 \mathrm{~B}$ as the major tyrosine phosphatase activity capable of dephosphorylatingand activating c-Src in several human breast cancer cell lines. J Biol Chem 275: 41439-41446, 2000

16. Bolen JB, Veillette A, Schwartz AM, Deseau V, Rosen N: Activation of pp60c-src protein kinase activity in human colon carcinoma. Proc. Natl. Acad. Sci. USA, 84: 22512255,1987

17. Bolen JB, Veillette A, Schwartz AM, Deseau V, Rosen N: Analysis of pp60c-src in human colon carcinoma and normal human colon mucosal cells. Oncogene Res 1: 149168,1987

18. Bondar VM, Sweeney-Gotsch B, Andreeff M, Mills GB, McConkey DJ: Inhibition of the phosphatidylinositol 3'-kinase-AKT pathway induces apoptosis in pancreatic carcinoma cells in vitro and in vivo. Mol Cancer Ther 1(12): 989-97, 2002

19. Bondzi C, Litz J, Dent P, Krystal GW: Src family kinase activity is required for Kitmediated mitogen-activated protein (MAP) kinase activation, however loss of functional retinoblastoma protein makes MAP kinase activation unnecessary for growth of small cell lung cancer cells. Cell Growth Differ 11: 305-314, 2000

20. Bougeret C, Jiang S, Keydar I, Avraham H: Functional analysis of Csk and CHK kinases in breast cancer cells. J Biol Chem 276: 33711-33720, 2001

21. Boyer B, Bourgeois Y, Poupon MF: Src kinase contributes to the metastatic spread of carcinoma cells. Oncogene 21: 2347-2356, 2002

22. Brooks PC, Stromblad S, Sanders LC, von Schalscha TL, Aimes RT, Stetler-Stevenson WG, Quigley JP, Cheresh DA: Localization of matrix metalloproteinase MMP-2 to the 
surface of invasive cells by interaction with integrin alpha v beta 3. Cell 85(5): 683-93, 1996

23. Brooks PC, Montgomery AMP, Cheresh DA: Use of the 10-day-old chick embryo model for studying angiogenesis. Methods Mol Biol 129: 257, 1999

24. Brown MT, Cooper JA: Regulation, substrates and functions of src. Biochim Biophys Acta 1287: 121-149, 1996

25. Brugge JS, Erikson RL: Identification of a transformation-specific antigen induced by an avian sarcoma virus. Nature 269: 346-348, 1977

26. Bruns CJ, Harbison MT, Kuniyasu H, Eue I, Fidler IJ: In vivo selection and characterization of metastatic variants from human pancreatic adenocarcinoma by using orthotopic implantation in nude mice. Neoplasia 1: 50-62, 1999

27. Bruns CJ, Harbison MT, Davis DW, Portera CA, Tsan R, McConkey DJ, Evans DB, Abbruzzese JL, Hicklin DJ, Radinsky R: Epidermal growth factor receptor blockade with C225 plus gemcitabine results in regression of human pancreatic carcinoma growing orthotopically in nude mice by antiangiogenic mechanisms. Clin Cancer Res; 6(5): 193648,2000

28. Bruns CJ, Koehl GE, Guba M, Yezhelyev M, Steinbauer M, Seeliger H, Schwend A, Hoehn A, Jauch KW, Geissler EK: Rapamycin-induced endothelial cell death and tumor vessel thrombosis potentiate cytotoxic therapy against pancreatic cancer. Clin Cancer Res 10(6): 2109-19, 2004

29. Bruns CJ, Shrader M, Harbison MT, Portera C, Solorzano CC, Jauch KW, Hicklin DJ, Radinsky R, Ellis LM: Effect of the vascular endothelial growth factor receptor-2 antibody DC101 plus gemcitabine on growth, metastasis and angiogenesis of human pancreatic cancer growing orthotopically in nude mice. Int J Cancer 10 102(2): 101-8, 2002

30. Bruns CJ, Solorzano CC, Harbison MT, Ozawa S, Tsan R, Fan D, Abbruzzese J, Traxler P, Buchdunger E, Radinsky R, Fidler IJ: Blockade of the epidermal growth factor receptor signaling by a novel tyrosine kinase inhibitor leads to apoptosis of endothelial cells and therapy of human pancreatic carcinoma. Cancer Res 60(11): 2926-35, 2000

31. Brunton VG, Ozanne BW, Paraskeva C, Frame MC: A role for epidermal growth factor receptor, c-Src and focal adhesion kinase in an in vitro model for the progression of colon cancer. Oncogene 14: 283-293, 1997

32. Buchsbaum DJ, Bonner JA, Grizzle WE, Stackhouse MA, Carpenter M, Hicklin DJ, Bohlen P, Raisch KP: Treatment of pancreatic cancer xenografts with Erbitux (IMCC225) anti-EGFR antibody, gemcitabine, and radiation. Int J Radiat Oncol Biol Phys 15 54(4): 1180-93, 2002

33. Budde RJ, Ke S, Levin VA: Activity of pp60c-src in 60 different cell lines derived from human tumors. Cancer Biochem Biophys 14: 171-175, 1994 
34. Burris 3rd HA, Moore MJ, Andersen $\mathrm{J}$ et al.: Improvements in survival and clinical benefit with gemcitabine as first-line therapy for patients with advanced pancreas cancer: a randomized trial. J Clin Oncol. 15: 2403-2413, 1997

35. Cam WR, Masaki T, Shiratori Y, Kato N, Ikenoue T, Okamoto M, Igarashi K, Sano T, Omata M: Reduced C-terminal Src kinase activity is correlated inversely with pp60(csrc) activity in colorectal carcinoma. Cancer 92: 61-70, 2001

36. Carmeliet P, Dor Y, Herbert J-M, Keshet E: Role of HIV-1 $\alpha$ in hypoxia-mediated apoptosis, cell proliferation and tumour angiogenesis. Nature 394: 485-90, 1998

37. Cartwright C. A., Meisler A. I., Eckhart W: Activation of the pp60c-src protein kinase is an early event in colonic carcinogenesis. Proc. Natl. Acad. Sci. USA 87: 558-562, 1990

38. Cartwright CA, Coad CA, Egbert BM: Elevated c-Src tyrosine kinase activity in premalignant epithelia of ulcerative colitis. J Clin Invest 93: 509-515, 1994

39. Cartwright CA, Eckhart W, Simon S, Kaplan PL: Cell transformation by pp60c-src mutated in the carboxy-terminal regulatory domain. Cell 49: 83-91, 1987

40. Cartwright CA, Kamps MP, Meisler AI, Pipas JM, Eckhart W: pp60c-src activation in human colon carcinoma. J Clin Invest 83: 2025-2033, 1989

41. Cartwright TH, Cohn A, Varkey JA et al.: Phase II study of oral capecitabine in patients with advanced or metastatic pancreatic cancer. J Clin Oncol 20: 160-164, 2002

42. Cascinu S, Graziano F, Catalano G: Chemotherapy for advanced pancreatic cancer: it may no longer be ignored. Ann Oncol 10: 105-109. 1999

43. Chang F, Lee JT, Navolanic PM, Steelman LS, Shelton JG, Blalock WL, Franklin RA, McCubrey JA: Involvement of PI3K/Akt pathway in cell cycle progression, apoptosis, and neoplastic transformation: a target for cancer chemotherapy. Leukemia 17(3): 590603,2003

44. Choi SH, Yamanashi Y, Shiota M, Takanashi M, Hojo I, Itoh T, Watanabe T, Yamamoto T, Mori S: Expression of Lyn protein on human malignant lymphomas. Lab Invest 69: 736-742, 1993

45. Courtneidge SA, Dhand R, Pilat D, Twamley GM, Waterfield MD, Roussel MF: Activation of Src family kinases by colony stimulating factor-1, and their association with its receptor. Embo J 12: 943-950, 1993

46. Cowgill SM, Muscarella P: The genetics of pancreatic cancer. Am J Surg 186(3): 279-86, 2003

47. Crossthwaite AJ, Valli H, Williams RJ: Inhibiting Src family tyrosine kinase activity blocks glutamate signalling to ERK1/2 and Akt/PKB but not JNK in cultured striatal neurones. J Neurochem 88(5): 1127-39, 2004

48. Crown J, Casper ES, Botet $\mathrm{J}$ et al.: Lack of efficacy of high-dose leucovorin and fluorouracil in patients with advanced pancreatic adenocarcinoma. J Clin Oncol 9: 16821686,1991 
49. Daigo Y, Furukawa Y, Kawasoe T, Ishiguro H, Fujita M, Sugai S, Nakamori S, Liefers GJ, Tollenaar RA, van de Velde CJ, Nakamura Y: Absence of genetic alteration at codon 531 of the human c-src gene in 479 advanced colorectal cancers from Japanese and Caucasian patients. Cancer Res 59: 4222-4224, 1999

50. DeCaprio JA, Mayer RJ, Gonin R et al.: Fluorouracil and high-dose leucovorin in previously untreated patients with advanced adenocarcinoma of the pancreas: results of a phase II trial. J Clin Oncol 9: 2128-2133, 1991

51. DeSeau V, Rosen N, Bolen JB: Analysis of pp60c-src tyrosine kinase activity and phosphotyrosyl phosphatase activity in human colon carcinoma and normal human colon mucosal cells. J Cell Biochem 35: 113-128, 1987

52. Donato NJ, Wu JY, Stapley J, Gallick G, Lin H, Arlinghaus R, Talpaz M: BCR-ABL independence and LYN kinase overexpression in chronic myelogenous leukemia cells selected for resistance to STI571. Blood 101: 690-698, 2003

53. Durkin AJ, Bloomston PM, Rosemurgy AS, Giarelli N, Cojita D, Yeatman TJ, Zervos EE: Defining the role of the epidermal growth factor receptor in pancreatic cancer grown in vitro. Am J Surg 186(5): 431-6, 2003

54. Ebert M, et al.: Induction of platelet-derived growth factor A and B chains and overexpression of their receptors in human pancreatic cancer. Int J Cancer 62(5): 529-35, 1995

55. Egan C, Pang A, Durda D, Cheng HC, Wang JH, Fujita DJ: Activation of Src in human breast tumor cell lines: Elevated levels of phosphotyrosine phosphatase activity that preferentially recognizes the Src carboxy terminal negative regulatory tyrosine 530 . Oncogene 18: 1227-1237, 1999

56. Eliceiri BP, Cheresh DA: The role of av integrins during angiogenesis. Biomed Prog 12: 61,1999

57. Eliceiri BP, Paul R, Schwartzberg PL, Hood JD, Leng J, Cheresh DA: Selective requirement for Src kinases during VEGF-induced angiogenesis and vascular permeability. Mol Cell 4: 915, 1999

58. Ellis LM, Staley CA, Liu W, FlemingRY, Parikh NU, Bucana CD, Gallick GE: Downregulation of vascular endothelial growth factor in a human colon carcinoma cell line transfected with an antisense expression vector specific for c-src. J Biol Chem 273: 1052-1057, 1998

59. Erpel T, G Alonso, S Roche, SA Courtneidge: The Src SH3 domain is required for DNA synthesis induced by platelet-derived growth factor and epidermal growth factor. J Biol Chem 271: 16807-16812, 1996

60. Etienne MC, Cheradame S, Fischel JL, Formento P, Dassonville O, Renee N, Schneider M, Thyss A, Demard F, Milano G: Response to fluorouracil therapy in cancer patients: the role of tumoral dihydropyrimidine dehydrogenase activity. J Clin Oncol 13(7): 166370,1995 
61. Fahy BN, Schlieman M, Virudachalam S, Bold RJ. AKT inhibition is associated with chemosensitisation in the pancreatic cancer cell line MIA-PaCa-2. Br J Cancer 89(2): 391-7, 2003

62. FanningP, Bulovas K, Saini KS, Libertino JA, Joyce AD, Summerhayes IC: Elevated expression of pp60c-src in low grade human bladder carcinoma. Cancer Res 52: $1457-$ 1462,1992

63. Fidler IJ, Ellis LM: The implications of angiogenesis for the biology and therapy of cancer metastasis. Cell 79: 185-8, 1994

64. FlemingRY, Ellis LM, Parikh NU, Liu W, Staley CA, Gallick GE: Regulation of vascular endothelial growth factor expression in human colon carcinoma cells by activity of src kinase. Surgery 122: 501-507, 1997

65. Flossmann-Kast BB, Jehle PM, Hoeflich A, Adler G, Lutz MP: Src stimulates insulinlike growth factor I (IGF-I)-dependent cell proliferation by increasingIGF-I receptor number in human pancreatic carcinoma cells. Cancer Res 58: 3551-3554, 1998

66. Folkman J: Angiogenesis in cancer, vascular, rheumatoid and other diseases. Nat Med 1: 27-31, 1995

67. Folkman J: Tumor angiogenesis, in the molecular basis of cancer. Philadelphia WB Saunders: 206-32, 1995

68. Frame MC: Newest findings on the oldest oncogene; how activated src does it. J Cell Sci 117 (Pt 7): 989-98, 2004

69. Frame MC: Src in cancer: Deregulation and consequences for cell behavior. Biochim Biophys Acta 1602: 114-130, 2002

70. Fujioka S, Sclabas GM, Schmidt C, Niu J, Frederick WA, Dong QG, Abbruzzese JL, Evans DB, Baker C, Chiao PJ: Inhibition of constitutive NF-kappa B activity by I kappa $\mathrm{B}$ alpha M suppresses tumorigenesis. Oncogene 22(9): 1365-70, 2003

71. Fujioka S, Yoshida K, Yanagisawa S, et al.: Angiogenesis in pancreatic carcinoma: thymidine phosphorylase expression in stromal cells and intratumoral microvessel density as independent predictors of overall and relapse-free survival. Cancer 92: 178897, 2002

72. Fukumura D et al.: Tumor induction of VEGF promoter activity in stromal cells. Cell 94: $715-25,1998$

73. Garcia R, Bowman TL, Niu G, Yu H, Minton S, Muro-Cacho CA, Cox CE, Falcone R, Fairclough R, Parsons S, Laudano A, Gazit A, Levitzki A, Kraker A, Jove R: Constitutive activation of Stat3 by the Src and JAK tyrosine kinases participates in growth regulation of human breast carcinoma cells. Oncogene 20: 2499-2513, 2001

74. Garcia R, Parikh NU, Saya H, Gallick GE: Effect of herbimycin A on growth and pp60csrc activity in human colon tumor cell lines. Oncogene 6: 1983-1989, 1991 
75. Gebbia N, Gebbia V: Single agent paclitaxel in the treatment of unresectable and/or metastatic pancreatic adenocarcinoma. Eur J Cancer 32A: 1822-1823, 1996

76. Giancotti FG, et al.: Integrin signaling. Science 285: 1028-1032, 1999

77. Griffin RJ, Williams BW, Wild R, Cherrington JM, Park H, Song CW: Simultaneous inhibition of the receptor kinase activity of vascular endothelial, fibroblast, and plateletderived growth factors suppresses tumor growth and enhances tumor radiation response. Cancer Res 62(6): 1702-6, 2002

78. Gutwein P, Oleszewski M, Mechtersheimer S, Agmon-Levin N, Krauss K, Altevogt P: Role of Src kinases in the ADAM-mediated release of L1 adhesion molecule from human tumor cells. J Biol Chem 275: 15490-15497, 2000

79. Guy CT, Muthuswamy SK, Cardiff RD, Soriano P, Muller WJ: Activation of the c-Src tyrosine kinase is required for the induction of mammary tumors in transgenic mice. Genes Dev 8: 23-32, 1994

80. Hall A: Rho GTPases and the actin cytoskeleton. Science 279: 509-514, 1998

81. Hallek M, Neumann C, Schaffer M, Danhauser-Riedl S, von Bubnoff N, de Vos G, Druker BJ, Yasukawa K, Griffin JD, Emmerich B: Signal transduction of inter-leukin-6 involves tyrosine phosphorylation of multiple cytosolic proteins and activation of Srcfamily kinases Fyn, Hck, and Lyn in multiple myeloma cell lines. Exp Hematol 25: 1367-1377, 1997

82. Han NM, Curley SA, Gallick GE: Differential activation of pp60(c-src) and pp62(c-yes) in human colorectal carcinoma liver metastases. Clin Cancer Res 2: 1397-1404, 1996

83. Harder KW, NP Moller, JW Peacock, FR Jirik: Protein-tyrosine phosphatase alpha regulates Src family kinases and alters cell-substratum adhesion. J Biol Chem 273: 31890-31900, 1998

84. Hecker TP, Grammer JR, Gillespie GY, Stewart J Jr., Gladson CL: Focal adhesion kinase enhances signaling through the Shc/extracellular signal-regulated kinase pathway in anaplastic astrocytoma tumor biopsy samples. Cancer Res 62: 2699-2707, 2002

85. Hofmann M, Zaper J, Bernd A, Bereiter-Hahn J, Kaufmann R, Kippenberger S: Mechanical pressure-induced phosphorylation of $\mathrm{p} 38$ mitogen-activated protein kinase in epithelial cells via Src and protein kinase C. Biochem Biophys Res Commun 316(3): $673-9,2004$

86. HungW, Elliott B: Co-operative effect of c-Src tyrosine kinase and Stat3 in activation of hepatocyte growth factor expression in mammary carcinoma cells. J Biol Chem 276: 12395-12403, 2001

87. Hunter T, Sefton BM: Transforminggene product of Rous sarcoma virus phosphorylates tyrosine. Proc Natl Acad Sci USA 77: 1311-1315, 1980 
88. Inaba M, Mitsuhashi J, Sawada H, Miike N, Naoe Y, Daimon A, Koizumi K, Tsujimoto H, Fukushima M. Reduced activity of anabolizing enzymes in 5-fluorouracil-resistant human stomach cancer cells. Jpn J Cancer Res 87(2): 212-20, 1996

89. Iravani S, Mao W, Fu L, Karl R, Yeatman T, Jove R, Coppola D: Elevated c-Src protein expression is an early event in colonic neoplasia. Lab Invest 78: 365-371, 1998

90. Irby R, Mao W, Coppola D, Jove R, Gamero A, Cuthbertson D, Fujita DJ, Yeatman TJ: Overexpression of normal c-Src in poorly metastatic human colon cancer cells enhances primary tumor growth but not metastatic potential. Cell Growth Differ 8: 1287-1295, 1997

91. Irby RB, Mao W, Coppola D, KangJ, Loubeau JM, Trudeau W, Karl R, Fujita DJ, Jove R, Yeatman TJ: ActivatingSRC mutation in a subset of advanced human colon cancers. Nat Genet 21: 187-190, 1999

92. Irby RB, Yeatman TJ: Increased Src activity disrupts cadherin/catenin-mediated homotypic adhesion in human colon cancer and transformed rodent cells. Cancer Res 62: 2669-2674, 2002

93. Irby RB, Yeatman TJ: Role of Src expression and activation in human cancer. Oncogene 19: $5636-5642,2000$

94. Itakura J, et al.: Concomitant over-expression of vascular endothelial growth factor and its receptors in pancreatic cancer. Int J Cancer; 85(1):27-34, 2000

95. Jacobs C, Rubsamen H: Expression of pp60c-src protein kinase in adult and fetal human tissue: High activities in some sarcomas and mammary carcinomas. Cancer Res 43: 1696-1702, 1983

96. Jankowski J, Coghill G, Hopwood D, Wormsley KG: Oncogenes and onco-suppressor gene in adenocarcinoma of the oesophagus. Gut 33: 1033-1038, 1992

97. Jiang BH, Semenza GL: V-Src induces expression of hypoxia-inducible factor 1 (HIF-1) and transcription of genes encoding vascular endothelial growth factor and anolase 1: involvement of HIV-1 in tumor progression. Cancer Res 1997;57:5328-35

98. Kaplan KB, Swedlow JR, Morgan DO, Varmus HE: c-Src enhances the spreading of src/ fibroblasts on fibronectin by a kinase-independent mechanism. Genes Dev 9: 15051517,1995

99. Karni R, Jove R, Levitzki A. Inhibition of pp60c-Src reduces Bcl-XL expression and reverses the transformed phenotype of cells overexpressing EGF and HER-2 receptors. Oncogene; 18(33):4654-62, 1999

100. Kawai N, Tsuji S, Tsujii M, Ito T, Yasumaru M, Kakiuchi Y, Kimura A, Komori M, Sasaki Y, Hayashi N, Kawano S, Dubois R, Hori M: Tumor necrosis factor alpha stimulates invasion of Src-activated intestinal cells. Gastroenterology 122: 331-339, 2002

101. Kerbel RS: A cancer therapy resistant to resistance. Nature 390: 335-6, 1997 
102. Kerbel RS: Tumor angiogenesis: past, present, and the near future. Carcinogenesis 21: $505-15,2000$

103. Kern SE: Molecular genetic alterations in ductal pancreatic adenocarcinomas. Med Clin North Am 84(3): 691-5, 2000.

104. Kobrin MS, et al.: Induction and expression of heparin-binding EGF-like growth factor in human pancreatic cancer. Biochem Biophys Res Commun 202(3):1705-9, 1994

105. Kollmannsberger C, Peters HD, Fink U: Chemotherapy in advanced pancreatic adenocarcinoma. Cancer Treat Rev 24: 133-156, 1998

106. Konstadoulakis MM, Antonakis PT, Tsibloulis BG et al.: A phase II study of 9nitrocamptothecin in patients with advanced pancreatic adenocarcinoma. Cancer Chemother Pharmacol 48: 417-420, 2001

107. Korc M: Role of growth factors in pancreatic cancer. Surg Oncol Clin N Am 7(1): 25-41, 1998

108. Kornmann M, et al.: Fibroblast growth factor-5 stimulates mitogenic signaling and is overexpressed in human pancreatic cancer: evidence for autocrine and paracrine actions. Oncogene 15(12): 1417-24, 1997

109. Kornmann MH, Beger G, Korc M: Role of fibroblast growth factors and their receptors in pancreatic cancer and chronic pancreatitis. Pancreas 17(2): 169-75, 1998

110. Koster A, Landgraf S, Leipold A, Sachse R, Gebhart E, Tulusan AH, Ronay G, Schmidt $\mathrm{C}$, Dingermann $\mathrm{T}$ : Expression of oncogenes in human breast cancer specimens. Anticancer Res 11: 193-201, 1991

111. Kuehn R, Lelkes PI, Bloechle C, Niendorf A, Izbicki JR: Angiogenesis, angiogenic growth factors, and cell adhesion molecules are upregulated in chronic pancreatic diseases: angiogenesis in chronic pancreatitis, and in pancreatic cancer. Pancreas 18: 96103, 1999

112. Kumble S, Omary MB, Cartwright CA, Triadafilopoulos G: Src activation in malignant and premalignant epithelia of Barrett's esophagus. Gastroenterology 112: 348-356, 1997

113. Kypta RM, GoldbergY, UlugET, Courtneidge SA: Association between the PDGF receptor and members of the src family of tyrosine kinases. Cell 62: 481-492, 1990

114. Laskin JJ, Sandler AB: Epidermal growth factor receptor: a promising target in solid tumours. Cancer Treat Rev 30(1): 1-17, 2004

115. Lee HJ, Kim E, Jee B, Hahn JH, Han K, JungKC, Park SH, Lee H: Functional involvement of src and focal adhesion kinase in a CD99 splice variant-induced motility of human breast cancer cells. Exp Mol Med 34: 177-183, 2002 
116. Lehrer S, O’Shaughnessy J, Song HK, Levine E, Savoretti P, Dalton J, Lipsztein R, Kalnicki S, Bloomer WD: Activity of pp60c-src protein kinase in human breast cancer. Mt Sinai J Med 56: 83-85, 1989

117. Li D, Xie K, Wolff R, Abbruzzese JL: Pancreatic cancer. Lancet 363(9414): 1049-57, 2004

118. Li Y, Ren J, Yu W, Li Q, Kuwahara H, Yin L, Carraway KL 3rd, Kufe D: The epidermal growth factor receptor regulates interaction of the human DF3/MUC1 carcinoma antigen with c-Src and beta-catenin. J Biol Chem 276: 35239-35242, 2001

119. Loganzo F Jr., Dosik JS, Zhao Y, Vidal MJ, Nanus DM, Sudol M, Albino AP: Elevated expression of protein tyrosine kinase c-Yes, but not c-Src, in human malignant melanoma. Oncogene 8: 2637-2644, 1993

120. Logsdon CD, Simeone DM, Binkley C, Arumugam T, Greenson JK, Giordano TJ, Misek DE, Kuick R, Hanash S: Molecular profiling of pancreatic adenocarcinoma and chronic pancreatitis identifies multiple genes differentially regulated in pancreatic cancer. Cancer Res 15 63(12): 3445, 2003

121. Lu Y, Yu Q, Liu JH, Zhang J, Wang H, Koul D, McMurray JS, Fang X, Yung WK, Siminovitch KA, Mills GB: Src family protein-tyrosine kinases alter the function of PTEN to regulate phosphatidylinositol 3-kinase/AKT cascades. J Biol Chem 278(41): 40057-66, 2003

122. Luo J, et al.: Pancreatic cancer cell-derived vascular endothelial growth factor is biologically active in vitro and enhances tumorigenicity in vivo. Int J Cancer 92(3): 361369,2001

123. Luttrell DK, Lee A, LansingTJ, Crosby RM, JungKD, Willard D, Luther M, Rodriguez M, Berman J, Gilmer TM: Involvement of pp60c-src with two major signaling pathways in human breast cancer. Proc Natl Acad Sci USA 91: 83-87, 1994

124. Luttrell LM, BE Hawes, T van Biesen, DK Luttrell, TJ Lansing, RJ Lefkowitz: Role of cSrc tyrosine kinase in G protein-coupled receptor- and Gbetagamma subunit-mediated activation of mitogen-activated protein kinases. J Biol Chem 271: 19443-19450, 1996

125. Lutz MP, Esser IB, Flossmann-Kast BB, Vogelmann R, Luhrs H, Friess H, Buchler MW, Adler G: Overexpression and activation of the tyrosine kinase Src in human pancreatic carcinoma. Biochem Biophys Res Commun 243: 503-508, 1998

126. Maa MC, Leu TH, McCarley DJ, Schatzman RC, Parsons SJ: Potentiation of epidermal growth factor receptor-mediated oncogenesis by c-Src: Implications for the etiology of multiple human cancers. Proc Natl Acad Sci USA 92: 6981-6985, 1995

127. MacMillan-Crow LA, Greendorfer JS, Vickers SM, Thompson JA: Tyrosine nitration of c-SRC tyrosine kinase in human pancreatic ductal adenocarcinoma. Arch Biochem Biophys 377: 350-356, 2000 
128. Malek RL, Irby RB, Guo QM, Lee K, WongS, He M, Tsai J, Frank B, Liu ET, Quackenbush J, Jove R, Yeatman TJ, Lee NH: Identification of Src transformation fingerprint in human colon cancer. Oncogene 21: 7256-7265, 2002

129. Manash K. Paul, Anup K. Mukhopadhyay: Tyrosine kinase - Role and significance in Cancer. Int J Med Sci 1(2): 101-15, 2004

130. Mao W, Irby R, Coppola D, Fu L, Wloch M, Turner J, Yu H, Garcia R, Jove R, Yeatman TJ: Activation of c-Src by receptor tyrosine kinases in human colon cancer cells with high metastatic potential. Oncogene 15: 3083-3090, 1997

131. Martin GS: The hunting of the Src. Nat Rev Mol Cell Biol 2: 467-475, 2001

132. Maulik G, Shrikhande A, Kijima T, Ma PC, Morrison PT, Salgia R: Role of the hepatocyte growth factor receptor, c-Met, in oncogenesis and potential for therapeutic inhibition. Cytokine Growth Factor Rev 13: 41-59, 2002

133. Mazurenko NN, Kogan EA, Zborovskaya IB, Kisseljov FL: Expression of pp60c-src in human small cell and non-small cell lungcarcinomas. Eur J Cancer 28: 372-377, 1992

134. McMullen M, Keller R, Sussman M, Pumiglia K: Vascular endothelial growth factormediated activation of p38 is dependent upon Src and RAFTK/Pyk2. Oncogene 2 23(6): 1275-82, 2004

135. Mellstrom K, Bjelfman C, Hammerling U, Pahlman S: Expression of c-src in cultured human neuroblastoma and small-cell lungcarcinoma cell lines correlates with neurocrine differentiation. Mol Cell Biol 7: 4178-4184, 1987

136. Metcalf CA III, van Schravendijk MR, Dalgarno DC, Sawyer TK: Targeting protein kinases for bone disease: Discovery and development of SRC inhibitors. Curr Pharm Des 8: 2049-2075, 2002

137. Migliaccio A, Di Domenico M, Castoria G, de Falco A, Bontempo P, Nola E, Auricchio F: Tyrosine kinase/ p21ras/MAP-kinase pathway activation by estradiol-receptor complex in MCF-7 cells. Embo J 15: 1292-1300, 1996

138. Migliaccio A, Piccolo D, Castoria G, Di Domenico M, Bilancio A, Lombardi M, GongW, Beato M, Auricchio F: Activation of the Src/p21ras/Erk pathway by progesterone receptor via cross-talk with estrogen receptor. Embo J 17: 2008-2018, 1998

139. Miyazaki T, Liu ZJ, Taniguchi T: Selective cooperation of HTLV-1-encoded p40tax-1 with cellular oncoproteins in the induction of hematopoietic cell proliferation. Onco-gene 12: 2403-2408, 1996

140. Moasser MM, Srethapakdi M, Sachar KS, Kraker AJ, Rosen N: Inhibition of Src kinases by a selective tyrosine kinase inhibitor causes mitotic arrest. Cancer Res 59: 6145-6152, 1999

141. Moore PS, Sipos B, Orlandini S, Sorio C, Real FX, Lemoine NR, Gress T, Bassi C, Kloppel G, Kalthoff H, Ungefroren H, Lohr M, Scarpa A: Genetic profile of 22 
pancreatic carcinoma cell lines. Analysis of K-ras, p53, p16, and DPC4/Smad4. Virchows Arch 439(6): 798-802, 2001

142. Morgan RT, Woods LK, Moore GE, Quinn LA, McGavran L, Gordon SG: Human cell line (COLO375) of metastatic pancreatic adenocarcinoma. Int J Cancer 25: 591-598, 1980

143. Mori S, Ronnstrand L, Yokote K, Engstrom A, Courtneidge SA, Claesson-Welsh L, Heldin $\mathrm{CH}$ : Identification of two juxtamembrane autophosphorylation sites in the PDGF beta-receptor; involvement in the interaction with Src family tyrosine kinases. Embo J 12: $2257-2264,1993$

144. Mukhopadhyay D, Tsiokas L, Zhou XM, Foster D, Brugge JS, Sukhatme VP: Hypoxic induction of human vascular endothelial growth factor expression through c-Src activation. Nature 375: 577-581, 1995

145. Muthuswamy SK, Siegel PM, Dankort DL, Webster MA, Muller WJ: Mammary tumors expressing the neu proto-oncogene possess elevated c-src tyrosine kinase activity. Mol Cell Biol 14: 735-743, 1994

146. Muthuswamy SK, Muller WJ: Activation of Src family kinases in Neu-induced mammary tumors correlates with their association with distinct sets of tyrosine phosphory-lated proteins in vivo. Oncogene 11: 1801-1810, 1995

147. Muthuswamy SK, Muller WJ: Activation of the Src family of tyrosine kinases in mammary tumorigenesis. Adv Cancer Res 64: 111-123, 1994

148. Muthuswamy SK, Muller WJ: Direct and specific interaction of c-Src with Neu is involved in signaling by the epidermal growth factor receptor. Oncogene 11: 271-279, 1995

149. Nagao MY, Kaziro: The Src family tyrosine kinase is involved in Rho-dependent activation of c-Jun N-terminal kinase by Galpha12. Oncogene 18: 4425-4434, 1999

150. Nakagawa T, Tanaka S, Suzuki H, Takayanagi H, Miyazaki T, Nakamura K, Tsuruo T: Overexpression of the csk gene suppresses tumor metastasis in vivo. Int $\mathrm{J}$ Cancer 88: 384-391, 2000

151. Nam JS, Ino Y, Sakamoto M, Hirohashi S: Src family kinase inhibitor PP2 restores the ECadherin/Catenin cell adhesion system in human cancer cells and reduces cancer metastasis. Clin Cancer Res 8: 2430-2436, 2002

152. Neufeld G, et al.: Vascular endothelial growth factor (VEGF) and its receptors. Faseb J 13(1): 9-22, 1999

153. Ng SS, Tsao MS, Nicklee T, Hedley DW: Wortmannin inhibits pkb/akt phosphorylation and promotes gemcitabine antitumor activity in orthotopic human pancreatic cancer xenografts in immunodeficient mice. Clin Cancer Res 7(10): 3269-75, 2001 
154. Ng SSW, Tsao MS, Chow S, Hedley DW: Inhibition of phosphatidylinositide 3-kinase enhances gemcitabine-induced apoptosis in human pancreatic cancer cells. Cancer Res.; 60(19):5451-5, 2000

155. Nicosia RF and Ottineri AA: Growth of microvessels in serum-free matrix culture of rat aorta: a quantitative assay of angiogenesis in vitro. Lab Invest 63: 115-22, 1990

156. Nilbert M, Fernebro E: Lack of activatingc-SRC mutations at codon 531 in rectal cancer. Cancer Genet Cytogenet 121: 94-95, 2000

157. O'Shaughnessy J, Deseau V, Amini S, Rosen N, Bolen JB: Analysis of the c-src gene product structure, abundance, and protein kinase activity in human neuroblastoma and glioblastoma cells. Oncogene Res 2: 1-18, 1987

158. Okada F, Kerbel RS: Impact of oncogenes in tumor angiogenesis: mutant K-ras upregulation of VEGF/vascular permeability factor is neccesary, but not sufficient for tumorigenicity of human colorectal carcinoma cells. Proc Natl Acad Sci USA 95: 360914,1998

159. Okada S, Sakata Y, Matsuno S et al. Phase II study of docetaxel in patients with metastatic pancreatic cancer: a Japanese cooperative study. Cooperative Group of Docetaxel for Pancreatic Cancer in Japan. Br J Cancer 80: 438-443, 1999.

160. Olayioye MA, Badache A, Daly JM, Hynes NE: An essential role for Src kinase in ErbB receptor signaling through the MAPK pathway. Exp Cell Res 267: 81-87, 2001

161. Ottenhoff-Kalff AE, Rijksen G, van Beurden EA, Hennipman A, Michels AA, Staal GE: Characterization of protein tyrosine kinases from human breast cancer: Involvement of the c-src oncogene product. Cancer Res 52: 4773-4778, 1992

162. Oude Weernink PA, Ottenhoff-Kalff AE, VendrigMP, van Beurden EA, Staal GE, Rijksen G: Functional interaction between the epidermal growth factor receptor and c-Src kinase activity. FEBS Lett 352: 296-300, 1994

163. Owens DW, McLean GW, Wyke AW, Paraskeva C, Parkinson EK, Frame MC, Brunton VG: The catalytic activity of the Src family kinases is required to disrupt cadherindependent cell-cell contacts. Mol Biol Cell 11: 51-64, 2000

164. P van der Geer, T Hunter and RA Lindberg: Receptor protein-tyrosine kinases and their signal transduction pathways. Annu Rev Cell Biol 10: 251-337, 1994

165. Pahlman S, HammerlingU: Src expression in small-cell lungcarcinoma and other neuroendocrine malignancies. Am Rev Respir Dis 142: S54-56, 1990

166. Pal S, Datta K, Mukhopadhyay D: Central role of $\mathrm{p} 53$ on regulation of vascular permeability factor/vascular endothelial growth factor (VPF/VEGF) expression in mammary carcinoma. Cancer Res 61: 6952-6957, 2001

167. Park J, Cartwright CA: Src activity increases and Yes activity decreases duringmitosis of human colon carcinoma cells. Mol Cell Biol 15: 2374-2382, 1995 
168. Peng ZY, Cartwright CA: Regulation of the Src tyrosine kinase and Syp tyrosine phosphatase by their cellular association. Oncogene 11: 1955-1962, 1995

169. Pengetnze Y, Steed M, Roby KF, Terranova PF, Taylor CC: Src tyrosine kinase promotes survival and resistance to chemotherapeutics in a mouse ovarian cancer cell line. Biochem Biophys Res Commun 09(2): 377-83, 2003

170. Penninger JM, Wallace VA, Kishihara K, Mak TW: The role of p561ck and p59fyn tyrosine kinases and CD45 protein tyrosine phosphatase in T-cell development and clonal selection. Immunol Rev 135: 183-214, 1993

171. Pepper MS: Manipulating angiogenesis. From basic science to the bedside. Arterioscler Thromb Vasc Biol 17: 605-19, 1997

172. Perlmutter RM: Control of T cell development by non-receptor protein tyrosine kinases. Cancer Surv 22: 85-95, 1995

173. Piwnica-Worms H, Saunders KB, Roberts TM, Smith AE, ChengSH: Tyrosine phosphorylation regulates the biochemical and biological properties of pp60c-src. Cell 49: 75-82, 1987

174. Pories SE, Hess DT, Swenson K, Lotz M, Moussa R, Steele G, Jr., Shibata D, RiegerChrist KM, Summerhayes C: Overexpression of pp60c-src elicits invasive behavior in rat colon epithelial cells. Gastroenterology 114: 1287-1295, 1998

175. Ptasznik A, Urbanowska E, Chinta S, Costa MA, Katz BA, Stanislaus MA, Demir G, Linnekin D, Pan ZK, Gewirtz AM: Crosstalk between BCR/ABL oncoprotein and CXCR4 signaling through a Src family kinase in human leukemia cells. J Exp Med 196: $667-678,2002$

176. Rahimi N, HungW, Tremblay E, Saulnier R, Elliott B: c-Src kinase activity is required for hepatocyte growth factor-induced motility and anchorage-independent growth of mammary carcinoma cells. J Biol Chem 273: 33714-33721, 1998

177. Rajala RV, Dehm S, Bi X, Bonham K, Sharma RK: Expression of N-myristoyltransferase inhibitor protein and its relationship to c-Src levels in human colon cancer cell lines. Biochem Biophys Res Commun 273: 1116-1120, 2000

178. Reissig D, Clement J, Sanger J, Berndt A, Kosmehl H, Bohmer FD: Elevated activity and expression of Src-family kinases in human breast carcinoma tissue versus matched nontumor tissue. J Cancer Res Clin Oncol 127: 226-230, 2001

179. Relf $\mathrm{M}$ at al.: Expression of the angiogenic factors in human primary breast cancer and its relation to angiogenesis. Cancer Res 57: 963-9, 1997

180. Roche S, M Koegl, MV Barone, MF Roussel, SA Courtneidge: DNA synthesis induced by some but not all growth factors requires Src family protein tyrosine kinases. Mol Cell Biol 15: 1102-1109, 1995 
181. Rodier JM, Valles AM, Denoyelle M, Thiery JP, Boyer B: pp60c-src is a positive regulator of growth factor-induced cell scatteringin a rat bladder carcinoma cell line. $\mathrm{J}$ Cell Biol 131: 761-773, 1995

182. Roginskaya V, Zuo S, Caudell E, Nambudiri G, Kraker AJ, Corey SJ: Therapeutic targeting of Src-kinase Lyn in myeloid leukemic cell growth. Leukemia 13: 855-861, 1999

183. Rosen N, Bolen JB, Schwartz AM, Cohen P, DeSeau V, Israel MA: Analysis of pp60csrc protein kinase activity in human tumor cell lines and tissues. J Biol Chem 261: $13754-13759,1986$

184. Rosen L: Antiangiogenic strategies and agents in clinical trials. Oncologist 5(1): 20-27, 2000

185. Rosenberg L: Treatment of pancreatic cancer. Promises and problems of tamoxifen, somatostatin analogs, and gemcitabine. Int J Pancreatol 22: 81-93, 1997

186. Rothenberg ML, Moore MJ, Cripps MC et al.: A phase II trial of gemcitabine in patients with 5-FU-refractory pancreas cancer. Ann Oncol 7: 347-353, 1996

187. Rougier P, Adenis A, Ducreux $\mathrm{M}$ et al.: A phase II study: docetaxel as first-line chemotherapy for advanced pancreatic adenocarcinoma. Eur J Cancer 36: 1016-1025, 2000

188. Rous P: A sarcoma of the fowl transmissible by an agent separable from the tumor cells. J Exp Med 13: 397-411, 1911

189. Russello SV, Shore SK: SRC in human carcinogenesis. Front Biosci 1 (9): 139-44, 2004

190. Sakai T, Kawakatsu H, Fujita M, Yano J, Owada MK: An epitope localized in c-Src negative regulatory domain is a potential marker in early stage of colonic neoplasms. Lab Invest 78: 219-225, 1998

191. Sato K, Nagao T, Iwasaki T, Nishihira Y, Fukami Y: Src-dependent phosphorylation of the EGF receptor Tyr-845 mediates Stat-p21waf1 pathway in A431 cells. Genes Cells 8(12): 995-1003, 2003

192. Sato K, N Gotoh, T Otsuki, M Kakumoto, M Aoto, AA Tokmakov, M Shibuya, Y Fukami: Tyrosine residues 239 and 240 of Shc are phosphatidylinositol 4,5bisphosphate-dependent phosphorylation sites by c-Src. Biochem Biophys Res Commun 240: 399-404, 1997

193. Sato M, Tanaka T, Maeno T, Sando Y, Suga T, Maeno Y, Sato H, Nagai R, Kurabayashi M: Inducible expression of endothelial PAS domain protein-1 by hypoxia in human lungadenocarcinoma A549 cells. Role of Src family kinases-dependent pathway. Am J Respir Cell Mol Biol 26: 127-134, 2002

194. Scapoli L, Ramos-Nino ME, Martinelli M, Mossman BT: Src-dependent ERK5 and Src/EGFR-dependent ERK1/2 activation is required for cell proliferation by asbestos. Oncogene 23(3): 805-13, 2004 
195. Schaller MD, JD Hildebrand, JD Shannon, JW Fox, RR Vines, JT Parsons: Autophosphorylation of the focal adhesion kinase, pp125FAK, directs SH2-dependent binding of pp60src. Mol Cell Biol 14: 1680-1688, 1994

196. Schlaepfer DD and T Hunter: Integrin signaling and tyrosine phosphorylation: Just the FAKs. Trends Cell Biol 8: 151-157, 1998

197. Schniewind B, Christgen M, Kurdow R, Haye S, Kremer B, Kalthoff H, Ungefroren H: Resistance of pancreatic cancer to gemcitabine treatment is dependent on mitochondriamediated apoptosis. Int J Cancer 109(2): 182-8, 2004

198. Sefton BM, Taddie JA: Role of tyrosine kinases in lymphocyte activation. Curr Opin Immunol 6: 372-379, 1994

199. Sefton BM: The lck tyrosine protein kinase. Oncogene 6: 683-686, 1991

200. Sheffield LG: C-Src activation by ErbB2 leads to attachment-independent growth of human breast epithe-lial cells. Biochem Biophys Res Commun 250: 27-31, 1998

201. Shibuya M: Structure and function of VEGF/VEGF-receptor system involved in angiogenesis. Cell Struct Funct 26(1): 25-35, 2001

202. Siddiqi I, et al.: Increased expression of keratinocyte growth factor in human pancreatic cancer. Biochem Biophys Res Commun 215(1): 309-15, 1995.

203. Silletti S, Cheresh DA: A link between integrins and MMP's in angiogenesis. Fibrinolysis Proteolysis 13: 226, 1999

204. Simeonova PP, Wang S, Hulderman T and Luster MI: c-Src-dependent activation of the epidermal growth factor receptor and mitogen-activated protein kinase pathway by arsenic. Role in carcinogenesis. J Biol Chem 277(4): 2945-50, 2002

205. Smith JJ, Derynck R, Korc M: Production of transforming growth factor alpha in human pancreatic cancer cells: evidence for a superagonist autocrine cycle. Proc Natl Acad Sci USA 84(21): 7567-70, 1987

206. Sounni NE, Roghi C, Chabottaux V, Janssen M, Munaut C, Maquoi E, Galvez BG, Gilles C, Frankenne F, Murphy G, Foidart JM, Noel A: Up-regulation of vascular endothelial growth factor-A by active membrane-type 1 matrix metalloproteinase through activation of Src-tyrosine kinases. J Biol Chem 279(14): 13564-74, 2004

207. Staley CA, Parikh NU, Gallick GE: Decreased tumori-genicity of a human colon adenocarcinoma cell line by an antisense expression vector specific for c-Src. Cell Growth Differ 8: 269-274, 1997

208. Stehelin D, Varmus HE, Bishop JM, Vogt PK: DNA related to the transforminggene(s) of avian sarcoma viruses is present in normal avian DNA. Nature 260: 170-173, 1976

209. Stipa F, Lucandri G, Limiti MR, et al.: Angiogenesis as a prognostic indicator in pancreatic ductal adenocarcinoma. Anticancer Res 22: 445-9, 2002 
210. Storniolo AM, Allerheiligen SR, Pearce HL: Preclinical, pharmacologic, and phase I studies of gemcitabine. Semin Oncol 24: S7-2-S7-7, 1997

211. Susa M, Teti A: Tyrosine kinase src inhibitors: Potential therapeutic applications. Drug News Perspect 13(3): 169-75, 2000

212. Tajiri H, Yoshimori M, Okazaki N et al.: Phase II study of continuous venous infusion of 5-fluorouracil in advanced pancreatic cancer. Oncology 48: 18-21, 1991

213. Takekura N, Yasui W, Yoshida K, Tsujino T, Nakayama H, Kameda T, Yokozaki H, Nishimura $\mathrm{Y}$, Ito $\mathrm{H}$, Tahara $\mathrm{E}$ : pp60c-src protein kinase activity in human gastric carcinomas. Int J Cancer 45: 847-851, 1990

214. Takenaka N, Mikoshiba K, Takamatsu K, Tsukada Y, Ohtani M, Toya S: Immunohistochemical detection of the gene product of Rous sarcoma virus in human brain tumors. Brain Res 337: 201-207, 1985

215. Talamonti MS, Roh MS, Curley SA, Gallick GE: Increase in activity and level of pp60csrc in progressive stages of human colorectal cancer. J Clin Invest 91: 53-60, 1993

216. Tanigawa N, Amaya H, Matsumura M, Lu C, Kitaoka A, Matsuyama K, Muraoka R: Tumor angiogenesis and mode of metastasis in patients with colorectal cancer. Cancer Res 57: 1043-6, 1997

217. Tanigawa N, Amaya H, Matsumura M, Shimomatsuya T: Correlation between expression of vascular endothelial growth factor and tumor vascularity, and patient outcome in human gastric carcinoma. J Clin Oncol 15: 826-32, 1997

218. Tanno S, Mitsuuchi Y, Altomare DA, Xiao GH, Testa JR: AKT activation up-regulates insulin-like growth factor I receptor expression and promotes invasiveness of human pancreatic cancer cells. Cancer Res 61: 589-593, 2001

219. Termuhlen PM, Curley SA, Talamonti MS, Saboorian MH, Gallick GE: Site-specific differences in pp60c-src activity in human colorectal metastases. J Surg Res 54: 293-298, 1993

220. Theurillat JP, Hainfellner J, Maddalena A, Weissenberger J, Aguzzi A: Early induction of angiogenetic signals in gliomas of GFAP-V-src transgenic mice. Am J Pathol 154: 581-590, 1999

221. Thomas SM, Brugge JS: Cellular functions regulated by Src family kinases. Annu Rev Cell Dev Biol 13: 513-609, 1997

222. Tilbrook PA, Palmer GA, Bittorf T, McCarthy DJ, Wright MJ, Sarna MK, Linnekin D, Cull VS, Williams JH, Ingley E, Schneider-Mergener J, Krystal G, Klinken SP: Maturation of erythroid cells and erythroleukemia development are affected by the kinase activity of Lyn. Cancer Res 61: 2453-2458, 2001 
223. Torigoe T, O'Connor R, Santoli D, Reed JC: Interleukin-3 regulates the activity of the LYN protein-tyrosine kinase in myeloid-committed leukemic cell lines. Blood 80: 617624,1992

224. Towbin H, Staehelin T, Gordon J. Electrophoretic transfer of proteins from polyacrylamide gels to nitrocellulose sheets: procedure and some applications.

225. Van Oijen MG, Rijksen G, ten Broek FW, SlootwegPJ: Overexpression of c-Src in areas of hyperproliferation in head and neck cancer, premalignant lesions and benign mucosal disorders. J Oral Pathol Med 27: 147-152, 1998

226. Van Trappen PO, Steele D, Lowe DG, Baithun S, Beasley N, Thiele W, Weich H, Krishnan J, Shepherd JH, Pepper MS, Jackson DG, Sleeman JP, Jacobs IJ: Expression of vascular endothelial growth factor (VEGF)-C and VEGF-D, and their receptor VEGFR3, during different stages of cervical carcinogenesis. J Pathol 201(4): 544-54, 2003

227. Veikkola $\mathrm{T}$, et al.: Regulation of angiogenesis via vascular endothelial growth factor receptors. Cancer Res 60(2): 203-12, 2000

228. Venkatakrishnan G, Salgia R, Groopman JE: Chemokine receptors CXCR-1/2 activate mitogen-activated protein kinase via the epidermal growth factor receptor in ovarian cancer cells. J Biol Chem 275: 6868-6875, 2000

229. Verbeek BS, Vroom TM, Adriaansen-Slot SS, Ottenhoff-Kalff AE, Geertzema JG, Hennipman A, Rijksen G: c-Src protein expression is increased in human breast cancer. An immunohistochemical and biochemical analysis. J Pathol 180: 383-388, 1996

230. Vercoutter-Edouart A, Lemoine J, Smart CE, Nurcombe V, Boilly B, Peyrat J, Hondermarck $\mathrm{H}$ : The mitogenic signaling pathway for fibroblast growth factor-2 involves the tyrosine phosphorylation of cyclin D2 in MCF-7 human breast cancer cells. FEBS Lett 478: 209-215, 2000

231. Verheul HM, Pinedo HM: The Role of Vascular Endothelial Growth Factor (VEGF) in Tumor angiogenesis and early clinical development of VEGF-Receptor kinase inhibitors. Clin Breast Cancer 1; Suppl 1: S80-4, 2000

232. Verheul HM, Pinedo HM: Vascular endothelial growth factor and its inhibitors. Drugs Today (Barc) 39; Suppl C: 81-93, 2003

233. Vezeridis MP, Tzanakakis GN, Agarwal KC, Veronikis DK: In vivo selection of a highly metastatic cell line from a human pancreatic carcinoma in the nude mouse. Cancer Apr 15 69(8): 2060-3, 1992

234. Visser CJ, Rijksen G, Woutersen RA and de Weger RA: Increased immunoreactivity and protein tyrosine kinase activity of the protooncogene pp60c-src in preneoplastic lesions in rat pancreas. Lab Invest 74: 2-11, 1996

235. Visser CJ, Rijksen G, Woutersen RA, De Weger RA: Increased immunoreactivity and protein tyrosine kinase activity of the protooncogene pp60c-src in preneoplastic lesions in rat pancreas. Lab Invest 74: 2-11, 1996 
236. Waddick KG, Chae HP, Tuel-Ahlgren L, Jarvis LJ, Dibirdik I, Myers DE, Uckun FM: Engagement of the CD19 receptor on human B-lineage leukemia cells activates LCK tyrosine kinase and facilitates radiation-induced apoptosis. Radiat Res 136: 313-319, 1993

237. Wagener DJ, Verdonk HE, Dirix LY et al.: Phase II trial of CPT-11 in patients with advanced pancreatic cancer, an EORTC early clinical trials group study. Ann Oncol 6: 129-132, 1995.

238. Warmuth M, Damoiseaux R, Liu Y, Fabbro D, Gray N: SRC family kinases: potential targets for the treatment of human cancer and leukemia. Curr Pharm Des 9(25): 2043-59, 2003.

239. Weber TK, Steele G, Summerhayes IC: Differential pp60c-src activity in well and poorly differentiated human colon carcinomas and cell lines. J Clin Invest 90: 815-821, 1992

240. Webster MA, Cardiff RD, Muller WJ: Induction of mammary epithelial hyperplasias and mammary tumors in transgenic mice expressing a murine mammary tumor virus/activated c-src fusion gene. Proc Natl Acad Sci USA 92: 7849-7853, 1995

241. Weissenberger J, Steinbach JP, Malin G, Spada S, Rulicke T, Aguzzi A: Development and malignant progression of astrocytomas in GFAP-v-src transgenic mice. Oncogene 14: 2005-2013, 1997

242. Whitehead RP, Jacobson J, Brown TD et al.: Phase II trial of paclitaxel and granulocyte colony-stimulating factor in patients with pancreatic carcinoma: a Southwest Oncology Group study. J Clin Oncol 15: 2414-2419, 1997

243. Wiener JR, Nakano K, Kruzelock RP, Bucana CD, Bast RC Jr., Gallick GE: Decreased Src tyrosine kinase activity inhibits malignant human ovarian cancer tumor growth in a nude mouse model. Clin Cancer Res 5: 2164-2170, 1999

244. Windham TC, Parikh NU, Siwak DR, Summy JM, McConkey DJ, Kraker AJ, Gallick GE: Src activation regulates anoikis in human colon tumor cell lines. Oncogene 21: 7797-7807, 2002

245. Xu W, Harrison SC, Eck MJ: Three-dimensional structure of the tyrosine kinase c-Src. Nature 385: 595-602, 1997

246. Yang M, Zhang H, Voyno-Yasenetskaya T, Ye RD: Requirement of Gbetagamma and cSrc in D2 dopamine receptor-mediated nuclear factor-kappaB activation. Mol Pharmacol 64(2): 447-55, 2003

247. Yano S, Kondo K, Yamaguchi M, Richmond G, Hutchison M, Wakeling A, Averbuch S, Wadsworth P: Distribution and function of EGFR in human tissue and the effect of EGFR tyrosine kinase inhibition. Anticancer Res 23(5A): 3639-50, 2003

248. Yip-Schneider MT, Wiesenauer CA, Schmidt CM. Inhibition of the phosphatidylinositol 3'-kinase signaling pathway increases the responsiveness of pancreatic carcinoma cells to sulindac. J Gastrointest Surg 7(3): 354-63, 2003 
249. Yokoyama YFH, Kobrin MS, Ebert M, Friess H, Büchler MW, Korc M: Betacellulin, a member of the EGF family is overexpressed in human pancreatic cancer. Int J Oncol 7: $825-829,1995$

250. ZhengXM, Resnick RJ, Shalloway D: A phosphotyrosine displacement mechanism for activation of Src by PTP alpha. Embo J 19: 964-978, 2000

251. Zhougang S, Schnellmann RG: H2O2-induced transactivation of EGF receptor requires Src and mediates ERK1/2, but not Akt, activation in renal cells. Am J Physiol Renal Physiol 286(5): 858-65, 2004

252. Zrihan-Licht S, Fu Y, Settleman J, Schinkmann K, Shaw L, Keydar I, Avraham S, Avraham H: RAFTK/Pyk2 tyrosine kinase mediates the association of p190 RhoGAP with RasGAP and is involved in breast cancer cell invasion. Oncogene 19: 1318-1328, 2000 


\section{Chapter 11}

\section{ABBREVIATIONS}

\begin{tabular}{ll}
\hline 5-FU & 5-Fluorouracil \\
\hline Ang1 & Angiopoietin 1 \\
\hline APS & Ammonium-persulfate \\
\hline ATP & Adenosine triphosphate \\
\hline AUR-3 & Aurora kinase \\
\hline BCA & Bicinchoninic acid \\
\hline bFGF & Basic fibroblast growth factor \\
\hline BSA & Bovine serum albumine \\
\hline cDNA & Cyclin-dependent kinase-2 \\
\hline Chk & Complementary deoxyribonucleic acid \\
CSF1-R & Csk-homologous kinase \\
\hline Csk & Colony stimulation factor-1 receptor \\
\hline DAPI & C-terminal Src kinase \\
\hline dFdCDP & 4',6-diamino-2-phenylindole \\
\hline dFdCTP & Gemcitabine-diphosphate \\
\hline DMEM & Gemcitabine-triphosphate \\
\hline DMSO & Dulbecco's modified Eagles medium \\
\hline DNA & Dimethylsulfoxide \\
\hline dTMP & Deoxyribonucleic acid \\
\hline DTT & Deoxythymidine-5'-monophosphate \\
\hline dUMP & D,1-Dithiothreitol \\
\hline ECL & Deoxyuridine-5'-monophosphate \\
\hline ECM & Enhanced chemiluminescence \\
\hline EDTA & Extracellular matrix \\
\hline ERF & Ethylenediamine-tetra acetic acid \\
\hline FACS & Epidermal growth factor \\
\hline FGS & Extracellular regulated kinase \\
\hline
\end{tabular}




\begin{tabular}{|c|c|}
\hline Flt-1 & fms-like tyrosine kinase 1 \\
\hline Flt3 & Fms like tyrosine kinase-3 \\
\hline GDP & Guanosine 5'-Diphosphate \\
\hline GTP & Guanosine 5'-Triphosphate \\
\hline $\mathrm{H} \& \mathrm{E}$ & Haematoxylin and eosin \\
\hline HGF & Hepatocyte growth factor \\
\hline HRP & Horseradish peroxidase \\
\hline HUVEC & Human umbilical vein endothelial cells \\
\hline $\operatorname{Ig}$ & Immunoglobulin \\
\hline IGF & Insulin growth factor \\
\hline IL & Interleukin \\
\hline JAK & Janus kinase \\
\hline JM & Juxtamembrane \\
\hline KDR & Kinase insert domain-containing receptor \\
\hline Lck & Lymphocyte-specific protein tyrosine kinase \\
\hline LN & Lymph node \\
\hline Lyn & Lck/Yes related novel tyrosine kinase \\
\hline MAPK & Mitogen-activated protein kinase \\
\hline MEK & Mitogen-activated protein kinase kinase \\
\hline MMP & Matrix metalloproteinase \\
\hline mRNA & Messenger ribonucleic acid \\
\hline MVD & Microvessel density \\
\hline $\mathrm{NF}-\kappa \mathrm{B}$ & Nuclear factor- $\kappa B$ \\
\hline PAGE & Polyacrylamid gel electrophoresis \\
\hline PDGF & Plateled-derived growth factor \\
\hline PI & Propidium iodide \\
\hline PI3-K & Phosphatidylinositol 3-kinase \\
\hline PKB & Protein kinase B \\
\hline PKC & Protein kinase $\mathrm{C}$ \\
\hline PML & Promyelocytic leukemia \\
\hline PMSF & Phenylmethylsulfonyl fluoride \\
\hline PP2 & $\begin{array}{l}\text { 4-Amino-5-(4-chlorophenyl)-7-(t-butyl)pyrazolo[3,4- } \\
\text { d]pyrimidine }\end{array}$ \\
\hline PTK & Protein tyrosine kinase \\
\hline PTP & Protein tyrosine phosphatase \\
\hline RNA & Ribonucleic acid \\
\hline RTK & Receptor tyrosine kinase \\
\hline SDS & Sodium dodecyl sulfate \\
\hline SFK & Src family kinase \\
\hline $\mathrm{SH}$ & Src homology \\
\hline Src & Raus sarcoma virus proto-oncogene product \\
\hline STAT & Signal transducers and activators of transcription \\
\hline TEMED & N,N,N',N'-Tetra-methylethylenediamine \\
\hline
\end{tabular}




\begin{tabular}{ll} 
TGF- $\beta$ & transforming growth factor- $\beta$ \\
TKD & Tyrosine kinase domain \\
TMB & $3,3^{\prime}, 5,5^{\prime}$-Tetramethylbenzidine \\
TNF- $\alpha$ & tumor necrosis factor- $\alpha$ \\
TS & Thymidylate synthase \\
TUNEL & $\begin{array}{l}\text { Terminal deoxynucleotidyl transferase-mediated nick end } \\
\text { labeling }\end{array}$ \\
VEGF & Vascular endothelial growth factor \\
Yes & Yamaguchi 73 and Esh avian sarcoma \\
\hline
\end{tabular}




\section{Chapter 12}

\section{CURRICULUM VITAE}

\section{Personal data}

Family name:

Ischenko

First name:

Ivan

Date of birth:

October, $25^{\text {th }}, 1979$

Place of birth:

Donetsk, Ukraine

Country of citizenship:

Ukraine

Marital status:

Single

Private address:

Pfingstrosenstr 62, app. 2/140

D-81377, München

Germany

Phone:

+49(0) 17620059007

E-mail:

ivan.ischenko@gmail.com

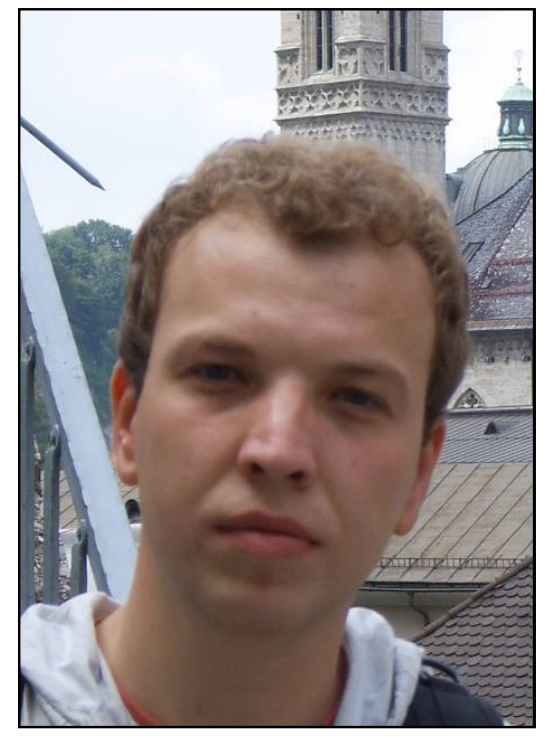

\section{Education}

1986-1994

Primary school in Donetsk, Ukraine

1994-1996

Secondary school in Donetsk, Ukraine

Academic education and scientific experience

1996-2002

2002-2003

2003-present
Studies of medicine at the Faculty of Medicine, Donetsk State

Medical University, Ukraine

Clinical training in the Department of Vascular Surgery at the University of Hannover (MHH), Germany

MD, graduate student

Supervisor: PD Dr. Christiane J. Bruns 


\section{Professional skills}

Basic cell culture techniques

In vitro and in vivo development of drug-resistant cell lines

Detection of viable cells

BrdU incorporation assay

Invasion and chemotaxis methods

Cell cycle analyses

Determination of apoptotic cells by FACS analysis

Enzyme-linked immunoassays

Immunoprecipitation analysis

Western blot analysis

In vitro kinase assays

Proteomics

Plasmid DNA isolation

Transfection techniques

Total RNA extraction and RT-PCR

Aortic ring assay

Spheroid angiogenesis assay

In vitro wound-healing assay

Murine Matrigel ${ }^{\mathrm{TM}}$ plug assay

In vivo allograft and xenograft tumor models

In vivo examination of antitumor activity

In vivo determination of tissue hypoxia

Immunohistochemistry of paraffin embedded tissues

Immunohistochemistry of snap-frozen tissues

Immunofluorescence staining and microscopy

Quantification of immunohistochemical and immunofluorescence tissue staining In vivo gene delivery of nacked DNA via hydrodynamic injection technique 


\section{Participation in scientific meetings}

\section{Posters:}

15th EORTC-NCI-AACR Symposium on Molecular Targets and Cancer Therapeutics, November 18-21, 2003, Boston, USA

Bruns, CJ., Yezhelyev M., Ischenko I., Guba M., Jauch K.-W., Ryan A., Barge A., Green T., Fennell M. Synergistic effect of the Src kinase inhibitor AZM475271 and gemcitabine in human pancreatic cancer growing orthotopically in nude mice

2004 8th Annual Meeting on Surgical Research (Chirurgische Forschungstage), 27-30 October, Mannheim, Germany

Ischenko, I., Yezhelyev, M., Papyan, A., Guba, M., Jauch, KW., Bruns, CJ. Effect of Src Kinase Inhibition on Metastasis and Tumor Angiogenesis in Human Pancreatic Cancer 8th Annual Meeting on Surgical Research (Chirurgische Forschungstage), 27-30 October, Mannheim, Germany

Schmid, G., Guba, M., Papyan, A., Ischenko, I., Brückel, M., Bruns, CJ., Jauch, KW., Graeb, C. Administration of FTY720 Inhibits Angiogenesis and reduces Tumor Growth First European Conference on Tumor Angiogenesis and Antiangiogenic Therapy, 1-3 October, Nymphenburger Chateau Munich, Germany Papyan, A., Werner,A., Ischenko, I., Teifel, M., Michaelis, U., Jauch, KW, Bruns, CJ. Combination of Standard Chemotherapy with MBT-0206 Enhances the Anti-tumor Efficacy in a Highly Metastatic Human Pancreatic Cancer Mouse Model

First European Conference on Tumor Angiogenesis and Antiangiogenic Therapy, 1-3 October, Nymphenburger Chateau Munich, Germany

Ischenko, I., Yezhelyev, M., Papyan, A., Guba, M., Jauch, KW., Bruns, CJ. Effect of Src Kinase Inhibition on Metastasis and Tumor Angiogenesis in Human Pancreatic Cancer March, Orlando, USA 
Bruell, D., Yezhelyev, M., Ischenko, I., Huhn, M., Bruns, CJ., Brabletz, T., Fischer, R., Finnern, R., Barth, S. Specific Cytotoxic Activity of a Recombinant Anti-EGF Receptor Immunotoxin 425(scFv)-ETA towards a Highly Metastatic Pancreatic Carcinoma Cell Line

March, Orlando, USA

Yezhelyev, M., Ischenko, I., Guba, M., Ryan, A., Barge, A., Jauch, K-W., Green, T., Fennell, M., Bruns, CJ. Synergistic Effect of the Src Kinase Inhibitor AZM475271 and Gemcitabine in Human Pancreatic Cancer Growing Orthotopically in Nude Mice

American Association for Cancer Research, 95th Annual Meeting, 27-31 March, Orlando, USA

Papyan, A., Ischenko, I., Werner, A., Yezhelyev, M., Teifel, M., Michaelis, U., Bruns, CJ. MBT-0206 Enhances the Anti-tumor Efficacy in a Highly Metastatic Human Pancreatic Cancer Mouse Model

Kongress der Deutschen Gesellschaft für Chirurgie, 27-30 April, Berlin, Germany

Papyan, A., Werner, A., Ischenko, I., Teifel, M., Michaelis, U., Jauch, KW., Bruns, CJ. Combination of Standard Chemotherapy with MBT-0206 Enhances the Anti-tumor Efficacy in a Highly Metastatic Human Pancreatic Cancer Mouse Model April, Anaheim, USA

Bruns, CJ., Ischenko, I., Papyan, A., Guba, M., Green, T., Fennel, M., Jauch, K-W. Effect of Src Kinase Inhibition on Metastasis and Tumor Angiogenesis in Human Pancreatic Cancer

9th Annual Meeting on Surgical Research (Chirurgische Forschungstage), 19-21 September, Frankfurt, Germany

Ischenko, I., Yezhelyev, M., Guba, M., Schmid, G., Jauch, K-W., Bruns, CJ. Inhibition of Src Tyrosine Kinase by AZM475271 Enhances the Efficacy of 5-Fluorouracil and Gemcitabine in Human Pancreatic Carcinoma Cells 
Schwarz, B., Ischenko, I., Guba, M., Schmid, G., Jauch, K-W., Bruns, CJ.

Blokade of Src Tyrosine Kinase Inhibits Angiogenesis and Reduces Growth of Pancreatic Carcinoma in vivo

9th Annual Meeting on Surgical Research (Chirurgische Forschungstage),

19-21 September, Frankfurt, Germany

Schmid, G., Guba, M., Papyan, A., Ischenko, I., Brückel, M., Bruns, CJ., Jauch, KW., Graeb, C. Administration of FTY720 Inhibits Angiogenesis and reduces Tumor Growth

ASCO Gastrointestinal Cancers Symposium, 26-28 January, San Francisco, USA

Ischenko, I., Čamaj, P., De Toni, E., Heeschen, C., Jauch, C-W., Bruns, CJ. The Effect of Src Kinase Inhibition on 5-Fluorouracil Chemosensitivity Is Related to Thymidylate Synthase Expression in Human Pancreatic Carcinoma Cells

Ischenko, I., Čamaj, P., De Toni, E., Heeschen, C., Jauch, C-W., Bruns, CJ. The Effect of Src Kinase Inhibition on 5-Fluorouracil Chemosensitivity Is Related to

Thymidylate Synthase Expression in Human Pancreatic Carcinoma Cells 10th Annual Meeting on Surgical Research (Chirurgische Forschungstage), 21-23 September, Muenster, Germany

Ischenko, I., Čamaj, P., De Toni, E., Heeschen, C., Jauch, C-W., Bruns, CJ. The Effect of Src Kinase Inhibition on 5-Fluorouracil Chemosensitivity Is Related to Thymidylate Synthase Expression in Human Pancreatic Carcinoma Cells

2006 10th Annual Meeting on Surgical Research (Chirurgische Forschungstage), 21-23 September, Muenster, Germany

Conrad, C., Valesky, M., Huss, R., Ischenko, I., Mojaat, A., Jauch, K-W., Nelson, PJ., Bruns, CJ. Homing of circulating MSC (CD 34-) in regenerating liver and hepatic coloncarcinoma metastases Therapy, September, Munich, Germany

Ischenko, I., Schmid, G., Huber, S., Guba, M., Jauch, K-W., Bruns, CJ. Involvement of Src Family Tyrosine Kinases in Lymphangiogenesis 
Second European Conference on Tumor Angiogenesis and Antiangiogenic Therapy, September, Munich, Germany

Čamaj, P., Brückel, M., De Toni, E., Ischenko, I., Guba, M., Jauch, K-W., Bruns, CJ. The interaction of apoptosis and angiogenesis in a tumor cell enviroment Therapy, September, Munich, Germany

Albrecht, U., Ischenko, I., Schwarz, B., Schrepfer, S., Schmid, G., Baumann, C., Guba, M., Heeschen, C., Jauch, K-W., Bruns, CJ. Efficacy of CXCR2 Inhibition on Tumor Angiogenesis in Pancreatic Cancer Second European Conference on Tumor Angiogenesis and Antiangiogenic Therapy, September, Munich, Germany Schmid, G., Huber, S., Ischenko, I., Guba, M., Joka, M., Schröferl, S., Bruns, CJ., Heeschen, C., Jauch, K-W., Graeb, C. Impact of FTY720 on Lymph- and Hemangiogenesis 


\section{Oral presentations:}

2006

Deutsche Krebskongress, 22-26 March, Berlin, Germany

Ischenko, I., Čamaj, P., De Toni, E., Heeschen, C., Jauch, C-W., Bruns,

CJ. The Effect of Src Kinase Inhibition on 5-Fluorouracil Chemosensitivity

Is Related to Thymidylate Synthase Expression in Human Pancreatic Carcinoma Cells

Kongress der Deutschen Gesellschaft für Chirurgie, 2-5 Mai, Berlin, Germany

Ischenko, I., Čamaj, P., De Toni, E., Heeschen, C., Jauch, C-W., Bruns, CJ. The Effect of Src Kinase Inhibition on 5-Fluorouracil Chemosensitivity Is Related to Thymidylate Synthase Expression in Human Pancreatic Carcinoma Cells 


\section{Chapter 13}

\section{OWN PUBLICATIONS}

Conrad, C., * Ischenko I., * Köhl, G., Wiegand, U., Guba, M., Yezhelyev, M., Ryan, AJ., Barge, A., Geissler, EK., Wedge SR., Jauch, K-W., Bruns, CJ. Antiangiogenic and antitumor activity of a novel VEGFR-2 tyrosine kinase inhibitor ZD6474 in a metastatic human pancreatic tumor model. Manuscript accepted for the publication in "Anticancer Drugs", 2007

Ischenko, I., Schmid, G., Huber, S., Guba, M., Jauch, K-W., Bruns, CJ. Involvement of Src Family Tyrosine Kinases in Lymphangiogenesis. Angiogenesis 2006 (manuscript in preparation)

Ischenko, I., Čamaj, P., Guba, M., Graeb, C., Jauch, K-W., Bruns, CJ. The Effect of Src Kinase Inhibition on 5-Fluorouracil Chemosensitivity Is Related to Thymidylate Synthase Expression in Human Pancreatic Carcinoma Cells. Clin Can Res 2006 (manuscript in preparation)

Ischenko, I., Yezhelyev, M., Guba, M., Papyan, A., Jauch, K-W., Bruns, CJ. Effect of Src Kinase Inhibition on Metastasis and Tumor Angiogenesis in Human Pancreatic Cancer. Angiogenesis 2006 (manuscript submitted)

Čamaj, P., Ziegelaar, B., Ischenko, I., Schmid, G., Jauch, K-W., Bruns, CJ. Antiangiogenic effect of primary human chondrocytes. Angiogenesis 2006 (manuscript submitted)

Schmid, G., Guba, M., Ischenko, I., Brückel, M., Bruns, CJ., Jauch, K-W., Graeb, C. Administration of FTY720 Inhibits Angiogenesis and reduces Tumor Growth. Transplant Proc, 2006

Guba, M., Yezhelyev, M., Eichhorn, ME., Schmid, G., Ischenko, I., Papyan, A., Graeb, C., Seeliger, H., Geissler, EK., Jauch, K-W., Bruns, CJ. Rapamycin Induces Tumor-specific Thrombosis via Tissue Factor in the Presence of VEGF. Blood 2005 
Bruell, D., Bruns, CJ., Yezhelyev, M., Huhn, M., Muller, J., Ischenko, I., Fischer, R., Finnern, R., Jauch, K-W., Barth, S. Recombinant Anti-EGFR Immunotoxin 425(scFv)-ETA Demonstrates Anti-tumor Activity Against Disseminated Human Pancreatic Cancer. Int J Mol Med 2005

* Both authors have contributed equally to this work 